Physics

Physics Research Publications

\title{
Sub-milliarcsecond imaging of quasars and active galactic nuclei. IV. Fine-scale structure
}

Y. Y. Kovalev, K. I. Kellermann, M. L. Lister, D. C. Homan, R. C. Vermeulen, M. H. Cohen, E. Ros, M. Kadler, A. P. Lobanov, J. A. Zensus, N. S. Kardashev,

L. I. Gurvits, M. F. Aller, and H. D. Aller 


\title{
SUB-MILLIARCSECOND IMAGING OF QUASARS AND ACTIVE GALACTIC NUCLEI. IV. FINE-SCALE STRUCTURE
}

\author{
Y. Y. Kovalev, ${ }^{1,2}$ K. I. Kellermann, ${ }^{3}$ M. L. Lister, ${ }^{4}$ D. C. Homan, ${ }^{5}$ R. C. Vermeulen, ${ }^{6}$ M. H. Cohen, ${ }^{7}$ \\ E. Ros, ${ }^{8}$ M. Kadler, ${ }^{8}$ A. P. Lobanov, ${ }^{8}$ J. A. Zensus, ${ }^{3,8}$ N. S. Kardashev, ${ }^{2}$ \\ L. I. Gurvits, ${ }^{9}$ M. F. Aller, ${ }^{10}$ AND H. D. Aller ${ }^{10}$ \\ Received 2005 March 23; accepted 2005 July 7
}

\begin{abstract}
We have examined the compact structure in 250 flat-spectrum extragalactic radio sources using interferometric fringe visibilities obtained with the Very Long Baseline Array (VLBA) at $15 \mathrm{GHz}$. With projected baselines out to $440 \mathrm{M} \lambda$, we are able to investigate source structure on typical angular scales as small as 0.05 mas. This scale is similar to the resolution of the VLBI Space Observatory Programme data obtained on longer baselines at a lower frequency and with somewhat poorer accuracy. For 171 sources in our sample, more than half of the total flux density seen by the VLBA remains unresolved on the longest baselines. There are 163 sources in our list with a median correlated flux density at $15 \mathrm{GHz}$ in excess of $0.5 \mathrm{Jy}$ on the longest baselines; these will be useful as fringe finders for shortwavelength VLBA observations. The total flux densities recovered in the VLBA images at $15 \mathrm{GHz}$ are generally close to the values measured around the same epoch at the same frequency with the RATAN-600 and University of Michigan Radio Astronomy Observatory telescopes.

We have modeled the core of each source with an elliptical Gaussian component. For about $60 \%$ of the sources, we have at least one observation in which the core component appears unresolved (generally smaller than 0.05 mas) in one direction, usually transverse to the direction into which the jet extends. BL Lac objects are on average more compact than quasars, while active galaxies are on average less compact. Also, in an active galaxy the submilliarcsecond core component tends to be less dominant. Intraday variability (IDV) sources typically have a more compact, more core-dominated structure on sub-milliarcsecond scales than non-IDV sources, and sources with a greater amplitude of intraday variations tend to have a greater unresolved VLBA flux density. The objects known to be $\mathrm{GeV}$ gamma-ray-loud appear to have a more compact VLBA structure than the other sources in our sample. This suggests that the mechanisms for the production of gamma-ray emission and for the generation of compact radio synchrotron-emitting features are related. The brightness temperature estimates and lower limits for the cores in our sample typically range between $10^{11}$ and $10^{13} \mathrm{~K}$, but they extend up to $5 \times 10^{13} \mathrm{~K}$, apparently in excess of the equipartition brightness temperature or the inverse Compton limit for stationary synchrotron sources. The largest component speeds are observed in radio sources with high observed brightness temperatures, as would be expected from relativistic beaming. Longer baselines, which can be obtained by space VLBI observations, will be needed to resolve the most compact high brightness temperature regions in these sources.
\end{abstract}

Key words: BL Lacertae objects: general — galaxies: active — galaxies: jets — quasars: general — radio continuum: galaxies - surveys

Online material: color figures, extended figure set, machine-readable tables

\section{INTRODUCTION}

Early interferometric observations of radio source structure were typically analyzed by examining how the amplitude of the fringe visibility varied with projected interferometer spacing (e.g., Rowson 1963). Although these techniques for conventional connected interferometers were later replaced by full synthesis imaging incorporating Fourier inversion, CLEAN (e.g., Högbom 1974), and self-calibration (see the review by Pearson

\footnotetext{
1 Jansky Fellow; National Radio Astronomy Observatory, P.O. Box 2, Green Bank, WV 24944; ykovalev@nrao.edu.

2 Astro Space Center of Lebedev Physical Institute, Profsoyuznaya 84/32, 117997 Moscow, Russia; nkardash@asc.rssi.ru.

3 National Radio Astronomy Observatory, 520 Edgemont Road, Charlottesville, VA 22903-2475; kkellerm@nrao.edu.

4 Department of Physics, Purdue University, 525 Northwestern Avenue, West Lafayette, IN 47907; mlister@physics.purdue.edu.

5 Department of Physics and Astronomy, Denison University, Granville, $\mathrm{OH}$ 43023; homand@denison.edu.

6 ASTRON, Netherlands Foundation for Research in Astronomy, P.O. Box 2, NL-7990 AA Dwingeloo, The Netherlands; rvermeulen@astron.nl.
}

\& Readhead 1984), the interpretation of early VLBI observations still was based on the examination of fringe amplitudes alone (see Cohen et al. 1975). Indeed, the discovery of superluminal motion in the source 3C 279 (Cohen et al. 1971; Whitney et al. 1971) was based on single-baseline observations of the change in spacing of the first minimum of the fringe visibility. However, after the development of phase-closure techniques, reliable full synthesis images have been produced from VLBI observations for more than 25 years. However, these tend to hide the information on the smallest scale structures because of the convolution with the synthesized beam (e.g., Fig. 1). A

\footnotetext{
${ }^{7}$ Department of Astronomy, California Institute of Technology, Mail Stop 105-24, Pasadena, CA 91125; mhc@astro.caltech.edu.

${ }^{8}$ Max-Planck-Institut für Radioastronomie, Auf dem Hügel 69, D-53121 Bonn, Germany; eros@mpifr-bonn.mpg.de, mkadler@mpifr-bonn.mpg.de, alobanov@mpifr-bonn.mpg.de, azensus@mpifr-bonn.mpg.de.

9 Joint Institute for VLBI in Europe, P.O. Box 2, 7990 AA Dwingeloo, The Netherlands; lgurvits@jive.nl.

${ }^{10}$ Department of Astronomy, University of Michigan, 830 Dennison Building, Ann Arbor, MI 48109-1090; mfa@umich.edu, haller@umich.edu.
} 

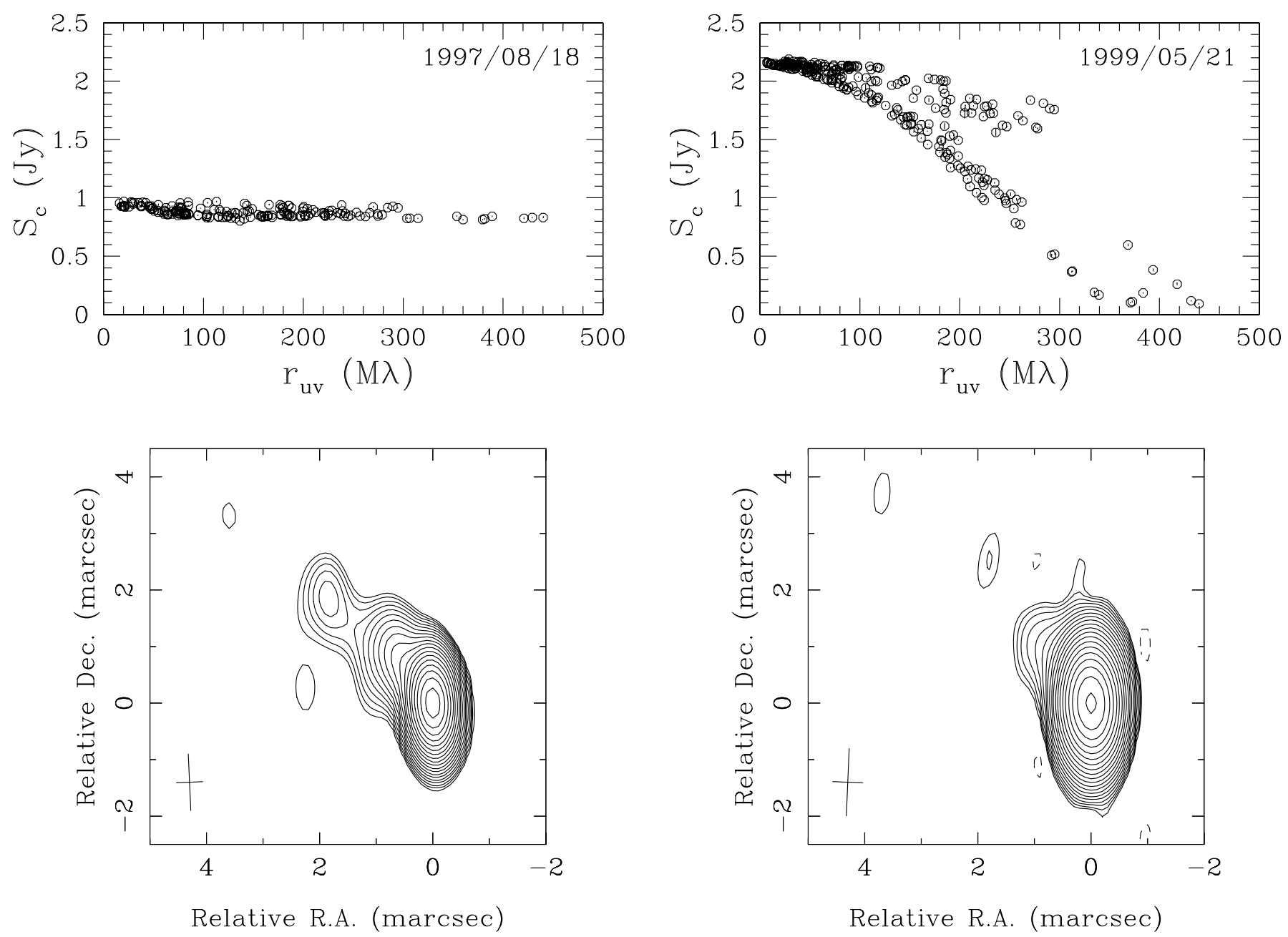

Fig. 1.-Comparison of two epochs for the quasar 0906+015. Top panels: Visibility function amplitude (i.e., correlated flux density) $S_{c}$ vs. projected spacing $r_{u v}$. Bottom panels: Naturally weighted CLEAN images. The lowest contour is plotted at the level of $0.16 \%$ and $0.13 \%$ of the peak brightness of 0.87 (epoch 1997 August 18) and 1.79 (epoch 1999 May 21) Jy beam ${ }^{-1}$, respectively. Other contours are shown at increasing powers of $\sqrt{2}$. The half-power width of the synthesized beam (with natural weighting) is shown in the lower left corners. The $(u, v)$-coverage of the two experiments was similar. One can clearly see (and model) from the $S_{c}-r_{u v}$ plots that an unresolved component observed at the first epoch at a level of about $0.8 \mathrm{Jy}$ is heavily resolved at the second epoch, which is not clear from the corresponding CLEAN images. This component dominates the $S_{c}-r_{u v}$ dependence.

more thorough discussion of nonimaging VLBI data analysis is given by Pearson (1999).

The best possible angular resolution is needed to study the environment close to supermassive black holes where relativistic particles are accelerated and collimated to produce radio jets. The greatest angular resolution to date was obtained in observations of interstellar scintillations (e.g., Kedziora-Chudczer et al. 1997, 2001; Macquart et al. 2000; Jauncey \& Macquart 2001; Rickett et al. 2001; Dennett-Thorpe \& de Bruyn 2002; Kraus et al. 2003; Lovell et al. 2003). The resolution achievable with VLBI can be improved by observing at shorter wavelengths (e.g., Moellenbrock et al. 1996; Lobanov et al. 2000; Lister 2001; Greve et al. 2002) or by increasing the physical baseline lengths using Earth-to-space interferometry. The first space VLBI missions (Levy et al. 1989; Hirabayashi et al. 1998) increased the available baseline lengths by a factor of about 3. Planned space VLBI observations such as RadioAstron (Kardashev 1997), the VLBI Space Observatory Programme 2 (VSOP-2) (Hirabayashi et al. 2004), and ARISE (Ulvestad 2000) will extend the baselines further.

For simple source structures, a direct study of the fringe visibilities can give a better angular resolution than an analysis of the images reconstructed from these data (e.g., Maltby \& Moffet
1962). In principle, a careful deconvolution of the images should give equivalent results. However, experience has shown that when confronted with even moderately complex images, it is dangerous to attempt to increase the resolution significantly beyond that of the CLEAN restoring beam size, a procedure referred to in early radio astronomy literature as "super-resolution."

In two previous papers (Kellermann et al. 1998, hereafter Paper I; Zensus et al. 2002, hereafter Paper II) we have described the sub-milliarcsecond-scale structure of 171 active galactic nuclei (AGNs), based on naturally weighted images made from observations with the Very Long Baseline Array (VLBA; Napier et al. 1994) at $15 \mathrm{GHz}$. In addition, in Paper II we have placed more restrictive limits on the sizes of unresolved sources by direct analysis of the fringe visibilities. In a third paper (Kellermann et al. 2004, hereafter Paper III) we have reported on the observed motions in the jets of 110 of these sources during the period 1994 2001.

In this paper we analyze $15 \mathrm{GHz}$ VLBA observations of the central regions of 250 extragalactic radio sources. We use the visibility function data to study the most compact structures and the way they change with time. The smallest features we are able to discern from these data have an extent of about $0.02-0.06$ mas. For the nearest object in our study, $1228+126$ (M87, Virgo A), this 
corresponds to a linear size of $10^{16} \mathrm{~cm}$ or several tens of Schwarzschild radii, if the mass of the central object is $3 \times 10^{9} M_{\odot}$ and the distance is $17.5 \mathrm{Mpc}$. We define our sample in $\S 2$ and describe the visibility data in $\S 3$ and the model fitting and analysis in $\oint 4$. In $\S 5$ we discuss the results, and the conclusions are summarized in $\S 6$.

Throughout this paper we use the following cosmological parameters: $H_{0}=70 \mathrm{~km} \mathrm{~s}^{-1} \mathrm{Mpc}^{-1}, \Omega_{m}=0.3$, and $\Omega_{\Lambda}=0.7$. We adopt the convention of using the term "quasar" to describe optical counterparts brighter than absolute magnitude -23 and "active galaxy" for the fainter objects.

\section{SAMPLE DEFINITION}

Our analysis is based on data obtained during the period 1994-2003 as part of the VLBA $15 \mathrm{GHz}$ monitoring survey of extragalactic sources (Papers I, II, and III; Lister \& Homan 2005; E. Ros et al. 2006, in preparation). We have also used additional observations made in 1998 and 1999 by L. I. Gurvits et al. (2006, in preparation) as part of a separate program to compare $15 \mathrm{GHz}$ source structure measured with the VLBA to $5 \mathrm{GHz}$ structure measured in the framework of the VSOP survey program (Hirabayashi et al. 2000; Lovell et al. 2004; Scott et al. 2004; Horiuchi et al. 2004). The program by Gurvits et al. used the same observing and data reduction procedures as the VLBA $15 \mathrm{GHz}$ monitoring survey and provides both additional sources and additional epochs.

Our data set consists of 1204 VLBA observations of 250 different compact extragalactic radio sources. The initial calibration of the data was carried out with the NRAO AIPS package (Greisen 1988) and was followed by imaging with the DIFMAP program (Shepherd 1997), mostly with the use of an automatic script (Paper I; Paper II ). The CLEAN images, as well as the visibility function data, are available on our Web sites. ${ }^{11}$

Most of the radio sources contained in our "full sample" of 250 sources have flat radio spectra $\left(\alpha>-0.5, S_{\nu} \sim \nu^{\alpha}\right)$ and a total flux density at $15 \mathrm{GHz}$ (often originally estimated by extrapolation from lower frequency data) greater than $1.5 \mathrm{Jy}$ for sources with declination $\delta>0^{\circ}$, or greater than 2 Jy for sources with $-20^{\circ}<\delta<0^{\circ}$. However, additional sources that did not meet these criteria but are of special interest were also included in the full sample.

Our full sample is useful for investigating fine-scale structure in a cross section of known extragalactic radio source classes and for planning future (space) VLBI observations. However, in order to compare observations with the theoretical predictions of relativistic beaming models, it is also useful to have a welldefined subsample selected on the basis of beamed, rather than total, flux density. We have therefore formed a flux densitylimited complete sample that has been used as the basis of our jet monitoring program since mid-2002, the MOJAVE (Monitoring of Jets in AGN with VLBA Experiments) program (Paper III; Lister \& Homan 2005). There are 133 sources in the MOJAVE subsample. The redshift distribution for these sources ranges up to 3.4 (quasar $0642+449$ ), although most sources have redshifts less than 2.5 , with a peak in the distribution near 0.8 .

Table 1 summarizes the properties of each source. Columns (1) and (2) give the IAU source designation and, where appropriate, a commonly used alias. The J2000.0 coordinates are in columns (3) and (4). The optical classification and redshift are shown in columns (5) and (6), respectively; these were obtained mainly from

\footnotetext{
11 See http://www.nrao.edu/2cmsurvey/ and http://www.physics.purdue.edu/ astro/MOJAVE/.
}

Véron-Cetty \& Véron (2003), as discussed below. In column (7) we give a radio spectral classification for each source based on the RATAN-600 radio telescope observations of broadband instantaneous spectra from 1 to $22 \mathrm{GHz}$ (Kovalev et al. 1999, 2000). These spectra are available on our Web site. For the few sources that were not observed at RATAN-600, we used published (nonsimultaneous) radio flux densities taken from the literature. We consider a radio spectrum to be flat if any portion of its spectrum in the range $0.6-22 \mathrm{GHz}$ has a spectral index flatter than -0.5 and steep if the radio spectral index is steeper than -0.5 over this entire region. In column (8) we indicate whether or not the radio source is associated with a gamma-ray detection by EGRET (Mattox et al. 2001; Sowards-Emmerd et al. 2003, 2004). Columns (9) and (10) indicate whether or not the source is a member of the complete correlated flux density-limited MOJAVE sample and the VSOP $5 \mathrm{GHz}$ AGN survey source sample (Hirabayashi et al. 2000; Lovell et al. 2004; Scott et al. 2004; Horiuchi et al. 2004). Column (11) gives references to papers reporting the intraday variability (IDV) of the source total flux density.

Of the 250 sources in the full sample, there are 179 quasars, 37 BL Lac objects, 23 active galaxies, and 11 sources that are optically unidentified. The MOJAVE complete sample of 133 sources includes 94 quasars, 22 BL Lac objects, 8 active galaxies, and 9 unidentified objects. These classifications come from Véron-Cetty \& Véron (2003), who defined a quasar as a starlike object, or an object with a starlike nucleus, with broad emission lines and brighter than absolute magnitude $M_{B}=-23$.

Véron-Cetty \& Véron (2003) provide a list of BL Lac objects, which historically were defined as bright galactic nuclei that are highly polarized in the optical regime and for which no emission or absorption lines have been detected. The precise delineation between BL Lac objects and optically violently variable quasars remains controversial (Véron-Cetty \& Véron 2000), since the original proposed $5 \AA$ limit (Stickel et al. 1991) is arbitrary (Scarpa \& Falomo 1997) and individual emission-line equivalent widths are now known to be highly variable over time. Indeed, the prototype, BL Lac itself, shows broad and narrow emission lines, as well as stellar absorption lines, in modern spectra; it no longer meets the classical definition of a BL Lac object (Vermeulen et al. 1995). The detectability of narrow and broad emission lines and absorption lines is set to a very significant degree by the variable continuum level, signal-to-noise ratio (SNR), starlight contribution, and other extrinsic and timedependent factors (see, e.g., Marcha \& Browne 1995). The situation is complicated further by proposed unification schemes (Urry \& Padovani 1995), which apparently led Véron-Cetty \& Véron (2003) to reclassify many BL Lac objects as quasars solely on the basis of their extended $5 \mathrm{GHz}$ luminosity being above the Fanaroff-Riley (FR) types I and II division.

Many of the objects in our sample are blazars, which are defined as the union of the original categories of BL Lac objects and optically violently variable quasars. Both groups are highly polarized and variable in the optical spectral region (e.g., Angel \& Stockman 1980). Since we are interested in comparing the radio properties of strong- and weak-lined blazars, we retain the original BL Lac object classifications for these objects and indicate these and other controversial classifications in the notes to Table 1. For our analysis, it would have been preferable to directly use optical-line equivalent width data; however, highquality, multiepoch spectra are currently available for only a small fraction of our sample. Nevertheless, the objects originally classified as BL Lac objects do, on average, have lower equivalent width spectral lines than classical quasars. This seems to be (1) partly the effect of dilution by a beamed nonthermal continuum 
TABLE 1

General Source Properties

\begin{tabular}{|c|c|c|c|c|c|c|c|c|c|c|}
\hline $\begin{array}{c}\text { IAU Name } \\
\text { (1) }\end{array}$ & $\begin{array}{c}\text { Alias } \\
(2)\end{array}$ & $\begin{array}{c}\text { R.A. } \\
(\mathrm{J} 2000.0) \\
(3)\end{array}$ & $\begin{array}{c}\text { Decl. } \\
(\mathrm{J} 2000.0) \\
(4)\end{array}$ & $\begin{array}{c}\text { Optical } \\
\text { Class } \\
(5)\end{array}$ & $\begin{array}{c}z \\
(6)\end{array}$ & $\begin{array}{c}\text { Radio } \\
\text { Spectrum } \\
(7)\end{array}$ & $\begin{array}{c}\text { EGRET } \\
\text { ID } \\
(8)\end{array}$ & $\begin{array}{c}\text { MOJAVE } \\
\text { Member } \\
(9)\end{array}$ & $\begin{array}{c}V S O P \\
\text { Sample } \\
(10)\end{array}$ & $\begin{array}{c}\text { IDV } \\
\text { Reference } \\
(11)\end{array}$ \\
\hline $0003-066 \ldots \ldots \ldots \ldots$ & NRAO 5 & 000613.8929 & -062335.3353 & $\mathrm{~B}^{\mathrm{b}}$ & 0.347 & Flat & $\ldots$ & $\mathrm{Y}$ & A & $\ldots$ \\
\hline $0007+106 \ldots \ldots \ldots \ldots$ & III Zw 2 & 001031.0059 & +105829.5041 & $\mathrm{G}$ & 0.089 & Flat & $\ldots$ & $\mathrm{Y}$ & $\ldots$ & $\ldots$ \\
\hline $0014+813 \ldots \ldots \ldots \ldots$ & & 001708.4750 & +813508.1360 & Q & 3.387 & Flat & $\ldots$ & $\ldots$ & $\ldots$ & $\ldots$ \\
\hline $0016+731 \ldots \ldots \ldots \ldots$ & & 001945.7864 & +732730.0175 & Q & 1.781 & Flat & $\ldots$ & $\mathrm{Y}$ & $\mathrm{A}, \mathrm{PR}$ & $\ldots$ \\
\hline $0026+346 \ldots \ldots \ldots \ldots$ & & 002914.2425 & +345632.2466 & $\mathrm{G}$ & 0.517 & Flat & $\ldots$ & $\ldots$ & $\mathrm{C}$ & $\ldots$ \\
\hline $0035+413 \ldots \ldots \ldots \ldots$ & & 003824.8436 & +413706.0006 & Q & 1.353 & Flat & $\ldots$ & $\ldots$ & $\mathrm{C}$ & $\ldots$ \\
\hline $0039+230 \ldots \ldots \ldots \ldots$ & & 004204.5451 & +232001.0610 & $\mathrm{U}$ & $\ldots$ & Peaked & $\ldots$ & $\ldots$ & A & $\ldots$ \\
\hline $0048-097 \ldots \ldots \ldots \ldots$ & & 005041.3174 & -092905.2102 & $\mathrm{~B}$ & $\ldots$ & Flat & $\ldots$ & $\mathrm{Y}$ & $\ldots$ & $\ldots$ \\
\hline $0055+300 \ldots \ldots \ldots \ldots$ & NGC 315 & 005748.8834 & +302108.8119 & G & 0.016 & Flat & $\ldots$ & $\ldots$ & $\ldots$ & $\ldots$ \\
\hline $0059+581 \ldots \ldots \ldots \ldots$ & & 010245.7624 & +582411.1366 & $\mathrm{U}$ & $\ldots$ & Flat & $\ldots$ & $\mathrm{Y}$ & $\ldots$ & $5^{*}, 6^{*}$ \\
\hline $0106+013 \ldots \ldots \ldots \ldots$ & & 010838.7711 & +013500.3171 & Q & 2.107 & Flat & $\ldots$ & $\mathrm{Y}$ & B & $\ldots$ \\
\hline $0108+388 \ldots \ldots \ldots \ldots$ & & 011137.3192 & +3906 27.9986 & $\mathrm{G}$ & 0.669 & Peaked & $\ldots$ & $\ldots$ & $\mathrm{C}$ & $\ldots$ \\
\hline $0109+224 \ldots \ldots \ldots \ldots$ & & $\begin{array}{lll}01 & 12 & 05.8247\end{array}$ & +224438.7862 & $\mathrm{~B}$ & $\ldots$ & Flat & $\ldots$ & $\mathrm{Y}$ & $\ldots$ & $\ldots$ \\
\hline $0112-017 \ldots \ldots \ldots \ldots$ & & 011517.1000 & -012704.5772 & Q & 1.365 & Flat & $\ldots$ & $\ldots$ & A & $\ldots$ \\
\hline $0113-118 \ldots \ldots \ldots \ldots$ & & 011612.5220 & -113615.4340 & Q & 0.672 & Flat & $\ldots$ & $\ldots$ & A & $\ldots$ \\
\hline $0119+041 \ldots \ldots \ldots \ldots$ & & 012156.8617 & +042224.7344 & Q & 0.637 & Flat & NP & $\ldots$ & $\mathrm{A}$ & $\ldots$ \\
\hline $0119+115 \ldots \ldots \ldots \ldots$ & $\mathrm{OC}+131$ & 012141.5950 & +114950.4131 & Q & 0.570 & Flat & $\ldots$ & $\mathrm{Y}$ & $\mathrm{A}$ & $\ldots$ \\
\hline $0122-003 \ldots \ldots \ldots \ldots$ & & 012528.8427 & -000555.9630 & Q & 1.070 & Flat & $\ldots$ & $\ldots$ & A & $\ldots$ \\
\hline $0133-203 \ldots \ldots \ldots \ldots$ & & 013537.5086 & -200845.8870 & $\mathrm{Q}$ & 1.141 & Flat & $\ldots$ & $\ldots$ & $\ldots$ & $\ldots$ \\
\hline $0133+476 \ldots \ldots \ldots \ldots$ & DA 55 & 013658.5948 & +475129.1001 & $\mathrm{Q}$ & 0.859 & Flat & $\ldots$ & $\mathrm{Y}$ & $\mathrm{A}, \mathrm{PR}$ & 1 \\
\hline $0138-097 \ldots \ldots \ldots \ldots$ & & 014125.8320 & -092843.6730 & B & 0.733 & Flat & $\ldots$ & $\ldots$ & B & $\ldots$ \\
\hline $0146+056 \ldots \ldots \ldots \ldots$ & & 014922.3709 & +055553.5680 & $\mathrm{Q}$ & 2.345 & Flat & $\ldots$ & $\ldots$ & $\mathrm{A}$ & $\ldots$ \\
\hline $0149+218 \ldots \ldots \ldots \ldots$ & & 015218.0590 & +220707.7000 & Q & 1.32 & Flat & $\ldots$ & $\ldots$ & $\mathrm{B}$ & $\ldots$ \\
\hline $0153+744 \ldots \ldots \ldots \ldots$ & & 015734.9649 & +744243.2300 & $\mathrm{Q}$ & 2.341 & Flat & $\ldots$ & $\ldots$ & $\mathrm{C}, \mathrm{PR}$ & $\ldots$ \\
\hline $0201+113 \ldots \ldots \ldots \ldots$ & & 020346.6571 & +113445.4096 & $\mathrm{Q}$ & 3.61 & Peaked & $\ldots$ & $\ldots$ & $\ldots$ & $\ldots$ \\
\hline $0202+149 \ldots \ldots \ldots \ldots$ & $4 C+15.05$ & 020450.4139 & +1514 11.0435 & $\mathrm{Q}^{\mathrm{c}}$ & 0.405 & Flat & YY & $\mathrm{Y}$ & $\mathrm{B}$ & $\ldots$ \\
\hline $0202+319 \ldots \ldots \ldots \ldots$ & & 020504.9254 & +321230.0956 & $\mathrm{Q}$ & 1.466 & Flat & $\ldots$ & $\mathrm{Y}$ & B & $\ldots$ \\
\hline $0212+735 \ldots \ldots \ldots \ldots$ & & 021730.8134 & +734932.6218 & $\mathrm{Q}$ & 2.367 & Flat & $\ldots$ & $\mathrm{Y}$ & $\mathrm{A}, \mathrm{PR}$ & $\ldots$ \\
\hline $0215+015 \ldots \ldots \ldots \ldots$ & & 021748.9547 & +014449.6991 & $\mathrm{~B}^{\mathrm{a}}$ & 1.715 & Flat & $\ldots$ & $\mathrm{Y}$ & A & $\ldots$ \\
\hline $0218+357 \ldots \ldots \ldots \ldots$ & & 022105.4740 & +35 5613.7315 & $\mathrm{Q}$ & 0.944 & Flat & $\ldots$ & $\ldots$ & $\mathrm{C}$ & $\ldots$ \\
\hline $0221+067 \ldots \ldots \ldots \ldots$ & $4 \mathrm{C}+07.11$ & 022428.4282 & +06 5923.3416 & $Q^{c}$ & 0.511 & Flat & $\ldots$ & $\ldots$ & $\mathrm{B}$ & $\ldots$ \\
\hline $0224+671 \ldots \ldots \ldots \ldots$ & $4 \mathrm{C}+67.05$ & 022850.0515 & +672103.0293 & $\mathrm{U}$ & $\ldots$ & Flat & $\ldots$ & $\mathrm{Y}$ & $\ldots$ & $\ldots$ \\
\hline $0234+285 \ldots \ldots \ldots \ldots$ & CTD 20 & 023752.4057 & +284808.9901 & $\mathrm{Q}$ & 1.207 & Flat & YP & $\mathrm{Y}$ & B & $\ldots$ \\
\hline $0235+164 \ldots \ldots \ldots \ldots .$. & & 023838.9301 & +163659.2747 & $\mathrm{~B}^{\mathrm{a}}$ & 0.940 & Flat & YY & $\mathrm{Y}$ & $\mathrm{C}$ & $1^{*}, 2^{*}, 6^{*}$ \\
\hline $0238-084 \ldots \ldots \ldots \ldots$ & NGC 1052 & 024104.7985 & -081520.7518 & $\mathrm{G}$ & 0.005 & Flat & $\ldots$ & $\mathrm{Y}$ & $\mathrm{C}$ & $\ldots$ \\
\hline $0248+430 \ldots \ldots \ldots \ldots$ & & 025134.5368 & +431515.8290 & $\mathrm{Q}$ & 1.310 & Flat & $\ldots$ & $\ldots$ & $\mathrm{A}$ & $\ldots$ \\
\hline $0300+470 \ldots \ldots \ldots \ldots$ & $4 \mathrm{C}+47.08$ & $\begin{array}{lll}03 & 03 & 35.2422\end{array}$ & +471616.2755 & B & $\ldots$ & Flat & $\ldots$ & $\mathrm{Y}$ & $\ldots$ & $\ldots$ \\
\hline $0310+013 \ldots \ldots \ldots \ldots$ & & 031243.6028 & +013317.5380 & $\mathrm{Q}$ & 0.664 & Flat & $\ldots$ & $\ldots$ & $\mathrm{B}$ & $\ldots$ \\
\hline $0316+162 \ldots \ldots \ldots \ldots$ & CTA 21 & 031857.8016 & +162832.7048 & $\mathrm{G}$ & $\ldots$ & Peaked & $\ldots$ & $\ldots$ & $\ldots$ & $\ldots$ \\
\hline $0316+413 \ldots \ldots \ldots \ldots$ & $3 \mathrm{C} 84$ & 031948.1601 & +413042.1031 & $\mathrm{G}$ & 0.017 & Flat & $\ldots$ & $\mathrm{Y}$ & $\mathrm{A}, \mathrm{PR}$ & $\ldots$ \\
\hline $0333+321 \ldots \ldots \ldots \ldots$ & NRAO 140 & 033630.1076 & +321829.3424 & $\mathrm{Q}$ & 1.263 & Flat & $\ldots$ & $\mathrm{Y}$ & B & 2 \\
\hline $0336-019 \ldots \ldots \ldots \ldots$ & CTA 26 & $\begin{array}{lll}03 & 39 & 30.9378\end{array}$ & -014635.8040 & Q & 0.852 & Flat & YY & $\mathrm{Y}$ & A & $2^{*}$ \\
\hline $0355+508 \ldots \ldots \ldots \ldots$ & NRAO 150 & 035929.7473 & +505750.1615 & $\mathrm{Q}$ & $\ldots$ & Flat & $\ldots$ & $\ldots$ & $\ldots$ & $\ldots$ \\
\hline $0402-362 \ldots \ldots \ldots \ldots$ & & 040353.7499 & -360501.9120 & $\mathrm{Q}$ & 1.417 & Peaked & $\ldots$ & $\ldots$ & A & $\ldots$ \\
\hline $0403-132 \ldots \ldots \ldots \ldots$ & & 040534.0034 & -130813.6911 & $\mathrm{Q}$ & 0.571 & Flat & $\ldots$ & $\mathrm{Y}$ & A & $\ldots$ \\
\hline $0405-385 \ldots \ldots \ldots \ldots$ & & 040659.0353 & -382628.0421 & $\mathrm{Q}$ & 1.285 & Flat & $\ldots$ & $\ldots$ & $\mathrm{B}$ & $3^{*}$ \\
\hline $0415+379 \ldots \ldots \ldots \ldots$ & $3 \mathrm{C} 111$ & 041821.2770 & +380135.9000 & $\mathrm{G}$ & 0.049 & Steep & $\ldots$ & $\mathrm{Y}$ & $\ldots$ & $\ldots$ \\
\hline $0420-014 \ldots \ldots \ldots \ldots$ & & 042315.8007 & -012033.0653 & $\mathrm{Q}$ & 0.915 & Flat & YY & $\mathrm{Y}$ & A & $\ldots$ \\
\hline $0420+022 \ldots \ldots \ldots \ldots$ & & 042252.2146 & +021926.9319 & $\mathrm{Q}$ & 2.277 & Flat & $\ldots$ & $\ldots$ & $\ldots$ & $\ldots$ \\
\hline $0422+004 \ldots \ldots \ldots \ldots$ & & 042446.8421 & +003606.3298 & $\mathrm{B}$ & $\ldots$ & Flat & $\ldots$ & $\mathrm{Y}$ & A & $3^{*}$ \\
\hline $0429+415 \ldots \ldots \ldots \ldots$ & 3C 119 & 043236.5026 & +413828.4485 & Q & 1.023 & Steep & $\ldots$ & $\ldots$ & $\ldots$ & $\ldots$ \\
\hline $0430+052 \ldots \ldots \ldots \ldots$ & $3 \mathrm{C} 120$ & 043311.0955 & +052115.6194 & $\mathrm{G}$ & 0.033 & Flat & $\ldots$ & $\mathrm{Y}$ & A & $\ldots$ \\
\hline $0438-436 \ldots \ldots \ldots \ldots$ & & 044017.1800 & -433308.6030 & $\mathrm{Q}$ & 2.852 & Flat & $\ldots$ & $\ldots$ & $\ldots$ & $\ldots$ \\
\hline $0440-003 \ldots \ldots \ldots \ldots$ & NRAO 190 & 044238.6608 & -001743.4191 & Q & 0.844 & Flat & YP & $\ldots$ & $\ldots$ & $3^{*}$ \\
\hline $0446+112 \ldots \ldots \ldots \ldots$ & & 044907.6711 & +112128.5966 & $\mathrm{Q}^{\mathrm{b}}$ & $\ldots$ & Flat & PY & $\mathrm{Y}$ & B & $\ldots$ \\
\hline $0454-234 \ldots \ldots \ldots \ldots$ & & 045703.1792 & -232452.0180 & $\mathrm{~B}^{\mathrm{a}}$ & 1.003 & Flat & YY & $\ldots$ & A & $\ldots$ \\
\hline $0454+844 \ldots \ldots \ldots \ldots$ & & 050842.3635 & +843204.5440 & B & $>1.34$ & Flat & $\ldots$ & $\ldots$ & $\mathrm{B}$ & $4^{*}$ \\
\hline $0458-020 \ldots \ldots \ldots \ldots$ & & 050112.8099 & -015914.2562 & Q & 2.291 & Flat & YY & $\mathrm{Y}$ & A & $\ldots$ \\
\hline $0521-365 \ldots \ldots \ldots \ldots$ & & 052257.9846 & -362730.8516 & $\mathrm{G}$ & 0.055 & Steep & $\ldots$ & $\ldots$ & $\ldots$ & $\ldots$ \\
\hline $0524+034 \ldots \ldots \ldots \ldots$ & & 052732.7030 & +033131.4500 & B & $\ldots$ & Flat & $\ldots$ & $\ldots$ & $\ldots$ & $\ldots$ \\
\hline $0528+134 \ldots \ldots \ldots \ldots$ & & 053056.4167 & +133155.1495 & $\mathrm{Q}$ & 2.07 & Flat & YY & $\mathrm{Y}$ & B & $\ldots$ \\
\hline $0529+075 \ldots \ldots \ldots \ldots$ & & 053238.9985 & +073243.3459 & $\mathrm{U}$ & $\ldots$ & Flat & $\ldots$ & $\mathrm{Y}$ & $\mathrm{C}$ & $\ldots$ \\
\hline $0529+483 \ldots \ldots \ldots \ldots$ & & 053315.8658 & +482252.8078 & $\mathrm{Q}$ & 1.162 & Flat & PY & $\mathrm{Y}$ & $\ldots$ & $\ldots$ \\
\hline $0537-286 \ldots \ldots \ldots \ldots$ & & 053954.2814 & -283955.9460 & Q & 3.104 & Flat & NP & $\ldots$ & A & $\ldots$ \\
\hline $0552+398 \ldots \ldots \ldots \ldots$ & DA 193 & 055530.8056 & +3948 49.1650 & $\mathrm{Q}$ & 2.363 & Peaked & $\ldots$ & $\mathrm{Y}$ & $\ldots$ & $\ldots$ \\
\hline $0602+673 \ldots \ldots \ldots \ldots$ & & 060752.6716 & +672055.4098 & Q & 1.97 & Flat & $\ldots$ & $\ldots$ & B & 4 \\
\hline
\end{tabular}


TABLE $1-$ Continued

\begin{tabular}{|c|c|c|c|c|c|c|c|c|c|c|}
\hline $\begin{array}{c}\text { IAU Name } \\
\text { (1) }\end{array}$ & $\begin{array}{c}\text { Alias } \\
(2)\end{array}$ & $\begin{array}{c}\text { R.A. } \\
\text { (J2000.0) } \\
(3)\end{array}$ & $\begin{array}{c}\text { Decl. } \\
(\mathrm{J} 2000.0) \\
(4)\end{array}$ & $\begin{array}{l}\text { Optical } \\
\text { Class } \\
(5)\end{array}$ & $\begin{array}{c}z \\
(6)\end{array}$ & $\begin{array}{c}\text { Radio } \\
\text { Spectrum } \\
(7)\end{array}$ & $\begin{array}{c}\text { EGRET } \\
\text { ID } \\
(8)\end{array}$ & $\begin{array}{l}\text { MOJAVE } \\
\text { Member } \\
(9)\end{array}$ & $\begin{array}{c}\text { VSOP } \\
\text { Sample } \\
(10)\end{array}$ & $\begin{array}{c}\text { IDV } \\
\text { Reference } \\
\text { (11) }\end{array}$ \\
\hline $0605-085 \ldots \ldots \ldots \ldots$ & \multirow[t]{3}{*}{$\mathrm{OH}-010$} & 060759.6992 & -083449.9781 & Q & 0.872 & Flat & $\ldots$ & $\mathrm{Y}$ & $\mathrm{A}$ & $\ldots$ \\
\hline $0607-157 \ldots \ldots \ldots \ldots$ & & 060940.9495 & -154240.6726 & Q & 0.324 & Flat & $\ldots$ & $\mathrm{Y}$ & A & $3^{*}$ \\
\hline $0615+820 \ldots \ldots \ldots \ldots$ & & 062603.0062 & +8202 25.5676 & $\mathrm{Q}$ & 0.71 & Flat & $\ldots$ & $\ldots$ & B & $\ldots$ \\
\hline $0642+449 \ldots \ldots \ldots \ldots$ & \multirow[t]{4}{*}{$\mathrm{OH} 471$} & 064632.0260 & +4451 16.5901 & Q & 3.408 & Peaked & $\ldots$ & $\mathrm{Y}$ & B & $\ldots$ \\
\hline $0648-165 \ldots \ldots \ldots \ldots$ & & 065024.5819 & -163739.7250 & $\mathrm{U}$ & $\ldots$ & Flat & $\ldots$ & $\mathrm{Y}$ & $\ldots$ & $\ldots$ \\
\hline $0707+476 \ldots \ldots \ldots \ldots$ & & 071046.1049 & +4732 11.1427 & Q & 1.292 & Flat & $\ldots$ & $\ldots$ & $\ldots$ & $\ldots$ \\
\hline $0710+439 \ldots \ldots \ldots \ldots$ & & 071338.1641 & +434917.2051 & G & 0.518 & Peaked & $\cdots$ & $\ldots$ & $\mathrm{B}$ & $\cdots$ \\
\hline $0711+356 \ldots \ldots \ldots \ldots$ & \multirow[t]{7}{*}{ OI 318} & 071424.8175 & +353439.7950 & Q & 1.620 & Peaked & $\ldots$ & $\ldots$ & $\mathrm{A}, \mathrm{PR}$ & 1 \\
\hline $0716+714 \ldots \ldots \ldots \ldots$ & & 072153.4485 & +712036.3634 & $\mathrm{~B}$ & $\ldots$ & Flat & YY & $\mathrm{Y}$ & $\ldots$ & $1^{*}, 2^{*}, 4^{*}, 6^{*}$ \\
\hline $0723-008 \ldots \ldots \ldots \ldots$ & & 072550.6400 & -005456.5444 & $\mathrm{~B}^{\mathrm{b}}$ & 0.127 & Flat & $\ldots$ & $\ldots$ & $\ldots$ & $\ldots$ \\
\hline $0727-115 \ldots \ldots \ldots \ldots$ & & 073019.1125 & -114112.6005 & Q & 1.591 & Flat & $\ldots$ & $\mathrm{Y}$ & $\ldots$ & $\ldots$ \\
\hline $0730+504 \ldots \ldots \ldots \ldots$ & & 073352.5206 & +502209.0621 & Q & 0.720 & Flat & $\ldots$ & $\mathrm{Y}$ & $\ldots$ & $\ldots$ \\
\hline $0735+178 \ldots \ldots \ldots \ldots$ & & 073807.3937 & +174218.9983 & $\mathrm{~B}$ & $>0.424$ & Flat & YY & $\mathrm{Y}$ & $\mathrm{A}$ & $1^{*}$ \\
\hline $0736+017 \ldots \ldots \ldots \ldots$ & & 073918.0339 & +013704.6180 & Q & 0.191 & Flat & $\ldots$ & $\mathrm{Y}$ & A & $\ldots$ \\
\hline $0738+313 \ldots \ldots \ldots \ldots$ & \multirow[t]{5}{*}{ OI 363} & $0741 \quad 10.7033$ & $+31 \quad 1200.2286$ & Q & 0.630 & Flat & $\ldots$ & $\mathrm{Y}$ & A & $\ldots$ \\
\hline $0742+103 \ldots \ldots \ldots \ldots$ & & 074533.0595 & +101112.6925 & Q & 2.624 & Peaked & $\ldots$ & $\mathrm{Y}$ & $\mathrm{B}$ & $\ldots$ \\
\hline $0745+241 \ldots \ldots \ldots \ldots$ & & 074836.1093 & +240024.1102 & $\mathrm{Q}^{\mathrm{c}}$ & 0.409 & Flat & $\ldots$ & $\ldots$ & $\mathrm{A}$ & $\ldots$ \\
\hline $0748+126 \ldots \ldots \ldots \ldots$ & & 075052.0457 & +123104.8282 & $\mathrm{Q}$ & 0.889 & Flat & $\ldots$ & $\mathrm{Y}$ & B & $\ldots$ \\
\hline $0754+100 \ldots \ldots \ldots \ldots$ & & 075706.6429 & +095634.8521 & $\mathrm{B}$ & 0.266 & Flat & $\ldots$ & $\mathrm{Y}$ & $\ldots$ & $5^{*}, 6^{*}$ \\
\hline $0804+499 \ldots \ldots \ldots \ldots$ & \multirow[t]{3}{*}{ OJ 508} & 080839.6663 & +495036.5305 & Q & 1.432 & Flat & $\ldots$ & $\mathrm{Y}$ & $\mathrm{B}$ & $1^{*}, 2^{*}, 4^{*}, 6^{*}$ \\
\hline $0805-077 \ldots \ldots \ldots \ldots$ & & 080815.5360 & -075109.8863 & Q & 1.837 & Flat & $\ldots$ & $\mathrm{Y}$ & $\mathrm{C}$ & $\ldots$ \\
\hline $0808+019 \ldots \ldots \ldots \ldots$ & & 081126.7073 & +014652.2200 & $\mathrm{~B}$ & 0.93 & Flat & $\ldots$ & $\mathrm{Y}$ & $\mathrm{A}$ & $3^{*}$ \\
\hline $0814+425 \ldots \ldots \ldots \ldots$ & OJ 425 & 081815.9996 & +422245.4149 & $\mathrm{~B}$ & $\ldots$ & Flat & $\ldots$ & $\mathrm{Y}$ & $\mathrm{A}, \mathrm{PR}$ & 1 \\
\hline $0821+394 \ldots \ldots \ldots \ldots$ & \multirow[t]{4}{*}{$4 C+39.23$} & 082455.4839 & +391641.9043 & Q & 1.216 & Flat & $\ldots$ & $\ldots$ & B & $\ldots$ \\
\hline $0823+033 \ldots \ldots \ldots \ldots$ & & 082550.3384 & +030924.5201 & $\mathrm{~B}$ & 0.506 & Flat & $\ldots$ & $\mathrm{Y}$ & $\mathrm{A}$ & $\ldots$ \\
\hline $0827+243 \ldots \ldots \ldots \ldots$ & & 083052.0862 & +241059.8205 & Q & 0.941 & Flat & YY & $\mathrm{Y}$ & $\ldots$ & $\ldots$ \\
\hline $0829+046 \ldots \ldots \ldots \ldots$ & & 083148.8770 & +042939.0853 & B & 0.18 & Flat & YY & $\mathrm{Y}$ & B & $\ldots$ \\
\hline $0831+557 \ldots \ldots \ldots \ldots$ & \multirow[t]{2}{*}{$4 C+55.16$} & 083454.9041 & +553421.0710 & G & 0.240 & Flat & $\ldots$ & $\ldots$ & $\mathrm{C}$ & $\ldots$ \\
\hline $0834-201 \ldots \ldots \ldots \ldots$ & & 083639.2152 & -201659.5035 & Q & 2.752 & Flat & $\ldots$ & $\ldots$ & $\ldots$ & $\ldots$ \\
\hline $0836+710 \ldots \ldots \ldots \ldots$ & $4 \mathrm{C}+71.08$ & 084124.3653 & +705342.1731 & Q & 2.218 & Flat & YY & $\mathrm{Y}$ & $\mathrm{A}, \mathrm{PR}$ & $\ldots$ \\
\hline $0838+133 \ldots \ldots \ldots \ldots$ & $3 \mathrm{C} 207$ & 084047.6848 & +13 1223.8790 & Q & 0.684 & Flat & $\ldots$ & $\ldots$ & B & $\ldots$ \\
\hline $0850+581 \ldots \ldots \ldots \ldots$ & $4 \mathrm{C}+58.17$ & 085441.9964 & +575729.9393 & Q & 1.322 & Flat & $\ldots$ & $\ldots$ & B & $\ldots$ \\
\hline $0851+202 \ldots \ldots \ldots \ldots$ & \multirow[t]{2}{*}{ OJ 287} & 085448.8749 & +200630.6409 & $\mathrm{~B}$ & 0.306 & Flat & YY & $\mathrm{Y}$ & $\mathrm{A}$ & $\ldots$ \\
\hline $0859-140 \ldots \ldots \ldots \ldots$ & & $\begin{array}{lll}09 & 02 & 16.8309\end{array}$ & -141530.8757 & Q & 1.339 & Steep & $\ldots$ & $\ldots$ & $\ldots$ & $\ldots$ \\
\hline $0859+470 \ldots \ldots \ldots \ldots$ & $4 C+47.29$ & $\begin{array}{lll}09 & 03 & 03.9901\end{array}$ & +465104.1375 & Q & 1.462 & Steep & $\ldots$ & $\ldots$ & $\mathrm{A}, \mathrm{PR}$ & $\ldots$ \\
\hline $0906+015 \ldots \ldots \ldots \ldots$ & \multirow[t]{4}{*}{$4 \mathrm{C}+01.24$} & 090910.0916 & +012135.6177 & Q & 1.018 & Flat & $\ldots$ & $\mathrm{Y}$ & A & $\ldots$ \\
\hline $0917+449 \ldots \ldots \ldots \ldots$ & & 092058.4585 & +444153.9851 & Q & 2.180 & Flat & NP & $\ldots$ & A & $\ldots$ \\
\hline $0917+624 \ldots \ldots \ldots \ldots$ & & 092136.2311 & +621552.1804 & Q & 1.446 & Flat & $\cdots$ & $\mathrm{Y}$ & $\mathrm{B}$ & $1^{*}, 2^{*}, 4^{*}$ \\
\hline $0919-260 \ldots \ldots \ldots . . .$. & & 092129.3538 & -261843.3850 & Q & 2.300 & Peaked & $\ldots$ & $\ldots$ & $\mathrm{B}$ & $\ldots$ \\
\hline $0923+392 \ldots \ldots \ldots \ldots$ & $4 C+39.25$ & 092703.0139 & +3902 20.8520 & Q & 0.698 & Flat & $\ldots$ & $\mathrm{Y}$ & $\mathrm{A}, \mathrm{PR}$ & $\ldots$ \\
\hline $0945+408 \ldots \ldots \ldots \ldots$ & $4 C+40.24$ & 094855.3381 & +403944.5872 & $\mathrm{Q}$ & 1.252 & Flat & $\ldots$ & $\mathrm{Y}$ & $\mathrm{B}$ & $\cdots$ \\
\hline $0953+254 \ldots \ldots \ldots \ldots$ & OK 290 & 095649.8754 & +251516.0498 & Q & 0.712 & Flat & $\ldots$ & $\ldots$ & $\mathrm{B}$ & $\ldots$ \\
\hline $0954+658 \ldots \ldots \ldots \ldots$ & & 095847.2451 & +653354.8181 & $\mathrm{~B}$ & 0.367 & Flat & YY & $\ldots$ & $\mathrm{B}$ & $1,2,4^{*}$ \\
\hline $0955+476 \ldots \ldots \ldots \ldots$ & OK 492 & 095819.6716 & +472507.8425 & $\mathrm{Q}$ & 1.873 & Flat & $\ldots$ & $\mathrm{Y}$ & $\mathrm{B}$ & $6^{*}$ \\
\hline $1012+232 \ldots \ldots \ldots \ldots$ & $4 C+23.24$ & 101447.0654 & +2301 16.5709 & Q & 0.565 & Flat & $\ldots$ & $\ldots$ & B & $6^{*}$ \\
\hline $1015+359 \ldots \ldots \ldots \ldots$ & & 101810.9877 & +354239.4380 & Q & 1.226 & Flat & $\ldots$ & $\ldots$ & $\ldots$ & $\ldots$ \\
\hline $1032-199 \ldots \ldots \ldots \ldots$ & & 103502.1553 & -201134.3597 & Q & 2.198 & Flat & $\ldots$ & $\ldots$ & A & $\ldots$ \\
\hline $1034-293 \ldots \ldots \ldots \ldots$ & & 103716.0797 & -293402.8120 & Q & 0.312 & Flat & $\ldots$ & $\ldots$ & A & $3^{*}$ \\
\hline $1036+054 \ldots \ldots \ldots \ldots$ & & 103846.7799 & +051229.0854 & $\mathrm{U}$ & $\ldots$ & Flat & $\ldots$ & $\mathrm{Y}$ & $\ldots$ & $\ldots$ \\
\hline $1038+064 \ldots \ldots \ldots \ldots$ & $4 \mathrm{C}+06.41$ & 104117.1625 & +06 1016.9238 & Q & 1.265 & Flat & $\ldots$ & $\mathrm{Y}$ & B & $\ldots$ \\
\hline $1045-188 \ldots \ldots \ldots \ldots$ & & 104806.6206 & -190935.7270 & Q & 0.595 & Flat & $\ldots$ & $\mathrm{Y}$ & $\mathrm{B}$ & $\ldots$ \\
\hline $1049+215 \ldots \ldots \ldots \ldots$ & $4 C+21.28$ & 105148.7891 & +211952.3142 & Q & 1.300 & Flat & $\ldots$ & $\ldots$ & B & $\ldots$ \\
\hline $1055+018 \ldots \ldots \ldots \ldots$ & $4 \mathrm{C}+01.28$ & 105829.6052 & +013358.8237 & Q & 0.888 & Flat & $\ldots$ & $\mathrm{Y}$ & A & $\ldots$ \\
\hline $1055+201 \ldots \ldots \ldots \ldots$ & $4 C+20.24$ & 105817.9025 & +195150.9018 & Q & 1.11 & Flat & $\ldots$ & $\ldots$ & B & $\ldots$ \\
\hline $1101+384 \ldots \ldots \ldots \ldots$ & Mrk 421 & 110427.3139 & +38 1231.7991 & $\mathrm{~B}$ & 0.031 & Flat & YY & $\ldots$ & $\ldots$ & $\ldots$ \\
\hline $1116+128 \ldots \ldots \ldots \ldots \ldots$ & & 111857.3014 & +123441.7180 & $\mathrm{Q}$ & 2.118 & Flat & $\ldots$ & $\ldots$ & A & $\ldots$ \\
\hline $1124-186 \ldots \ldots \ldots \ldots$ & $\mathrm{OM}-148$ & 112704.3924 & -185717.4417 & Q & 1.048 & Flat & $\ldots$ & $\mathrm{Y}$ & B & $\ldots$ \\
\hline $1127-145 \ldots \ldots \ldots \ldots$ & & 113007.0526 & -144927.3882 & Q & 1.187 & Flat & $\ldots$ & $\mathrm{Y}$ & $\ldots$ & $\ldots$ \\
\hline $1128+385 \ldots \ldots \ldots \ldots$ & & 113053.2826 & +381518.5470 & $\mathrm{Q}$ & 1.733 & Flat & $\ldots$ & $\ldots$ & $\ldots$ & $\ldots$ \\
\hline $1144+402 \ldots \ldots \ldots \ldots$ & & 114658.2979 & +395834.3046 & $\mathrm{Q}$ & 1.089 & Flat & $\ldots$ & $\ldots$ & $\ldots$ & $\ldots$ \\
\hline $1145-071 \ldots \ldots \ldots \ldots$ & & 114751.5540 & -072441.1411 & $\mathrm{Q}$ & 1.342 & Flat & $\ldots$ & $\ldots$ & $\mathrm{A}$ & $\ldots$ \\
\hline $1148-001 \ldots \ldots \ldots \ldots$ & $4 C-00.47$ & 115043.8708 & -002354.2049 & Q & 1.980 & Peaked? & $\ldots$ & $\ldots$ & B & $\ldots$ \\
\hline $1150+812 \ldots \ldots \ldots \ldots$ & & 115312.4991 & +8058 29.1545 & Q & 1.25 & Flat & $\ldots$ & $\mathrm{Y}$ & B & 1 \\
\hline $1155+251 \ldots \ldots \ldots \ldots$ & & 115825.7875 & +245017.9640 & $\mathrm{Q}$ & 0.202 & Flat & $\ldots$ & $\ldots$ & $\mathrm{C}$ & $\ldots$ \\
\hline $1156+295 \ldots \ldots \ldots \ldots$ & $4 C+29.45$ & 115931.8339 & +291443.8269 & Q & 0.729 & Flat & YP & $\mathrm{Y}$ & B & $5^{*}, 6^{*}$ \\
\hline $1213-172 \ldots \ldots \ldots \ldots$ & & 121546.7518 & -173145.4029 & $\mathrm{U}$ & $\ldots$ & Flat & $\ldots$ & $\mathrm{Y}$ & A & $\ldots$ \\
\hline $1219+044 \ldots \ldots \ldots \ldots$ & $\mathrm{ON}+231$ & 122222.5496 & +041315.7763 & $\mathrm{Q}$ & 0.965 & Flat & $\ldots$ & $\mathrm{Y}$ & $\ldots$ & $\ldots$ \\
\hline $1219+285 \ldots \ldots \ldots \ldots$ & W Com & 122131.6905 & +281358.5002 & $\mathrm{B}$ & 0.102 & Flat & PP & $\cdots$ & $\cdots$ & $\cdots$ \\
\hline & & & & 2477 & & & & & & \\
\hline
\end{tabular}


TABLE 1-Continued

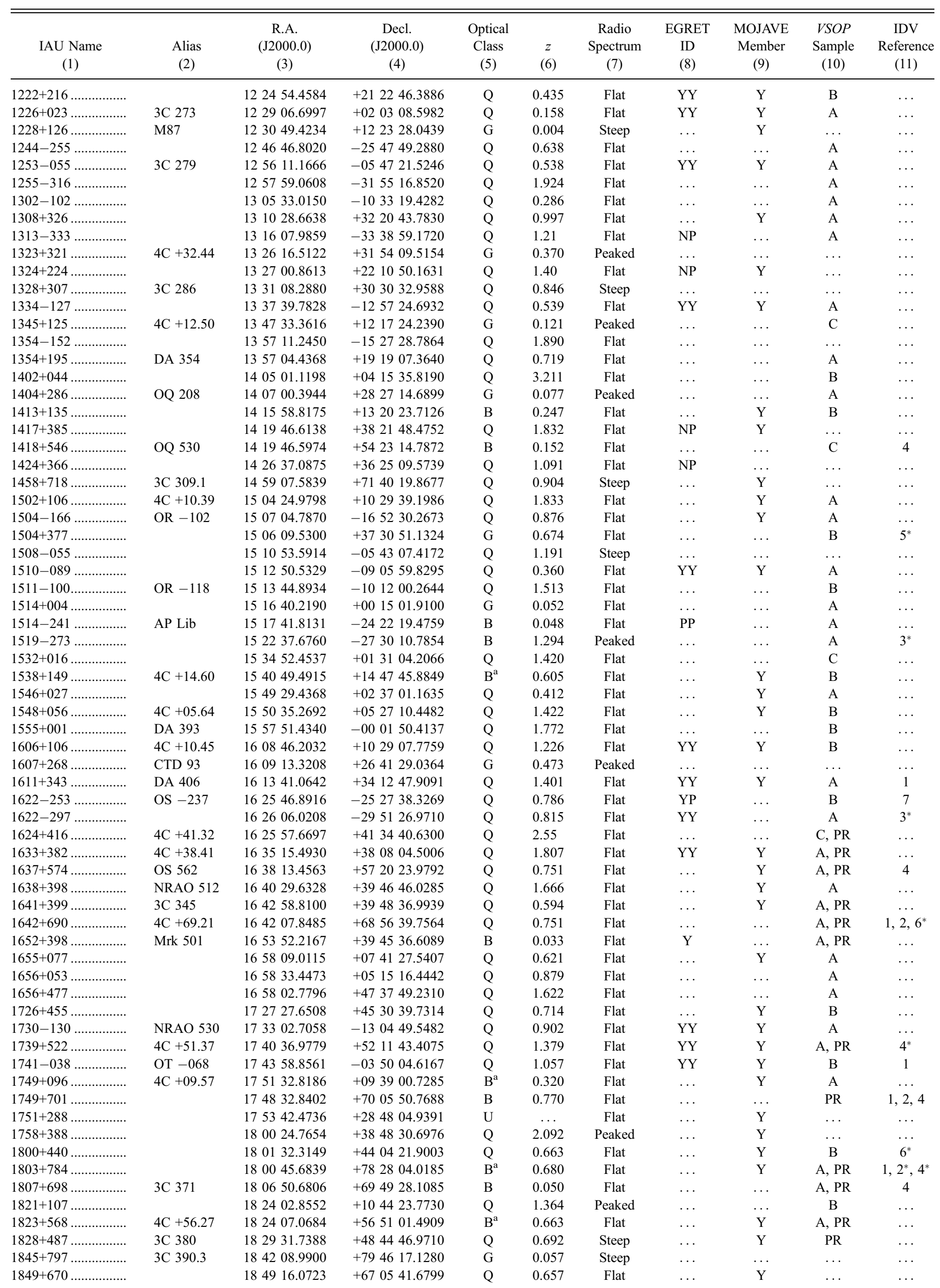


TABLE 1-Continued

\begin{tabular}{|c|c|c|c|c|c|c|c|c|c|c|}
\hline $\begin{array}{c}\text { IAU Name } \\
\text { (1) }\end{array}$ & $\begin{array}{l}\text { Alias } \\
(2)\end{array}$ & $\begin{array}{c}\text { R.A. } \\
\text { (J2000.0) } \\
(3)\end{array}$ & $\begin{array}{c}\text { Decl. } \\
(\mathrm{J} 2000.0) \\
(4)\end{array}$ & $\begin{array}{c}\text { Optical } \\
\text { Class } \\
(5)\end{array}$ & $\begin{array}{c}z \\
(6)\end{array}$ & $\begin{array}{c}\text { Radio } \\
\text { Spectrum } \\
(7)\end{array}$ & $\begin{array}{c}\text { EGRET } \\
\text { ID } \\
(8)\end{array}$ & $\begin{array}{c}\text { MOJAVE } \\
\text { Member } \\
(9)\end{array}$ & $\begin{array}{c}V S O P \\
\text { Sample } \\
(10)\end{array}$ & $\begin{array}{c}\text { IDV } \\
\text { Reference } \\
\quad(11)\end{array}$ \\
\hline $1901+319 \ldots \ldots \ldots \ldots \ldots \ldots$ & 3 C 395 & 190255.9389 & +315941.7021 & Q & 0.635 & Steep & $\ldots$ & $\ldots$ & A & $\ldots$ \\
\hline $1908-201 \ldots \ldots \ldots \ldots \ldots . .$. & & 191109.6528 & -200655.1080 & Q & 1.119 & Flat & YY & $\ldots$ & $\mathrm{B}$ & $\ldots$ \\
\hline $1921-293 \ldots \ldots \ldots \ldots \ldots \ldots$ & $\mathrm{OV}-236$ & 192451.0560 & -291430.1212 & Q & 0.352 & Flat & $\ldots$ & $\ldots$ & A & $\ldots$ \\
\hline $1928+738 \ldots \ldots \ldots \ldots \ldots \ldots$ & $4 C+73.18$ & 192748.4952 & +735801.5700 & Q & 0.303 & Flat & $\ldots$ & $\mathrm{Y}$ & A, PR & $\ldots$ \\
\hline $1936-155 \ldots \ldots \ldots \ldots \ldots \ldots$ & & 193926.6577 & -152543.0583 & Q & 1.657 & Flat & PY & $\mathrm{Y}$ & $\ldots$ & $\ldots$ \\
\hline 1937-101 ….............. & & 193957.2566 & -100241.5210 & Q & 3.787 & Flat & $\ldots$ & $\ldots$ & $\ldots$ & $\ldots$ \\
\hline $1954-388 \ldots \ldots \ldots \ldots \ldots \ldots$ & & 195759.8192 & -384506.3560 & Q & 0.630 & Flat & $\ldots$ & $\ldots$ & $\mathrm{B}$ & $\ldots$ \\
\hline $1954+513 \ldots \ldots \ldots \ldots \ldots \ldots . .$. & OV 591 & 195542.7383 & +513148.5462 & Q & 1.223 & Flat & $\ldots$ & $\ldots$ & $\mathrm{B}, \mathrm{PR}$ & 4 \\
\hline $1957+405 \ldots \ldots \ldots \ldots \ldots \ldots$ & Cyg A & 195928.3567 & +404402.0966 & $\mathrm{G}$ & 0.056 & Steep & $\cdots$ & $\mathrm{Y}$ & $\cdots$ & $\cdots$ \\
\hline $1958-179 \ldots \ldots \ldots \ldots \ldots \ldots$ & & 200057.0904 & -174857.6725 & Q & 0.652 & Flat & $\cdots$ & $\mathrm{Y}$ & A & $\cdots$ \\
\hline $2000-330 \ldots \ldots \ldots \ldots \ldots . .$. & & 200324.1163 & -325145.1320 & Q & 3.783 & Peaked & $\ldots$ & $\ldots$ & $\mathrm{B}$ & $\ldots$ \\
\hline $2005+403 \ldots \ldots \ldots \ldots \ldots \ldots \ldots$ & & 200744.9449 & +402948.6041 & Q & 1.736 & Flat & $\ldots$ & $\mathrm{Y}$ & $\ldots$ & $\ldots$ \\
\hline $2007+777 \ldots \ldots$ & & 200531.0035 & +775243.2248 & $\mathrm{~B}$ & 0.342 & Flat & $\ldots$ & $\ldots$ & A & $1,2,4$ \\
\hline $2008-159 \ldots \ldots \ldots \ldots \ldots \ldots . .$. & & 201115.7109 & -154640.2538 & Q & 1.180 & Peaked & $\ldots$ & $\mathrm{Y}$ & A & $\ldots$ \\
\hline $2010+463 \ldots \ldots \ldots \ldots \ldots \ldots$ & & 201205.6374 & +462855.7770 & $\mathrm{U}$ & $\ldots$ & Flat & $\cdots$ & $\cdots$ & $\cdots$ & $\cdots$ \\
\hline $2021+317 \ldots \ldots \ldots \ldots \ldots \ldots$ & $4 C+31.56$ & 202319.0174 & +315302.3059 & $\mathrm{U}$ & $\cdots$ & Flat & $\cdots$ & $\mathrm{Y}$ & $\cdots$ & $\cdots$ \\
\hline $2021+614 \ldots \ldots \ldots \ldots \ldots \ldots \ldots$ & OW 637 & 202206.6817 & +613658.8047 & G & 0.227 & Flat & $\ldots$ & $\mathrm{Y}$ & $\mathrm{A}, \mathrm{PR}$ & $\ldots$ \\
\hline $2029+121 \ldots \ldots$ & & 203154.9942 & +12 1941.3400 & Q & 1.215 & Flat & NP & $\ldots$ & B & $\ldots$ \\
\hline 2037+511 …................. & $3 \mathrm{C} 418$ & 203837.0348 & +511912.6627 & Q & 1.687 & Flat & $\cdots$ & $\mathrm{Y}$ & $\cdots$ & $\cdots$ \\
\hline $2059+034 \ldots \ldots \ldots \ldots \ldots \ldots . .$. & & 210138.8341 & +034131.3200 & $\mathrm{Q}$ & 1.015 & Flat & $\ldots$ & $\ldots$ & A & $\ldots$ \\
\hline $2113+293 \ldots \ldots \ldots \ldots \ldots \ldots$ & & 211529.4135 & +2933 38.3669 & Q & 1.514 & Flat & $\cdots$ & $\cdots$ & $\mathrm{B}$ & $\cdots$ \\
\hline $2121+053 \ldots \ldots \ldots \ldots \ldots \ldots$ & OX 036 & 212344.5174 & +053522.0932 & Q & 1.941 & Flat & $\cdots$ & $\mathrm{Y}$ & $\mathrm{B}$ & $6^{*}$ \\
\hline $2126-158 \ldots \ldots \ldots \ldots \ldots \ldots$ & & 212912.1758 & -153841.0400 & Q & 3.28 & Flat & $\ldots$ & $\ldots$ & A & $\ldots$ \\
\hline $2128+048 \ldots \ldots \ldots \ldots \ldots \ldots \ldots$ & DA 550 & 213032.8775 & +05 0217.4747 & G & 0.99 & Peaked & $\ldots$ & $\ldots$ & $\ldots$ & $\ldots$ \\
\hline $2128-123 \ldots \ldots \ldots \ldots \ldots \ldots$ & & 213135.2618 & -120704.7959 & $\mathrm{Q}$ & 0.501 & Flat & $\ldots$ & $\mathrm{Y}$ & B & $\ldots$ \\
\hline $2131-021 \ldots \ldots \ldots \ldots \ldots \ldots . .$. & $4 C-02.81$ & 213410.3096 & -015317.2389 & $\mathrm{~B}^{\mathrm{a}}$ & 1.285 & Flat & $\ldots$ & $\mathrm{Y}$ & $\ldots$ & $\ldots$ \\
\hline $2134+004 \ldots \ldots \ldots \ldots \ldots \ldots \ldots$ & & 213638.5863 & +004154.2133 & $\mathrm{Q}$ & 1.932 & Peaked & $\ldots$ & $\mathrm{Y}$ & A & $\ldots$ \\
\hline $2136+141 \ldots \ldots \ldots \ldots \ldots \ldots \ldots$ & OX 161 & 213901.3093 & +142335.9920 & Q & 2.427 & Flat & $\ldots$ & $\mathrm{Y}$ & A & $\ldots$ \\
\hline $2144+092 \ldots \ldots \ldots \ldots \ldots \ldots$ & & 214710.1630 & +09 2946.6723 & Q & 1.113 & Flat & $\cdots$ & $\cdots$ & $\mathrm{B}$ & $\cdots$ \\
\hline $2145+067$..................... & $4 C+06.69$ & 214805.4587 & +06 5738.6042 & Q & 0.999 & Flat & $\ldots$ & $\mathrm{Y}$ & $\mathrm{B}$ & $\ldots$ \\
\hline $2155-152 \ldots \ldots \ldots \ldots \ldots \ldots$ & OX -192 & 215806.2819 & $\begin{array}{lll}-15 & 01 & 09.3281\end{array}$ & Q & 0.672 & Flat & $\ldots$ & $\mathrm{Y}$ & A & $\ldots$ \\
\hline $2200+420 \ldots \ldots \ldots \ldots \ldots \ldots \ldots$ & BL Lac & 220243.2914 & +42 1639.9799 & B & 0.069 & Flat & YY & $\mathrm{Y}$ & $\mathrm{A}, \mathrm{PR}$ & 4 \\
\hline $2201+171 \ldots \ldots \ldots \ldots \ldots \ldots \ldots$ & & 220326.8937 & +172548.2478 & Q & 1.076 & Flat & $\cdots$ & $\mathrm{Y}$ & $\ldots$ & $\cdots$ \\
\hline $2201+315 \ldots \ldots \ldots \ldots \ldots \ldots \ldots$ & $4 C+31.63$ & 220314.9758 & +314538.2699 & Q & 0.298 & Flat & $\cdots$ & $\mathrm{Y}$ & B & $\cdots$ \\
\hline $2209+236 \ldots \ldots \ldots \ldots \ldots \ldots \ldots$ & & 221205.9663 & +235540.5439 & Q & 1.125 & Flat & YY & $\mathrm{Y}$ & A & $\cdots$ \\
\hline $2216-038 \ldots \ldots \ldots \ldots \ldots \ldots \ldots$ & & 221852.0377 & -033536.8794 & Q & 0.901 & Flat & $\cdots$ & $\mathrm{Y}$ & A & $\ldots$ \\
\hline $2223-052 \ldots \ldots \ldots \ldots \ldots \ldots$ & $3 \mathrm{C} 446$ & 222547.2593 & -045701.3907 & Q & 1.404 & Flat & $\cdots$ & $\mathrm{Y}$ & A & $\cdots$ \\
\hline $2227-088 \ldots \ldots \ldots \ldots \ldots \ldots$ & PHL 5225 & 222940.0843 & -083254.4354 & Q & 1.562 & Flat & $\ldots$ & $\mathrm{Y}$ & A & $\ldots$ \\
\hline $2230+114$....................... & CTA 102 & 223236.4089 & +114350.9041 & Q & 1.037 & Flat & YP & $\mathrm{Y}$ & $\cdots$ & $\ldots$ \\
\hline $2234+282 \ldots \ldots \ldots \ldots \ldots \ldots \ldots$ & CTD 135 & 223622.4709 & +28 2857.4133 & Q & 0.795 & Flat & $\cdots$ & $\cdots$ & A & $\cdots$ \\
\hline $2243-123 \ldots \ldots \ldots \ldots \ldots \ldots$ & & 224618.2320 & -120651.2773 & Q & 0.630 & Flat & $\ldots$ & $\mathrm{Y}$ & A & $\ldots$ \\
\hline $2251+158 \ldots \ldots \ldots \ldots \ldots \ldots \ldots . .$. & $3 \mathrm{C} 454.3$ & 225357.7479 & +160853.5609 & Q & 0.859 & Flat & YY & $\mathrm{Y}$ & A & $\ldots$ \\
\hline $2255-282 \ldots \ldots \ldots \ldots \ldots \ldots$ & & 225805.9629 & -275821.2567 & Q & 0.927 & Peaked & $\mathrm{Y}$ & $\cdots$ & B & $\cdots$ \\
\hline $2318+049 \ldots \ldots \ldots \ldots \ldots \ldots$ & & 232044.8566 & +05 1349.9527 & Q & 0.623 & Flat & $\ldots$ & $\ldots$ & A & $\ldots$ \\
\hline $2329-162 \ldots \ldots \ldots \ldots \ldots \ldots$ & & 233138.6524 & -155657.0080 & Q & 1.153 & Flat & $\cdots$ & $\cdots$ & A & $\cdots$ \\
\hline $2331+073 \ldots \ldots \ldots \ldots \ldots \ldots$ & & 233412.8282 & +073627.5520 & $\mathrm{U}$ & $\cdots$ & Flat & $\cdots$ & $\mathrm{Y}$ & $\cdots$ & $\cdots$ \\
\hline $2345-167 \ldots \ldots \ldots \ldots \ldots \ldots . .$. & & 234802.6085 & -163112.0220 & Q & 0.576 & Flat & $\ldots$ & $\mathrm{Y}$ & $\ldots$ & $\ldots$ \\
\hline $2351+456 \ldots \ldots \ldots \ldots \ldots \ldots \ldots$ & $4 \mathrm{C}+45.51$ & 235421.6803 & +45 5304.2365 & Q & 1.986 & Flat & PP & $\mathrm{Y}$ & B & $\ldots$ \\
\hline
\end{tabular}

Notes.-Units of right ascension are hours, minutes, and seconds, and units of declination are degrees, arcminutes, and arcseconds. Col. (1): IAU name (B1950.0).

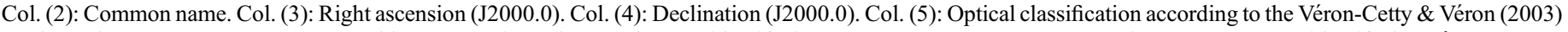

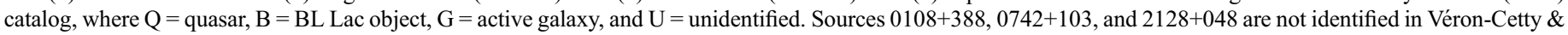

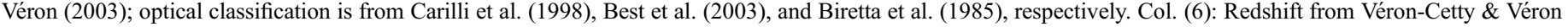

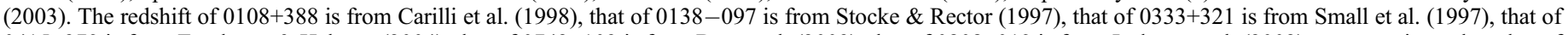

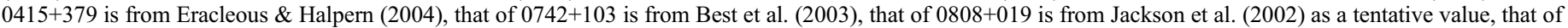

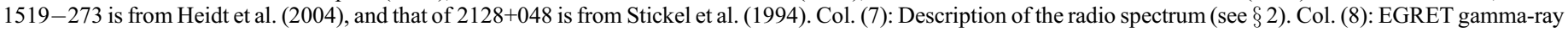

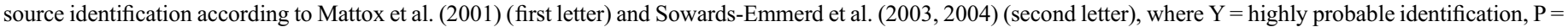

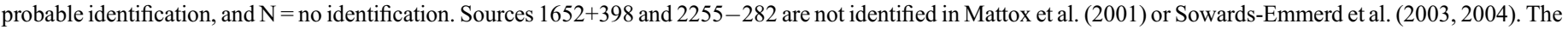

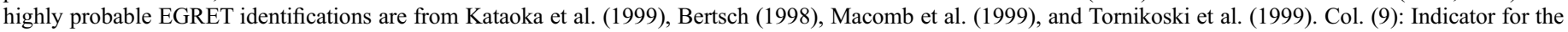

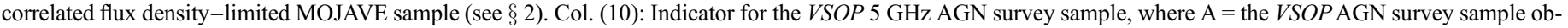

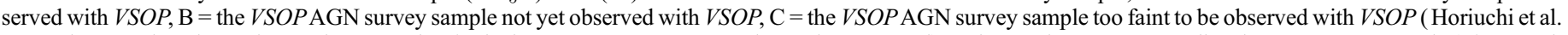

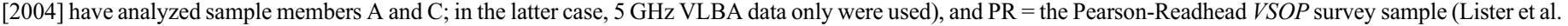

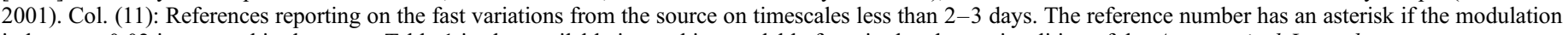
index $m>0.02$ is reported in the paper. Table 1 is also available in machine-readable form in the electronic edition of the Astronomical Journal.

a Source classified as a quasar in the Véron-Cetty \& Véron (2003) catalog.

b Source classified as a probable or possible BL Lac object in the Véron-Cetty \& Véron (2003) catalog.

c Source classified as a galaxy in the Véron-Cetty \& Véron (2003) catalog.

REFERENCES.-(1) Quirrenbach et al. 1992; (2) Quirrenbach et al. 2000; (3) Kedziora-Chudczer et al. 2001; (4) Kraus et al. 2003; (5) Lovell et al. 2003; (6) Ojha et al. 2004; (7) Bignall et al. 2002. 
(e.g., Wills et al. 1983) and (2) partly because many of these objects are intrinsically different from classical quasars, as shown by their diffuse radio emission, which is similar to that of an FR I radio galaxy (e.g., Kollgaard et al. 1992; Rector \& Stocke 2001). These two effects cannot be clearly separated using only VLBI data. We show here that on average, objects historically called "BL Lac objects" differ statistically from classical quasars in their parsec-scale radio properties. Physical interpretation depends on separating the above two effects.

\section{VISIBILITY FUNCTIONS}

Our $15 \mathrm{GHz}$ VLBA images, made with natural weighting of the visibility data, have a nominal resolution of 0.5 mas in the east-west direction and $0.6-1.3$ mas in the north-south direction. The fringe spacing of the VSOP survey at $5 \mathrm{GHz}$ (Lovell et al. 2004; Scott et al. 2004; Horiuchi et al. 2004) is similar to that of the VLBA at $15 \mathrm{GHz}$, but the effective resolution of the VLBA is better, thanks to the relatively high SNR on the longest baselines and to the good relative calibration of the fringe visibilities, which can be determined with self-calibration using higher quality images based on many more interferometer baselines and full hour angle coverage. Typically, the dynamic range of the VLBA images (the ratio of the peak flux density to the rms noise level) is better than $1000: 1$ (Paper I; Paper II; Lister \& Homan 2005).

Figure Set 2 shows the visibility function amplitudes (correlated flux density vs. projected baseline length) for each source in the full sample at the epoch when the amplitude is the highest at the longest projected spacings. ${ }^{12}$ These plots are independent of any assumptions about the source structure, imaging artifacts, or beam smoothing, and they show the presence of structure on scales smaller than the synthesized beam. Also, as illustrated in Figure 3, many of these sources are variable. Changes with time in the observed visibility data, especially those on the longest baselines, corresponding to flux density variations in the unresolved components, are not easily seen in the synthesized images constructed from these data (see, e.g., Fig. 1), but they are apparent when comparing visibility function plots. Variability characteristics are discussed in more detail in $\S 5.5$.

Examination of the observed amplitudes of the visibility functions in Figure Set 2 suggests that they can be divided into the following categories:

1. Barely resolved sources for which the fringe visibility decreases only slowly with increasing spacing (e.g., $0235+164$, $0716+714,1726+455)$. For sources with good SNR, we can confidently determine that these sources are resolved, even if the fractional fringe visibility on the longest baselines is as large as 0.95-0.98, which corresponds to an angular size of only $0.056-$ 0.036 mas in the direction corresponding to the largest spacings (see the detailed discussion of the resolution criterion in $\S 4$ ). There are no sources that are completely unresolved. However, the maximum resolution of the VLBA is obtained within a narrow range of position angles close to the east-west direction. In other directions, the resolution is poorer by a factor of 2-3.

2. Sources with a well-resolved component plus an unresolved or barely resolved component. In these, the fringe visibility initially decreases with increasing spacing and then remains constant or decreases slowly (e.g., 0106+013, 0923+392, 1213-

\footnotetext{
12 A version of Fig. Set 2 with plots for all the epochs observed in the $15 \mathrm{GHz}$ VLBA monitoring program until 2003 August 28 is published in the electronic version of the Astronomical Journal.
}

172). For these sources we can place comparable limits on the size of an unresolved feature, as in case 1 above.

3. More complex or multicomponent sources that have visibility functions that vary significantly with baseline. If there is an upper envelope to the visibility function, which decreases only slowly to larger spacings, then the structure is primarily onedimensional, and the upper envelope indicates the smallest dimension (e.g., 1045-188, 1538+149, 2007+777). If there is a well-defined lower envelope, which monotonically decreases to larger spacings (e.g., 0014+813, 0917+624, 1656+053), this can be used as a measure of the overall dimensions of the source. If minima are observed in the lower envelope (e.g., 0224+671, 2131-021, 2234+282), they correspond to the spacing of the major components.

\section{DERIVED PARAMETERS AND MODEL FITTING}

The total flux density of each image, $S_{\mathrm{VLBA}}$, is the sum of the flux densities of all components of the CLEAN model; this should be equivalent to the visibility function amplitude $S_{c}$ (the correlated flux density) on the shortest projected baselines. In most cases in our sample, $S_{c}$ at the shortest spacings and $S_{\mathrm{VLBA}}$ are equal to within a few percent, which is a consequence of the hybrid imaging procedure. We define the $(u, v)$-radius as $r_{u v}=$ $\left(u^{2}+v^{2}\right)^{1 / 2}$. The unresolved ("compact") flux density $S_{\text {unres }}$ is defined as the upper envelope (with $90 \%$ of the visibilities below it) of the visibility function amplitude $S_{c}$ at projected baselines $r_{u v}>360 \mathrm{M} \lambda$, which is approximately $0.8 r_{u v, \max }$. The overall uncertainty in $S_{\mathrm{VLBA}}$ and $S_{\text {unres }}$ is determined mainly by the accuracy of the flux density (amplitude) calibration, which we estimate to be about $5 \%$ (consistent with estimates of Homan et al. 2002).

We have used the program DIFMAP (Shepherd 1997) to fit the complex visibility functions with simple models, consisting of two elliptical Gaussian components, one representing the VLBA core and the other the inner part of a one-sided jet. By the "core" we mean the bright unresolved feature typically found at the end of so-called core-jet sources; this is usually thought to be the base of a continuous jet and does not necessarily correspond to the nucleus of the object. The main objective of our procedure was to obtain a robust characterization of the core. We have verified the suitability of our method for that purpose in several ways. Varying the initial values for the iterative fitting procedure did not significantly change the final core parameter values. Using more complex models consisting of three or four components also did not significantly change the parameter values for the core component in most sources, even fairly complex ones; instead, the additional components tended to cover additional parts of the jets. We have also compared the modeling results obtained in this study with the more elaborate models obtained for all MOJAVE sources in the work of Lister \& Homan (2005); those models were built up by adding new components until the thermal noise level was reached in the residual image. For about $90 \%$ of the sources in which the core was modeled by Lister \& Homan (2005) as an elliptical Gaussian component, the parameters derived by the two methods agree to within $10 \%$. However, for 23 sources with complex structure we found that a twocomponent model overestimates the flux density and the angular size of the core, and we have added more components to model these sources. We do not present or use any modeling results for an additional 11 sources, which have very complex structure, such as the two-sided radio galaxy NGC 1052 (Vermeulen et al. 2003; see also the sources in Figure 2, Paper III). We conclude that, for most of the sources in our sample, the core can be characterized accurately and robustly with the two-component 

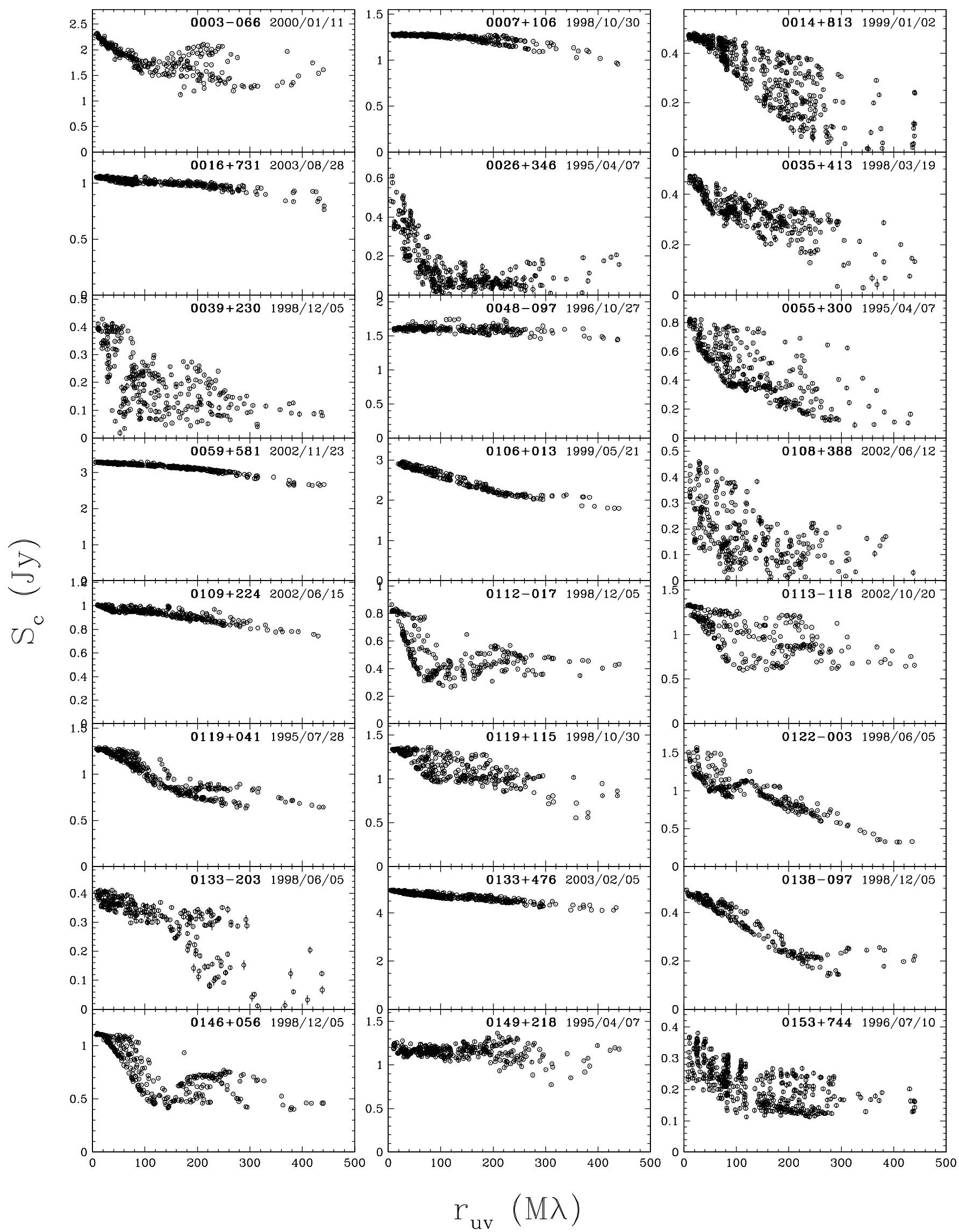

FIG. SET 2.-Amplitude of the visibility function (i.e., correlated flux density) $S_{c}$ vs. projected spacing $r_{u v}$. Each point represents a coherent average over one $4-6$ minute observation on an individual interferometer baseline. The error bars, which represent only the statistical errors, are often smaller than the symbol. Errors of the absolute flux density calibration are not shown here and are about $5 \%$. For each source, the data are presented at the epoch when $S_{\text {unres }}$ is maximum. [The plots for all the epochs observed in the $15 \mathrm{GHz}$ VLBA monitoring program until 2003 August 28 are shown in Figs. 2.1-2.250 in the electronic version of the Astronomical Journal.] 

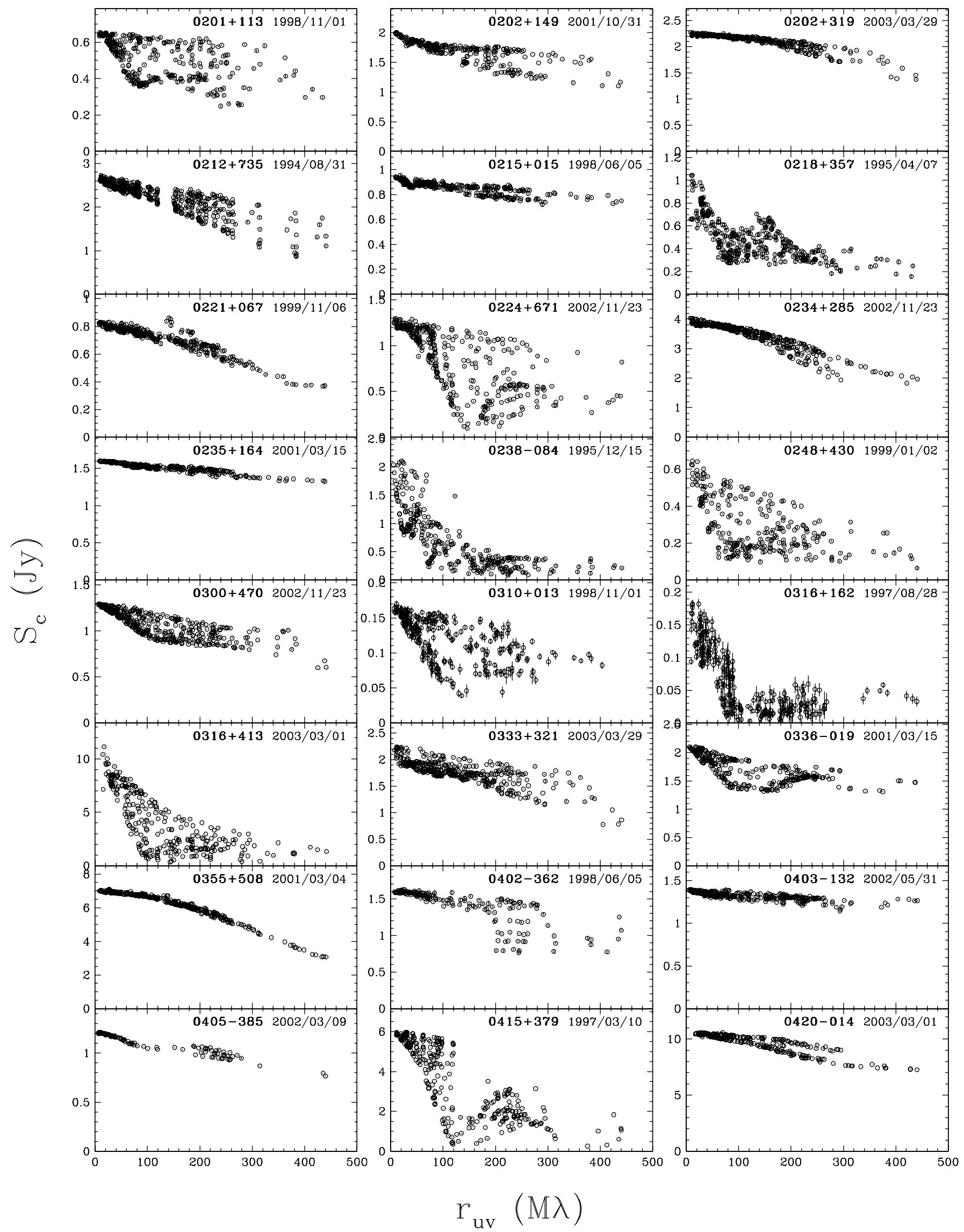

FIg. Set 2.-Continued 

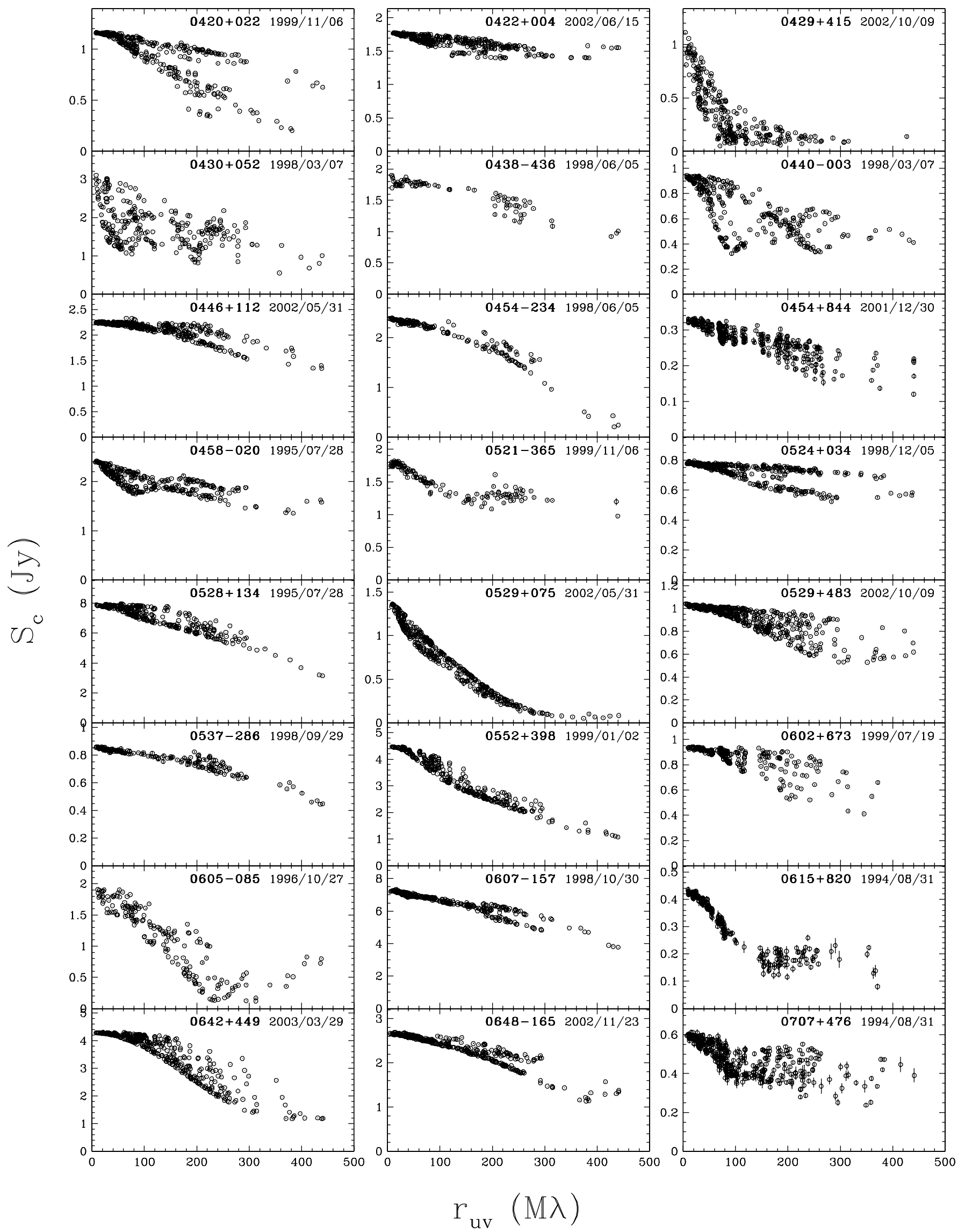

Fig. Set 2.-Continued 

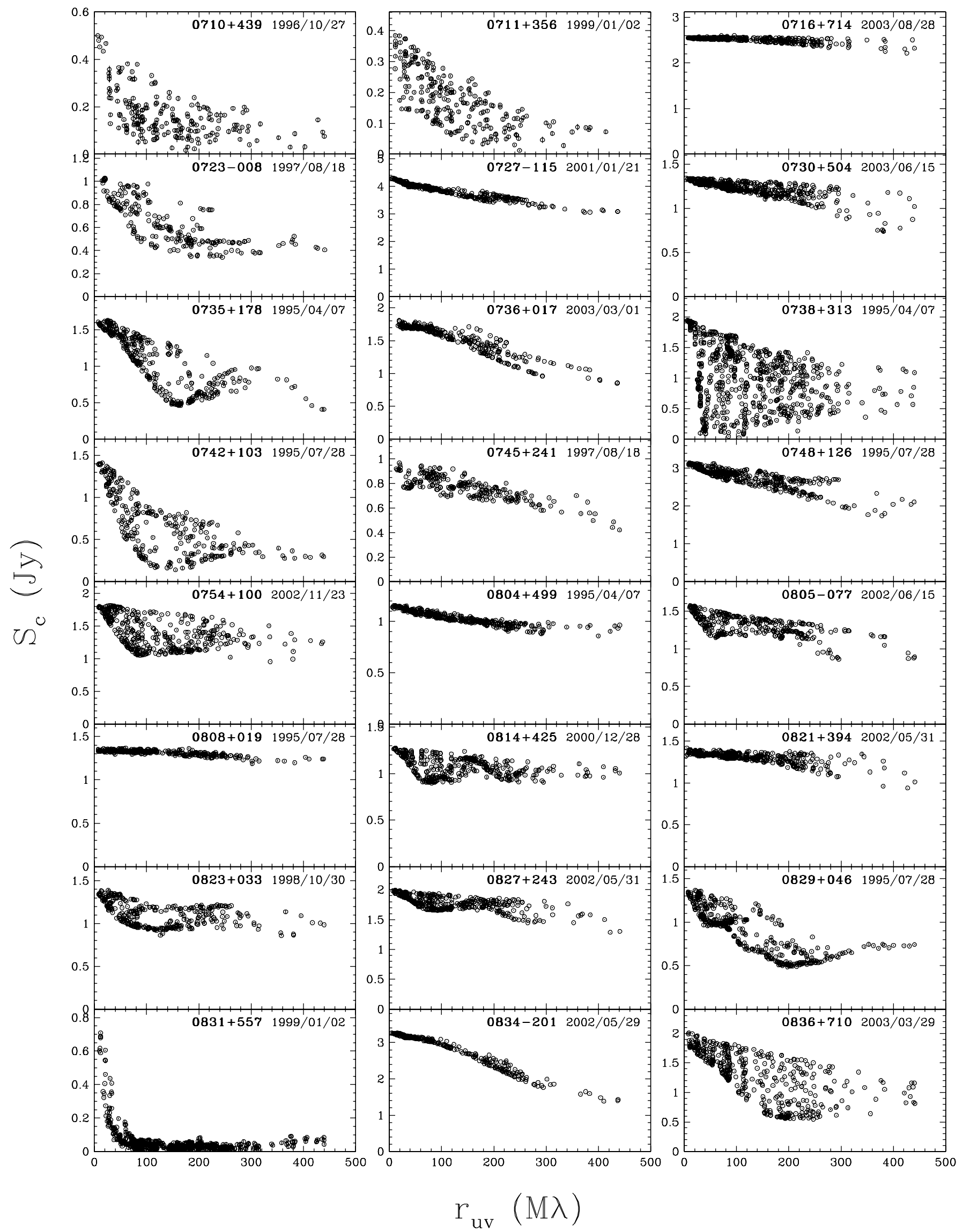

Fig. Set 2.-Continued 

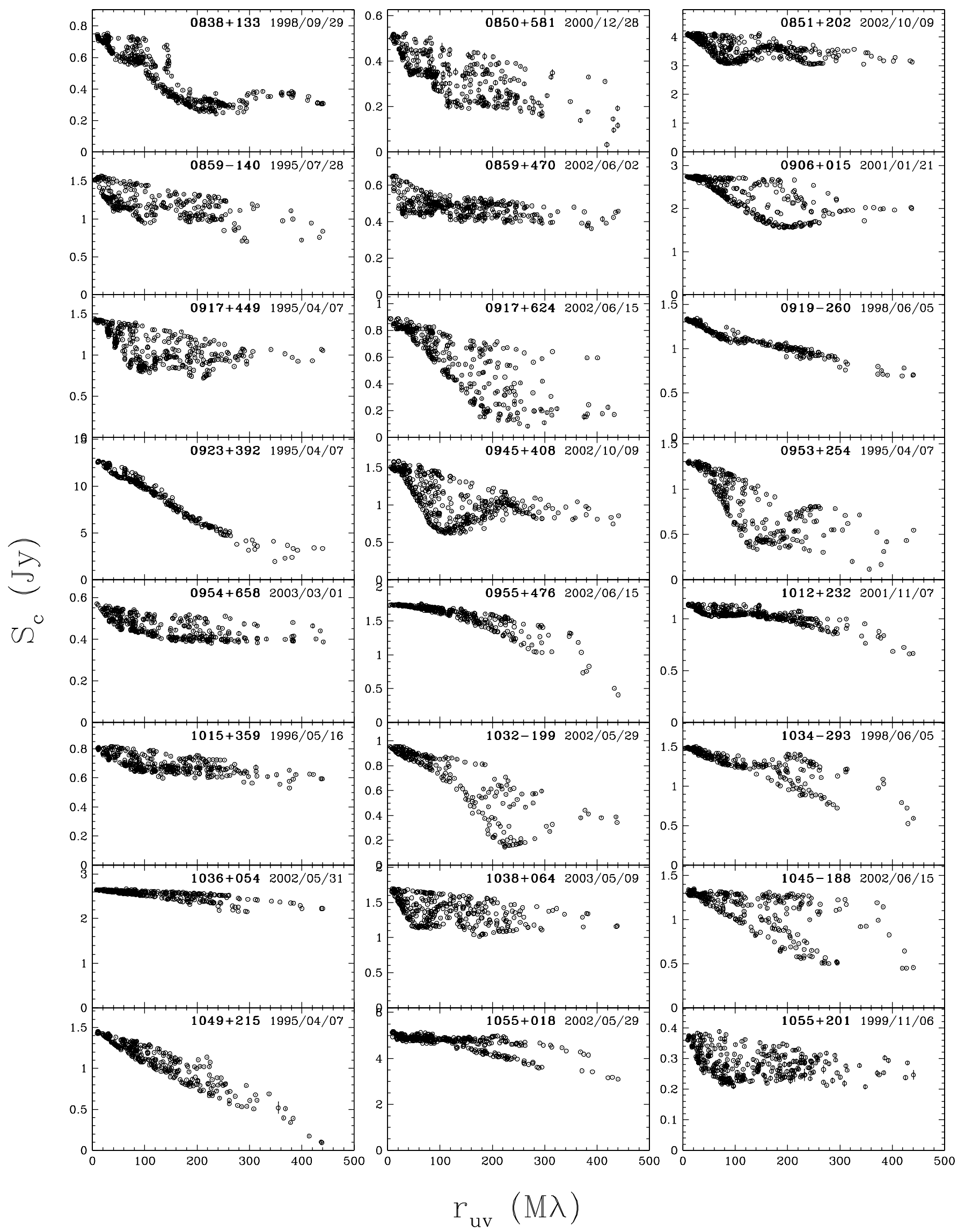

FIG. Set 2.-Continued 

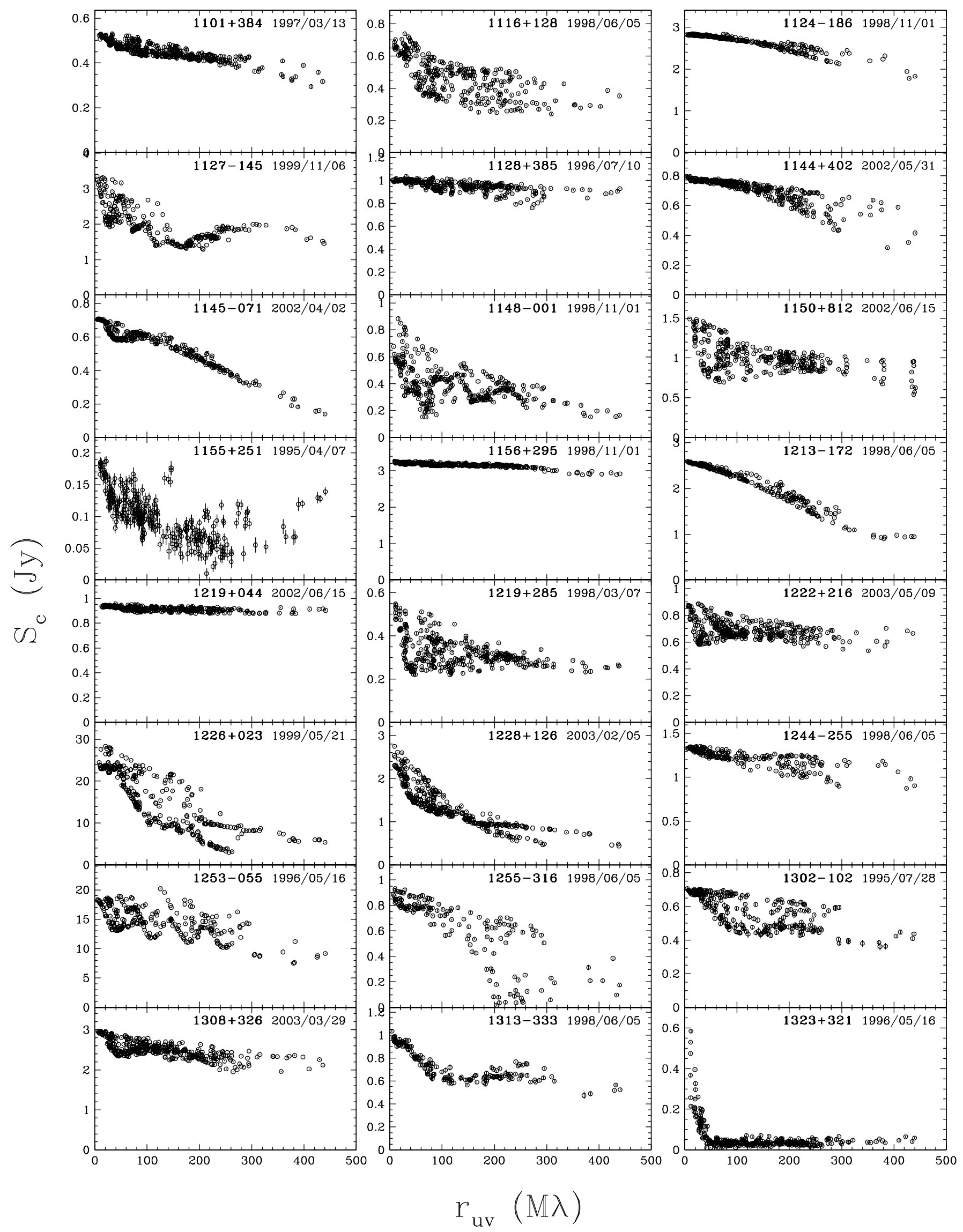

Fig. Set 2.-Continued 

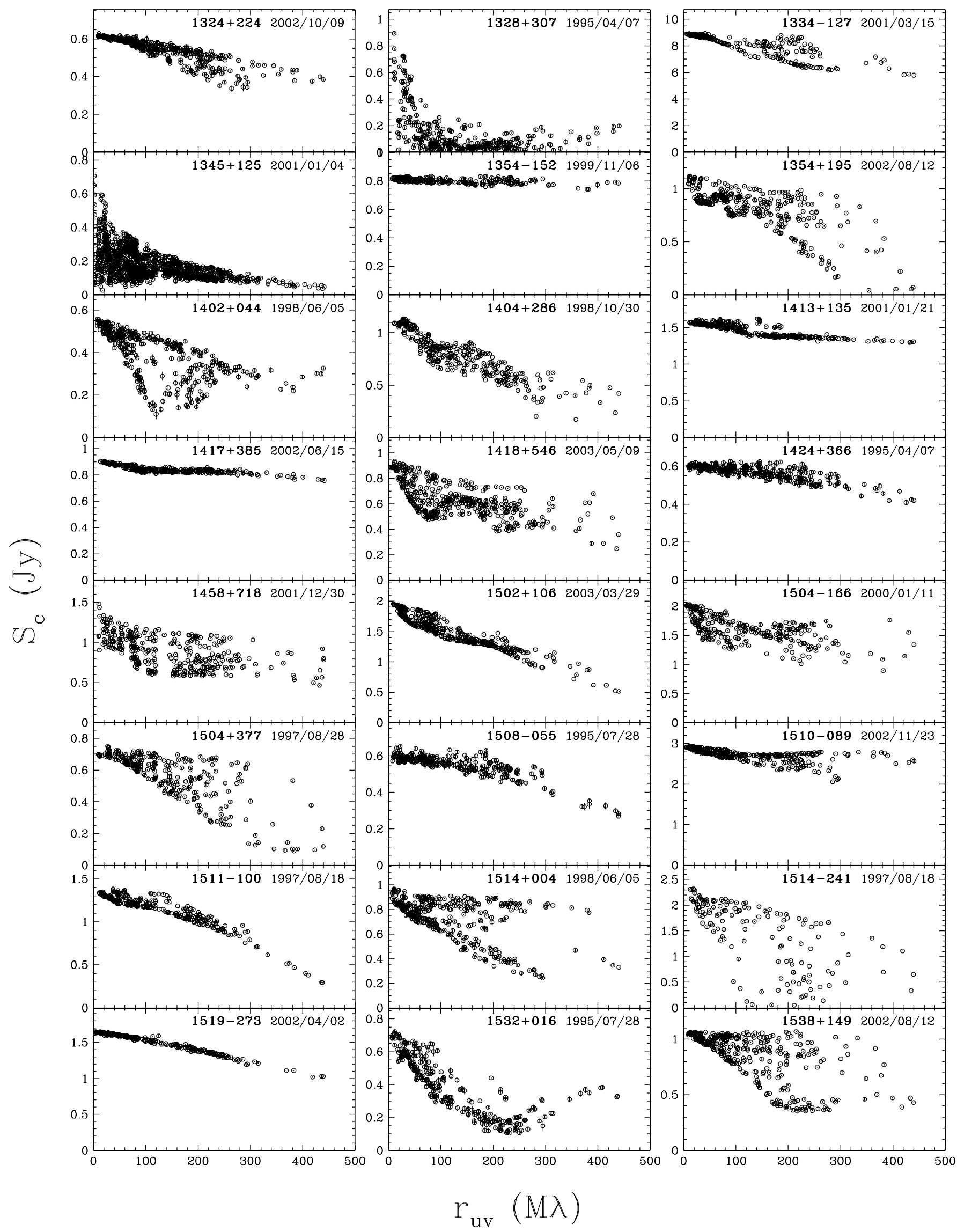

FIG. Set 2.-Continued 

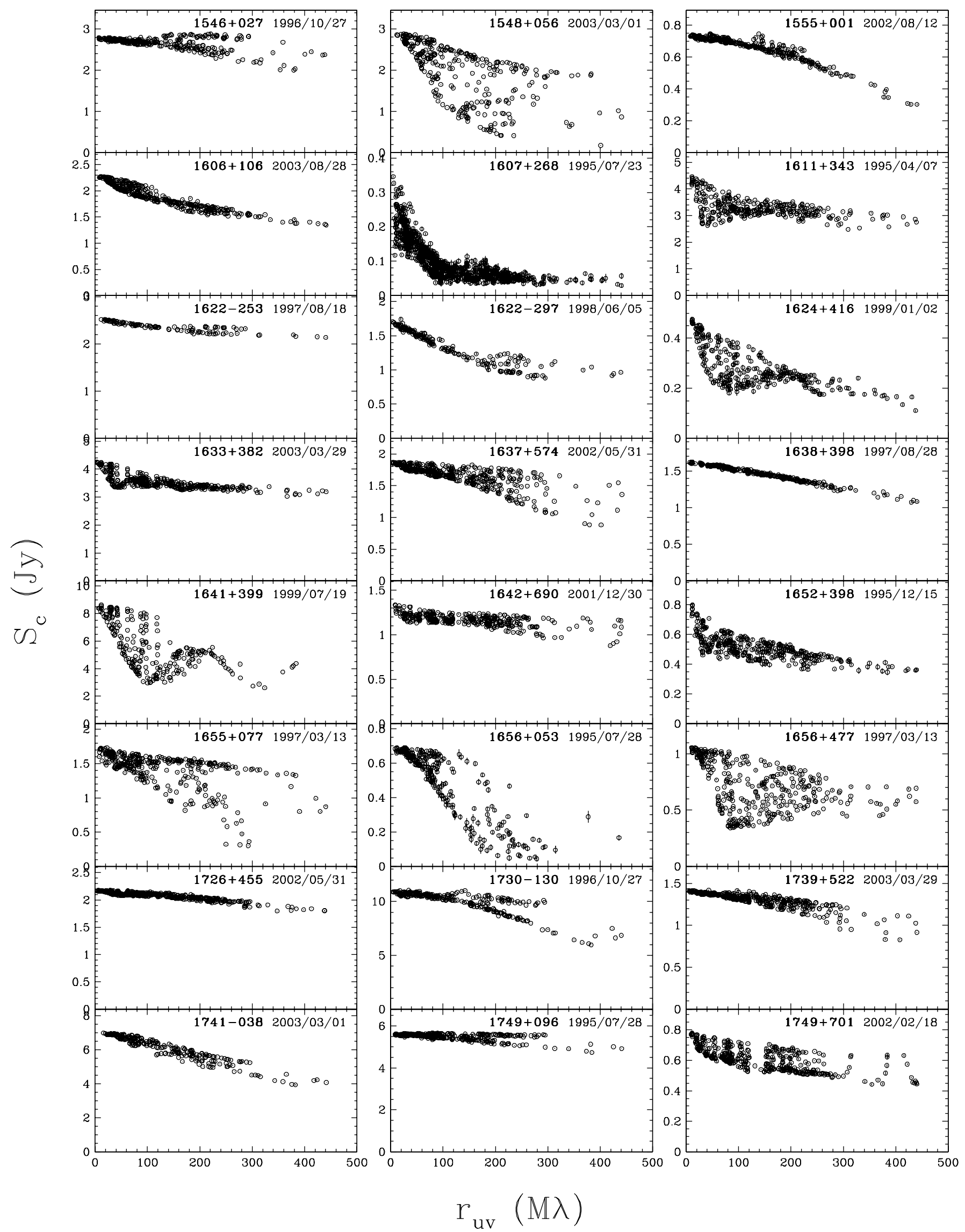

Fig. Set 2.-Continued 

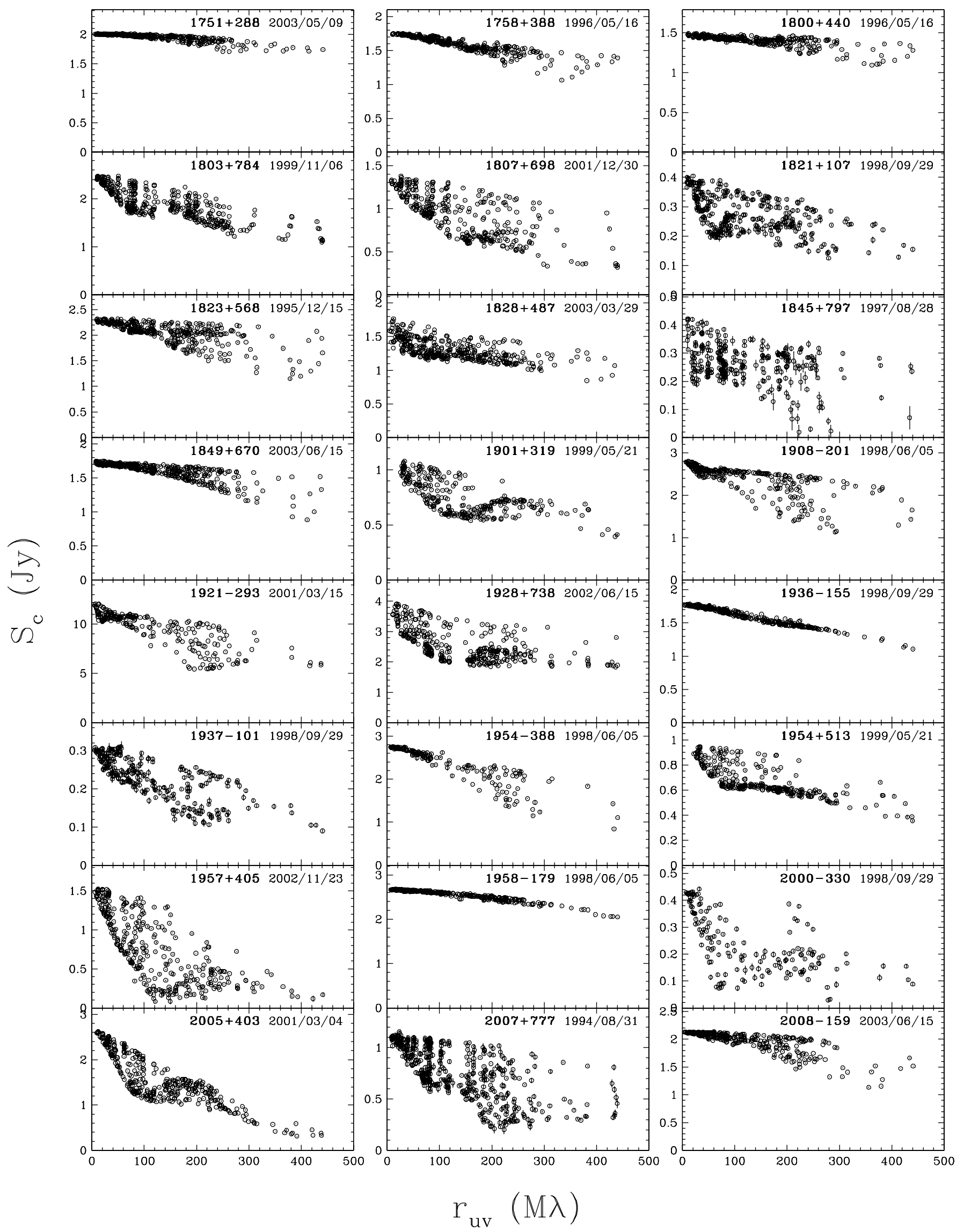

FIg. Set 2.-Continued 

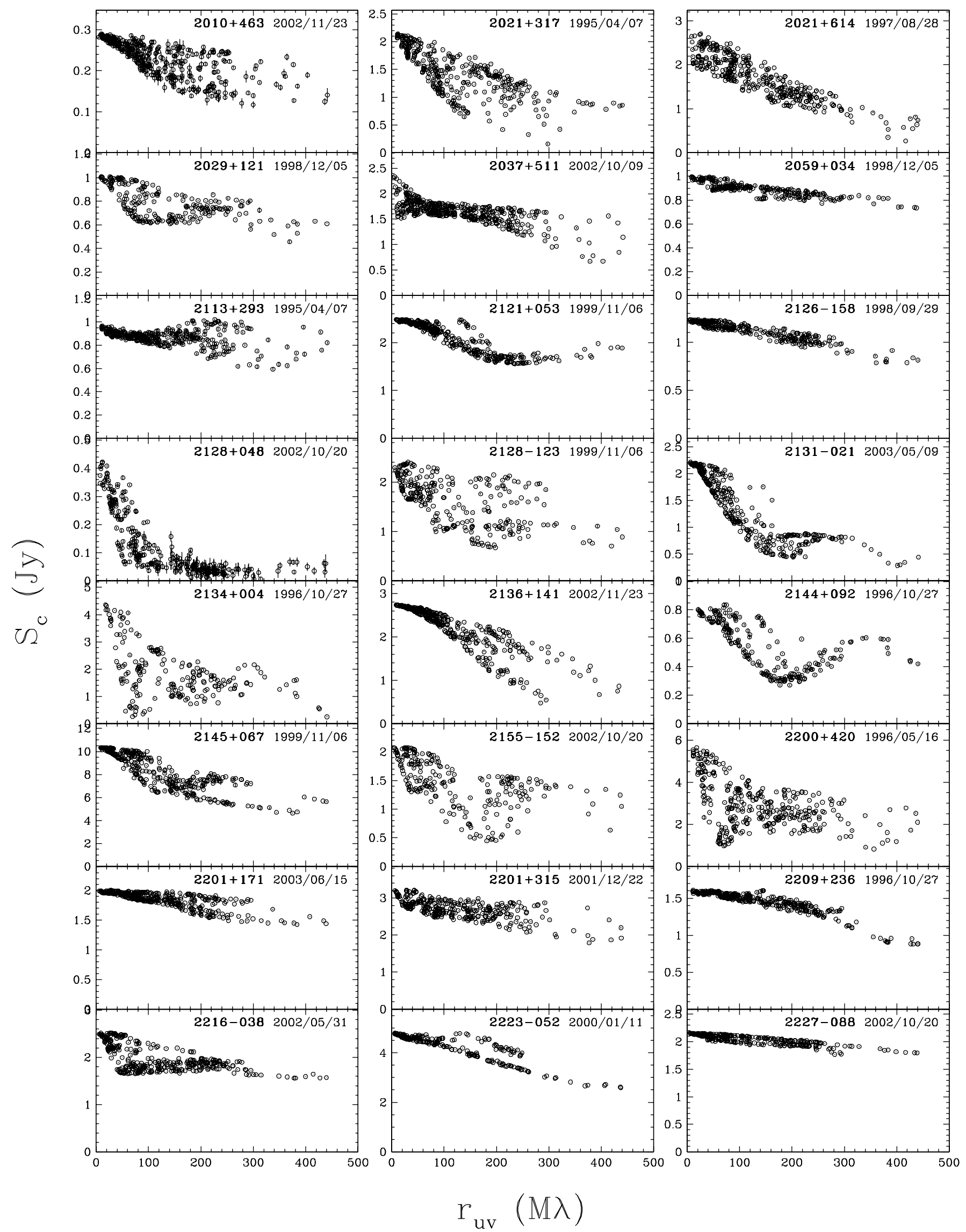

Fig. Set 2.-Continued 

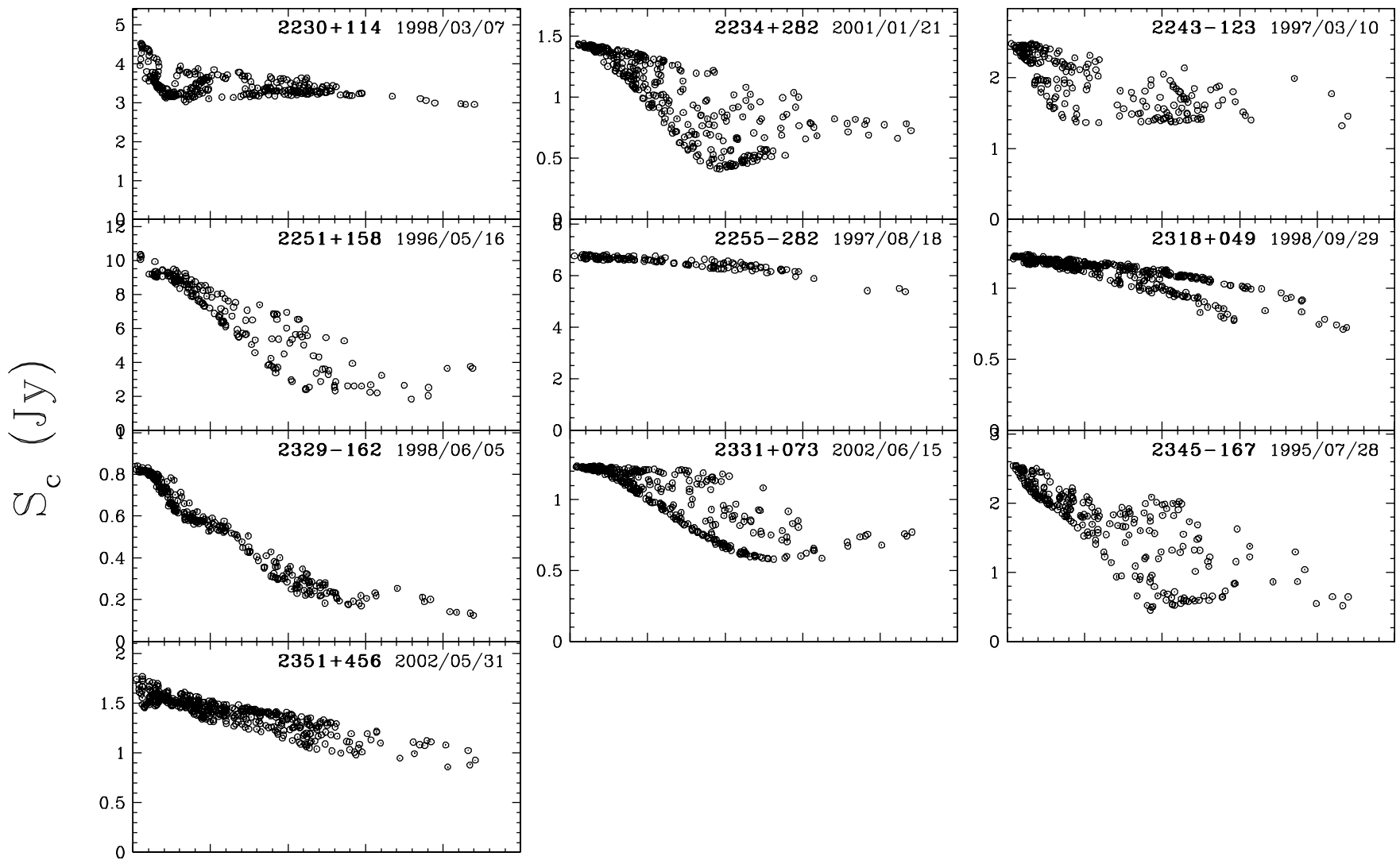

\section{$r_{\mathrm{uv}}(\mathrm{M} \lambda)$}

Fig. Set 2.-Continued

modeling method used, because the beamed emission of the compact core dominates the $15 \mathrm{GHz}$ structure (median value of $S_{\text {core }} / S_{\mathrm{VLBA}}=0.80$ for the full sample).

In about one-quarter of the data sets the core is only slightly resolved on the longest baselines. Following Lobanov (2005), we derive a resolution criterion for VLBI core components by considering a visibility distribution $\mathcal{V}\left(r_{u v}\right)$ corresponding to the core; $\mathcal{V}\left(r_{u v}\right)$ is normalized by the flux density $S_{\text {core }}$, so that $\mathcal{V}(0) \equiv 1$. The core is resolved if

$$
1-\mathcal{V}\left(r_{u v, \max }\right) \leq \sigma_{\text {core }} / S_{\text {core }}=1 / \mathrm{SNR}
$$

Here, $\sigma_{\text {core }}$ is the rms noise level in the area of the image occupied by the core component (to exclude possible contamination from the jet). In order to measure $\sigma_{\text {core }}$ for each data set, we have first subtracted the derived model from the image and then used the residual pixel values in the area of the core component convolved with the synthesized beam (truncated at the half-power level). For naturally weighted VLBI data, the beam size, with major and minor axes $b_{\text {maj }}$ and $b_{\text {min }}$ measured at the half-power point, yields the largest observed $(u, v)$-spacing as follows: $r_{u v, \max }=\left(\pi b_{\text {maj }} b_{\min }\right)^{-1 / 2}$. The visibility distribution corresponding to a Gaussian feature of angular size $d$ is given by $\mathcal{V}\left(r_{u v}\right)=$ $\exp \left[-\left(\pi d r_{u v}\right) 2 /(4 \ln 2)\right]$. With these relations, the resolution criterion given by equation (1) yields a minimum resolvable size of a Gaussian component fitted to naturally weighted VLBI data of

$$
\theta_{\lim }=b_{\psi} \sqrt{\frac{4 \ln 2}{\pi} \ln \left(\frac{\mathrm{SNR}}{\mathrm{SNR}-1}\right)} .
$$

Here, $b_{\psi}$ is the half-power beam size measured along an arbitrary position angle $\psi$. For all data sets we have derived $\theta_{\text {lim }}$ corresponding to the position angles of the major and minor axis $\left(\theta_{\text {maj }}\right.$, $\left.\theta_{\min }\right)$ of the fitted Gaussian core component. Whenever either one or both of the two axes were smaller than the respective $\theta_{\lim }$, the Gaussian component was considered to be unresolved; $\theta_{\text {lim }}$ was then used as an upper limit to the size of the component, which yields a lower limit to its brightness temperature. It should be noted that at high SNR, $\theta_{\text {lim }}$ can be significantly smaller than the size of the resolving beam and the Rayleigh limit. This is the result of applying a specific a priori hypothesis about the shape of the emitting region (a two-dimensional Gaussian, in our case) to fit the observed brightness distribution. A similar approach is employed to provide the theoretical basis for the technique of super-resolution (Bertero \& De Mol 1996).

In our analysis we have also used the total flux density $S_{\text {tot }}$ at $15 \mathrm{GHz}$, determined from observations with single antennas. We have incorporated the data from the University of Michigan Radio Astronomy Observatory (UMRAO) monitoring program (Aller et al. 1985, 1992, 2003), ${ }^{13}$ as well as instantaneous $1-$ $22 \mathrm{GHz}$ broadband radio spectra obtained during the long-term monitoring of compact extragalactic sources with the RATAN600 radio telescope of the Special Astrophysical Observatory (Kovalev 1998; Kovalev et al. 1999, 2000). We have interpolated the UMRAO observations in time and the RATAN-600 data in both frequency (between 11 and $22 \mathrm{GHz}$ ) and time to obtain the effective filled-aperture total flux density, $S_{\text {tot }}$, at the

\footnotetext{
${ }^{13}$ See also http://www.astro.lsa.umich.edu/obs/radiotel/umrao.html.
} 


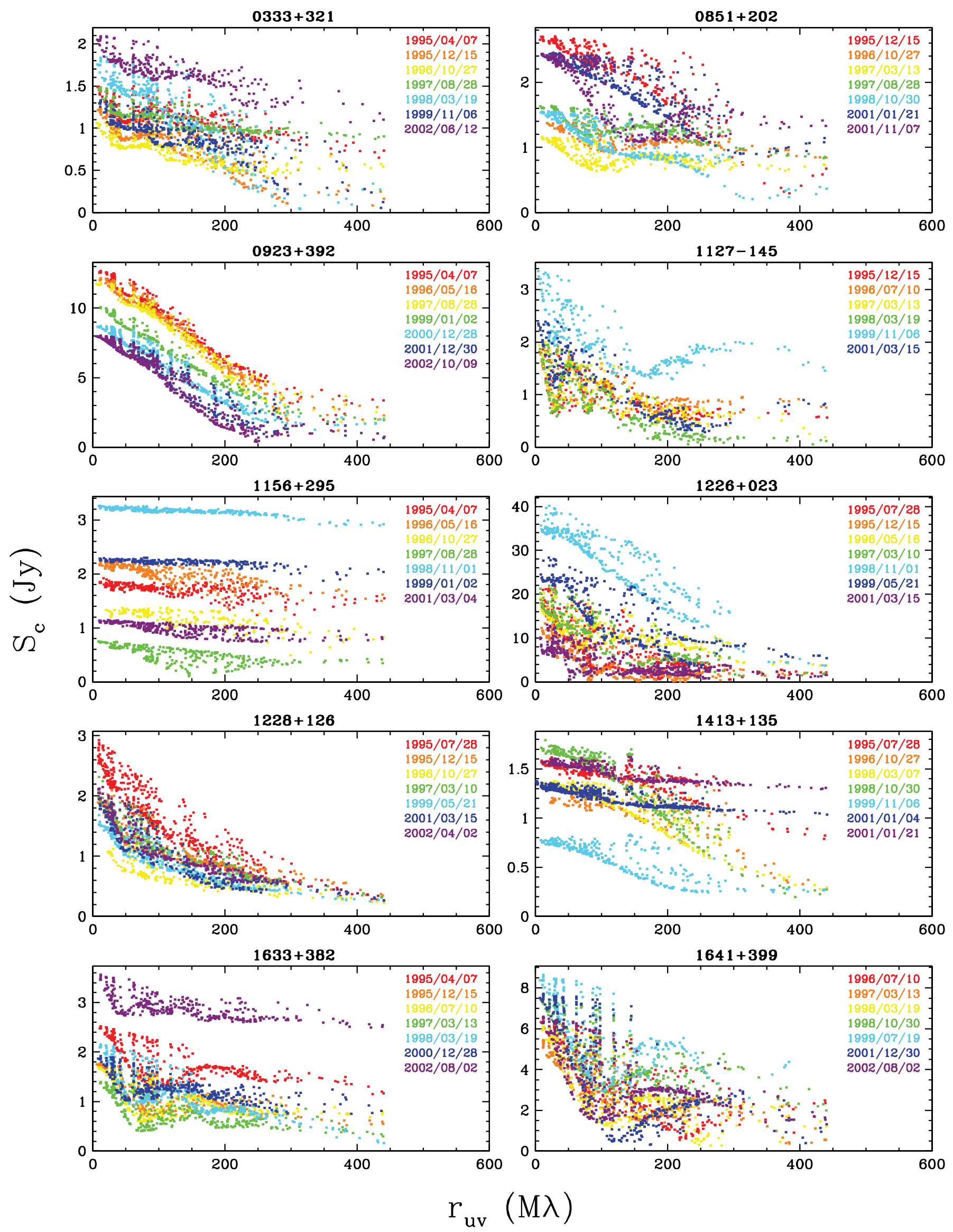

FIG. 3.-Examples of the time variability of the correlated flux density vs. projected spacing for 10 representative sources. Different epochs are denoted by different colors in their spectrum-color order. 

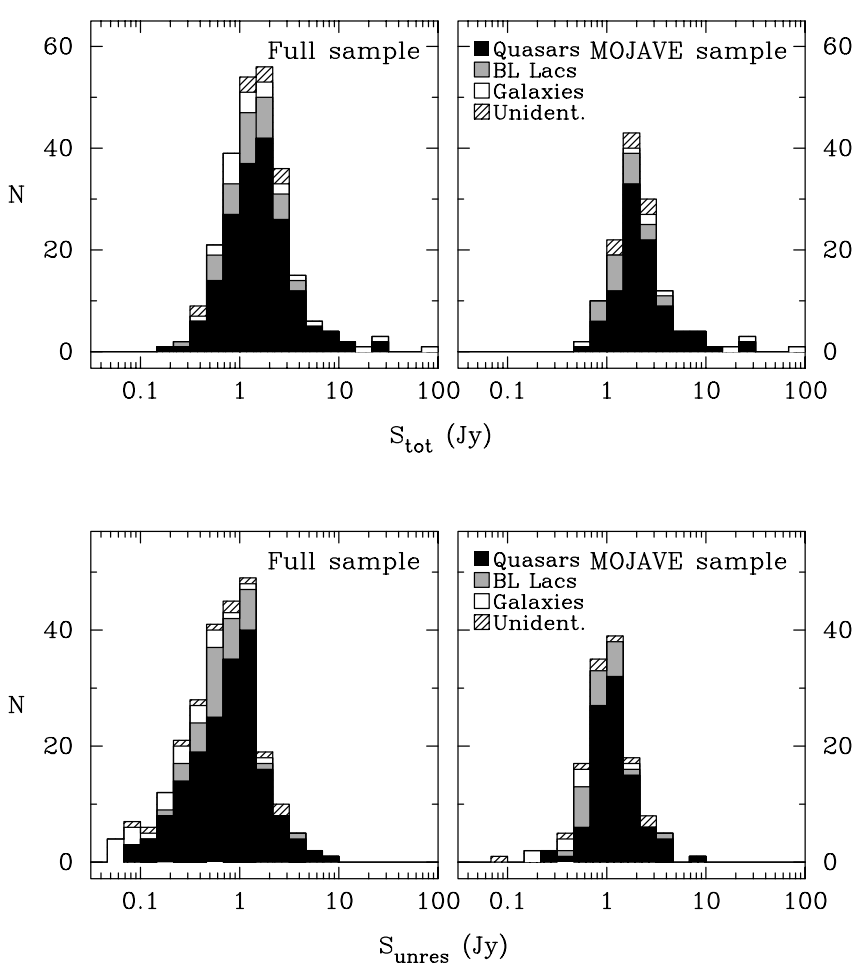

FIG. 4.-Distribution of the flux density in the full and MOJAVE samples showing the median single-antenna flux density, $S_{\text {tot }}$ (top panels), and the median flux density of the most compact component, $S_{\text {unres }}$ (bottom panels).

epoch and frequency of the VLBA observations. The main contribution to the total uncertainty in the $S_{\text {tot }}$ values comes from the nonsimultaneity of the VLBA and the single-dish observations. This can give errors up to $20 \%-30 \%$, but the typical uncertainties are below $5 \%$.

\section{RESULTS AND DISCUSSION}

\subsection{Source Compactness}

Figure 4 shows the distributions in our sample of the total flux densities, $S_{\text {tot }}$, from single-dish measurements and the correlated flux densities, $S_{\text {unres }}$, from long VLBA spacings. The peak in the distribution of $S_{\text {tot }}$ corresponds to our nominal flux density limit of 1.5 or $2 \mathrm{Jy}$ (depending on declination). The tail to lower flux densities in both panels is due to variability, and in the full sample (Fig. 4, left panels) the tail also includes some sources of particular interest, which we included in the observations but did not meet our flux density criteria. Figure 5 gives the distributions of the "indices of compactness" on arcsecond scales, $S_{\mathrm{VLBA}} / S_{\text {tot }}$, and sub-milliarcsecond scales, $S_{\text {unres }} / S_{\mathrm{VLBA}}$, as well as of the VLBA core dominance, $S_{\text {core }} / S_{\text {VLBA }}$.

Many sources in our sample have considerable flux on spatial scales sampled by the longest VLBA baselines. In Figure 4 (bottom left) we see that more than $90 \%$ of the sources have an unresolved flux density greater than $0.1 \mathrm{Jy}$ at projected baselines longer than $360 \mathrm{M} \lambda$, while Figure 5 (middle left) shows that $68 \%$ of the sources have a median $S_{\text {unres }} / S_{\mathrm{VLBA}}>0.5$. For 163 sources the median flux density of the most compact component is greater than $0.5 \mathrm{Jy}$. Table 2 lists, for each source, flux densities and model fitting results (as well as some other data) at the epoch for which its unresolved flux density $S_{\text {unres }}$ was greatest. ${ }^{14}$ These

\footnotetext{
${ }^{14}$ A version of Table 2 with the parameters at all epochs is published in the electronic edition of the Astronomical Journal.
}
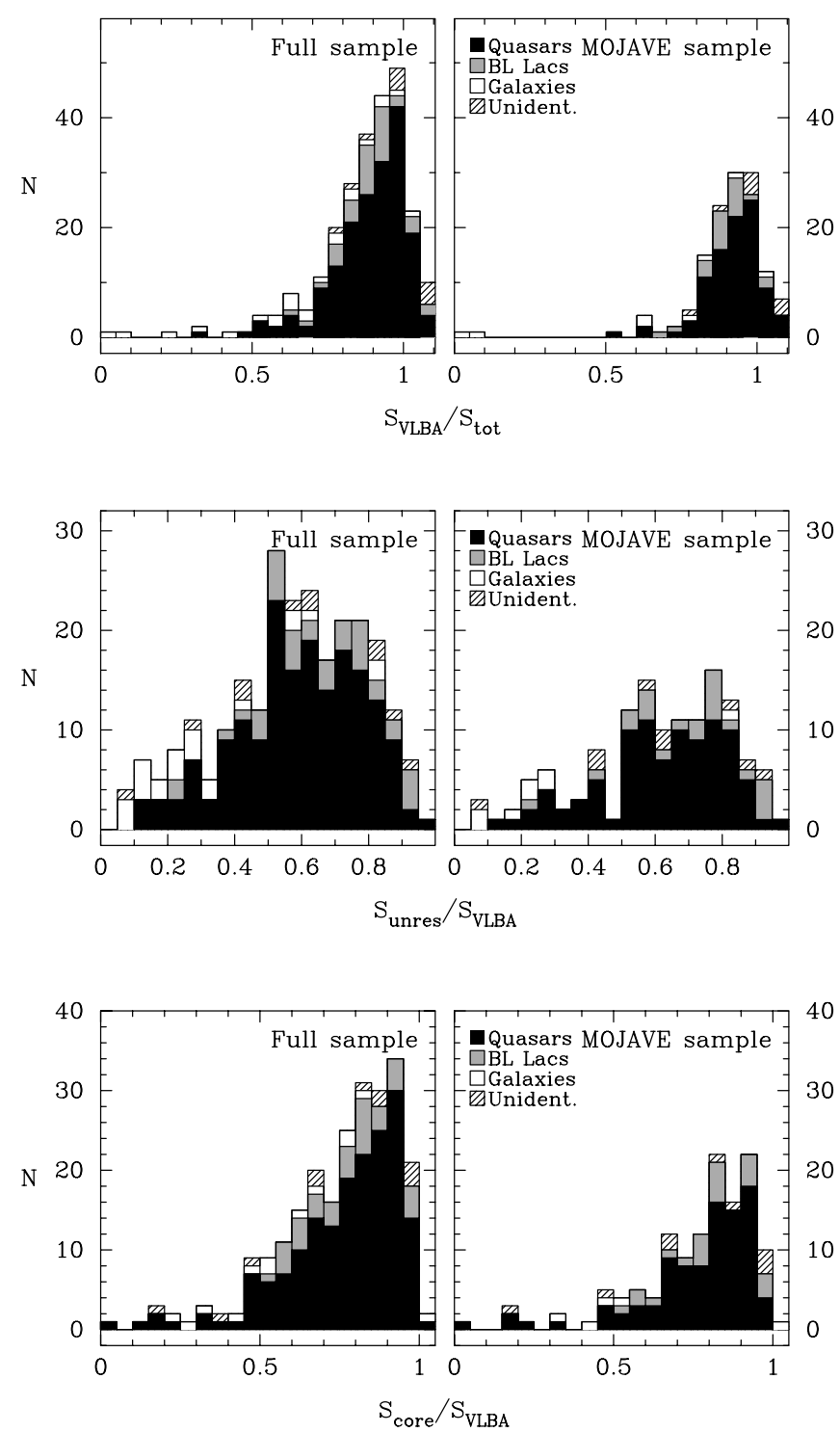

FIG. 5.-Distributions of the median compactness indices on arcsecond scales $S_{\mathrm{VLBA}} / S_{\mathrm{tot}}$ (top panels) and on sub-milliarcsecond scales $S_{\mathrm{unres}} / S_{\mathrm{VLBA}}$ (middle panels), as well as the VLBA core dominance $S_{\text {core }} / S_{\mathrm{VLBA}}$ (bottom panels). A few sources have an apparent compactness index at arcsecond scales $S_{\mathrm{VLBA}} / S_{\text {tot }}>1$; this is due to source variability and the nonsimultaneity of the VLBA and singleantenna observations.

data will be of value for various purposes, including planning future VLBI observations using Earth-space baselines.

We have compared the measured values of $S_{\mathrm{VLBA}}$ and $S_{\mathrm{tot}}$. Figure 5 indicates that there are no significant systematic errors in the independently constructed VLBA/RATAN/UMRAO flux density scales. The median compactness index on arcsecond scales, $S_{\mathrm{VLBA}} / S_{\text {tot }}$, is 0.91 for the full sample and 0.93 for the MOJAVE sample, which indicates that for most sources the VLBA image contains nearly all the flux density. Some sources have an apparent compactness on arcsecond scales $S_{\mathrm{VLBA}} / S_{\text {tot }}>$ 1. Most likely, this is due to source variability and the nonsimultaneity of the VLBA and single-antenna observations. Sources with compactness index close to unity (see Table 2) are well suited as calibrators for other VLBA observations.

\subsection{Source Classes}

The curves in Figure 6 show the mean visibility amplitude versus projected $(u, v)$-spacing, averaged over all sources in the 
TABLE 2

Source Parameters at Maximum Unresolved Flux Density

\begin{tabular}{|c|c|c|c|c|c|c|c|c|c|c|c|c|}
\hline $\begin{array}{l}\text { Source } \\
\text { (1) }\end{array}$ & $\begin{array}{l}\text { Epoch } \\
\text { (2) }\end{array}$ & $\begin{array}{l}S_{\text {tot }} \\
(3)\end{array}$ & $\begin{array}{l}S_{\mathrm{VLBA}} \\
(4)\end{array}$ & $\begin{array}{l}S_{\text {unres }} \\
(5)\end{array}$ & $\begin{array}{l}\frac{S_{\mathrm{VLBA}}}{S_{\mathrm{tot}}} \\
(6)\end{array}$ & $\begin{array}{l}S_{\text {core }} \\
(7)\end{array}$ & $\begin{array}{l}\theta_{\text {maj }} \\
(8)\end{array}$ & $\begin{array}{l}\theta_{\min } \\
(9)\end{array}$ & $\begin{array}{c}T_{b} \\
(10)\end{array}$ & $\begin{array}{l}\mathrm{PA}_{\text {jet }} \\
(11)\end{array}$ & $\begin{array}{c}\text { No. of } \\
\text { Epochs } \\
\text { (12) }\end{array}$ & $\begin{array}{l}\text { No. Unresolved } \\
\text { (13) }\end{array}$ \\
\hline $0003-066$............... & $2000 / 01 / 11$ & 2.51 & 2.28 & 1.97 & 0.88 & 1.85 & 0.50 & $<0.06$ & $>4.60 \mathrm{e}+11$ & -79 & 7 & 1 \\
\hline $0007+106 \ldots \ldots \ldots \ldots$ & $1998 / 10 / 30$ & 1.21 & 1.28 & 1.11 & 1.01 & 1.28 & 0.15 & 0.06 & $9.05 \mathrm{e}+11$ & $\ldots$ & 6 & 4 \\
\hline $0014+813 \ldots \ldots \ldots \ldots$ & $1999 / 01 / 02$ & 0.50 & 0.47 & 0.24 & 0.94 & 0.37 & 0.54 & 0.14 & $1.20 \mathrm{e}+11$ & 167 & 1 & 0 \\
\hline $0016+731 \ldots \ldots \ldots \ldots$ & $2003 / 08 / 28$ & 1.11 & 1.06 & 0.93 & 0.85 & 1.02 & 0.13 & 0.09 & $1.39 \mathrm{e}+12$ & 130 & 6 & 2 \\
\hline $0026+346 \ldots \ldots \ldots \ldots$ & $1995 / 04 / 07$ & 0.70 & 0.65 & 0.21 & 0.66 & $\ldots$ & $\ldots$ & $\ldots$ & $\ldots$ & 55 & 7 & $\ldots$ \\
\hline $0035+413 \ldots \ldots \ldots \ldots$ & $1998 / 03 / 19$ & 0.50 & 0.47 & 0.29 & 0.93 & 0.38 & 0.43 & 0.18 & $6.16 \mathrm{e}+10$ & 101 & 6 & 3 \\
\hline $0039+230 \ldots \ldots \ldots \ldots$ & $1998 / 12 / 05$ & 0.42 & 0.45 & 0.13 & 1.07 & 0.16 & 0.31 & 0.22 & $>1.34 \mathrm{e}+10$ & -164 & 1 & 0 \\
\hline 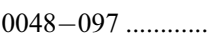 & $1996 / 10 / 27$ & 2.09 & 1.60 & 1.60 & 0.85 & 1.61 & 0.08 & $<0.05$ & $>2.37 \mathrm{e}+12$ & -12 & 5 & 2 \\
\hline $0055+300 \ldots \ldots \ldots \ldots$ & $1995 / 04 / 07$ & 0.70 & 0.82 & 0.33 & 0.98 & 0.47 & 0.48 & $<0.05$ & $>1.11 \mathrm{e}+11$ & -53 & 6 & 3 \\
\hline $0059+581 \ldots \ldots \ldots \ldots$ & $2002 / 11 / 23$ & 3.12 & 3.32 & 2.72 & 1.06 & 3.25 & 0.13 & 0.11 & $>1.22 \mathrm{e}+12$ & -126 & 1 & 0 \\
\hline $0106+013 \ldots \ldots \ldots \ldots$ & $1999 / 05 / 21$ & 2.99 & 2.98 & 2.09 & 0.90 & 2.32 & 0.16 & 0.10 & $2.47 \mathrm{e}+12$ & -121 & 9 & 4 \\
\hline $0108+388^{\mathrm{a}} \ldots \ldots \ldots \ldots$ & $2002 / 06 / 12$ & 0.53 & 0.46 & 0.17 & 0.83 & 0.13 & 0.29 & 0.25 & $1.57 \mathrm{e}+10$ & -106 & 2 & 0 \\
\hline 0109+224 ............... & $2002 / 06 / 15$ & 1.02 & 1.01 & 0.78 & 1.03 & 0.96 & 0.15 & 0.04 & $>7.71 \mathrm{e}+11$ & 88 & 2 & 1 \\
\hline $0112-017 \ldots \ldots \ldots \ldots$ & $1998 / 12 / 05$ & 0.93 & 0.82 & 0.46 & 0.88 & 0.48 & 0.32 & $<0.02$ & $>8.28 \mathrm{e}+11$ & 120 & 6 & 4 \\
\hline $0113-118 \ldots \ldots \ldots \ldots$ & $2002 / 10 / 20$ & 1.39 & 1.32 & 0.86 & 0.96 & 1.00 & 0.35 & 0.05 & $5.27 \mathrm{e}+11$ & -31 & 2 & 1 \\
\hline 0119+041 …............... & $1995 / 07 / 28$ & 1.25 & 1.28 & 0.72 & 0.95 & 1.11 & 0.29 & 0.20 & $1.65 \mathrm{e}+11$ & 79 & 6 & 3 \\
\hline $0119+115 \ldots \ldots \ldots \ldots \ldots$ & $1998 / 10 / 30$ & 1.35 & 1.35 & 0.95 & 0.94 & 1.20 & 0.36 & 0.12 & $2.33 \mathrm{e}+11$ & 0 & 3 & 0 \\
\hline $0122-003 \ldots \ldots \ldots . . .$. & $1998 / 06 / 05$ & 1.59 & 1.56 & 0.43 & 0.98 & 1.16 & 0.33 & 0.11 & $3.58 \mathrm{e}+11$ & -96 & 3 & 0 \\
\hline $0133-203 \ldots \ldots \ldots \ldots$ & $1998 / 06 / 05$ & 0.49 & 0.41 & 0.20 & 0.84 & 0.38 & 0.67 & 0.17 & $3.77 \mathrm{e}+10$ & 16 & 1 & 0 \\
\hline $0133+476 \ldots \ldots \ldots \ldots$ & $2003 / 02 / 05$ & 4.74 & 4.97 & 4.33 & 0.90 & 4.71 & 0.12 & 0.08 & $4.99 \mathrm{e}+12$ & -29 & 8 & 2 \\
\hline $0138-097 \ldots \ldots \ldots . . . .$. & $1998 / 12 / 05$ & 0.48 & 0.48 & 0.26 & 1.06 & 0.37 & 0.33 & 0.21 & $5.08 \mathrm{e}+10$ & -113 & 2 & 1 \\
\hline $0146+056 \ldots \ldots \ldots \ldots$ & $1998 / 12 / 05$ & 1.06 & 1.10 & 0.53 & 1.02 & 0.78 & 0.30 & 0.18 & $2.67 \mathrm{e}+11$ & 112 & 2 & 0 \\
\hline $0149+218 \ldots \ldots \ldots \ldots$ & $1995 / 04 / 07$ & 1.20 & 1.26 & 1.22 & 1.02 & 1.19 & 0.28 & $<0.04$ & $>1.40 \mathrm{e}+12$ & -15 & 7 & 1 \\
\hline $0153+744^{\mathrm{a}} \ldots \ldots \ldots \ldots$ & $1996 / 07 / 10$ & 0.49 & 0.37 & 0.20 & 0.77 & 0.19 & 0.20 & 0.07 & $2.55 \mathrm{e}+11$ & 72 & 7 & 4 \\
\hline $0201+113 \ldots \ldots \ldots \ldots$ & 1998/11/01 & 0.66 & 0.65 & 0.51 & 1.00 & 0.49 & 0.40 & $<0.03$ & $>9.44 \mathrm{e}+11$ & -29 & 2 & 1 \\
\hline $0202+149 \ldots \ldots \ldots \ldots$ & $2001 / 10 / 31$ & 2.73 & 2.01 & 1.59 & 0.76 & 1.76 & 0.30 & 0.09 & $4.82 \mathrm{e}+11$ & -53 & 6 & 1 \\
\hline $0202+319 \ldots \ldots \ldots \ldots$ & $2003 / 03 / 29$ & 2.26 & 2.25 & 1.81 & 1.00 & 2.21 & 0.19 & 0.12 & $1.29 \mathrm{e}+12$ & 9 & 7 & 1 \\
\hline $0212+735 \ldots \ldots \ldots \ldots$ & $1994 / 08 / 31$ & 3.53 & 2.70 & 1.75 & 0.90 & 2.40 & 0.32 & 0.13 & $1.08 \mathrm{e}+12$ & 114 & 6 & 0 \\
\hline $0215+015 \ldots \ldots \ldots \ldots$ & $1998 / 06 / 05$ & 1.03 & 0.93 & 0.79 & 0.90 & 0.83 & 0.12 & 0.06 & $1.74 \mathrm{e}+12$ & 111 & 3 & 1 \\
\hline $0218+357 \ldots \ldots \ldots \ldots$ & $1995 / 04 / 07$ & 1.14 & 1.13 & 0.31 & 0.76 & 0.54 & 0.46 & 0.24 & $5.13 \mathrm{e}+10$ & 50 & 3 & 0 \\
\hline $0221+067 \ldots \ldots \ldots \ldots$ & 1999/11/06 & 0.84 & 0.83 & 0.39 & 0.99 & 0.74 & 0.23 & $<0.05$ & $>5.87 \mathrm{e}+11$ & -67 & 3 & 3 \\
\hline $0224+671 \ldots \ldots \ldots \ldots$ & $2002 / 11 / 23$ & 1.20 & 1.30 & 0.82 & 1.08 & 0.59 & 0.26 & $<0.03$ & $>3.94 \mathrm{e}+11$ & 4 & 1 & 1 \\
\hline $0234+285 \ldots \ldots \ldots \ldots$ & $2002 / 11 / 23$ & 4.04 & 4.06 & 2.22 & 0.96 & 0.55 & 0.33 & $<0.04$ & $>4.51 \mathrm{e}+11$ & -13 & 7 & 2 \\
\hline $0235+164 \ldots \ldots \ldots \ldots$ & $2001 / 03 / 15$ & 1.51 & 1.60 & 1.36 & 0.93 & 1.56 & 0.16 & 0.11 & $9.08 \mathrm{e}+11$ & -92 & 5 & 0 \\
\hline $0238-084 \ldots \ldots \ldots \ldots$ & $1995 / 12 / 15$ & 2.60 & 2.09 & 0.37 & 0.80 & $\ldots$ & $\ldots$ & $\ldots$ & $\ldots$ & 68 & 13 & $\ldots$ \\
\hline $0248+430^{\mathrm{a}} \ldots \ldots \ldots \ldots$ & $1999 / 01 / 02$ & 0.80 & 0.65 & 0.25 & 0.81 & 0.28 & 0.37 & 0.09 & $1.08 \mathrm{e}+11$ & 149 & 1 & 0 \\
\hline $0300+470 \ldots \ldots \ldots \ldots$ & $2002 / 11 / 23$ & 1.36 & 1.28 & 1.01 & 0.94 & 1.03 & 0.19 & 0.04 & $>8.46 \mathrm{e}+11$ & 147 & 1 & 0 \\
\hline $0310+013 \ldots \ldots \ldots \ldots$ & 1998/11/01 & 0.20 & 0.16 & 0.10 & 0.80 & 0.12 & 0.58 & 0.04 & $4.20 \mathrm{e}+10$ & 143 & 1 & 0 \\
\hline $0316+162 \ldots \ldots \ldots \ldots$ & $1997 / 08 / 28$ & 0.85 & 0.26 & 0.06 & 0.31 & $\ldots$ & $\ldots$ & $\ldots$ & $\ldots$ & $\ldots$ & 3 & $\ldots$ \\
\hline $0316+413^{\mathrm{a}} \ldots \ldots \ldots \ldots$ & $2003 / 03 / 01$ & 16.35 & 10.39 & 1.73 & 0.64 & 3.63 & 0.66 & 0.21 & $1.45 \mathrm{e}+11$ & -136 & 1 & 0 \\
\hline $0333+321 \ldots \ldots \ldots \ldots$ & $2003 / 03 / 29$ & 2.54 & 2.23 & 1.66 & 0.90 & 1.84 & 0.27 & 0.06 & $1.29 \mathrm{e}+12$ & 123 & 11 & 4 \\
\hline $0336-019 \ldots \ldots \ldots . . .$. & $1997 / 03 / 13$ & 2.50 & 2.24 & 1.50 & 0.93 & 1.78 & 0.21 & $<0.03$ & $>3.24 \mathrm{e}+12$ & 65 & 6 & 3 \\
\hline $0355+508 \ldots \ldots \ldots \ldots$ & $2001 / 03 / 04$ & 7.21 & 7.09 & 3.77 & 0.98 & 6.96 & 0.23 & 0.22 & $>7.43 \mathrm{e}+11$ & 48 & 5 & 0 \\
\hline $0402-362 \ldots \ldots \ldots \ldots$ & $1998 / 06 / 05$ & 2.20 & 1.60 & 1.25 & 0.73 & 1.54 & 0.44 & 0.10 & $4.66 \mathrm{e}+11$ & 23 & 1 & 0 \\
\hline $0403-132 \ldots \ldots \ldots \ldots$ & $2002 / 05 / 31$ & 2.37 & 1.40 & 1.28 & 0.52 & 1.34 & 0.24 & 0.06 & $8.18 \mathrm{e}+11$ & -177 & 2 & 1 \\
\hline $0405-385$............... & $2002 / 03 / 09$ & 1.40 & 1.21 & 0.80 & 0.85 & 1.15 & 0.26 & 0.16 & $3.40 \mathrm{e}+11$ & -90 & 2 & 0 \\
\hline $0415+379^{\mathrm{a}} \ldots \ldots \ldots \ldots$ & $1997 / 03 / 10$ & 6.96 & 5.98 & 1.84 & 0.61 & 2.60 & 0.42 & $<0.05$ & $>6.74 \mathrm{e}+11$ & 64 & 13 & 6 \\
\hline $0420-014 \ldots \ldots \ldots \ldots$ & $2003 / 03 / 01$ & 11.22 & 10.62 & 7.62 & 0.94 & 8.75 & 0.09 & $<0.02$ & $>5.18 \mathrm{e}+13$ & -165 & 6 & 4 \\
\hline $0420+022 \ldots \ldots \ldots \ldots$ & 1999/11/06 & 1.18 & 1.16 & 0.78 & 0.96 & 1.05 & 0.54 & 0.06 & $5.62 \mathrm{e}+11$ & -100 & 2 & 0 \\
\hline $0422+004 \ldots \ldots \ldots \ldots$ & $2002 / 06 / 15$ & 1.65 & 1.76 & 1.58 & 1.01 & 1.57 & 0.20 & 0.03 & $>1.38 \mathrm{e}+12$ & 4 & 2 & 1 \\
\hline $0429+415 \ldots \ldots \ldots \ldots$ & $2002 / 10 / 09$ & 1.79 & 1.06 & 0.14 & 0.59 & $\ldots$ & $\ldots$ & $\ldots$ & $\ldots$ & $\ldots$ & 1 & $\ldots$ \\
\hline $0430+052^{\mathrm{a}} \ldots \ldots \ldots \ldots$ & $1998 / 03 / 07$ & 4.93 & 3.09 & 1.27 & 0.77 & 1.71 & 0.26 & $<0.04$ & $>9.19 \mathrm{e}+11$ & -117 & 15 & 11 \\
\hline $0438-436 \ldots \ldots \ldots \ldots$ & $1998 / 06 / 05$ & 2.50 & 1.77 & 1.01 & 0.71 & 1.79 & 0.37 & 0.18 & $5.58 \mathrm{e}+11$ & $\ldots$ & 1 & 0 \\
\hline $0440-003 \ldots \ldots \ldots . . .$. & $1998 / 03 / 07$ & 1.40 & 0.94 & 0.52 & 0.82 & 0.62 & 0.36 & 0.07 & $2.31 \mathrm{e}+11$ & -119 & 6 & 0 \\
\hline $0446+112 \ldots \ldots \ldots \ldots$ & $2002 / 05 / 31$ & 2.51 & 2.29 & 1.74 & 0.95 & 2.04 & 0.17 & $<0.02$ & $>2.74 \mathrm{e}+12$ & 116 & 4 & 2 \\
\hline $0454-234 \ldots \ldots \ldots \ldots$ & $1998 / 06 / 05$ & 2.67 & 2.42 & 0.51 & 0.91 & 2.33 & 0.31 & $<0.04$ & $>2.13 \mathrm{e}+12$ & $\ldots$ & 1 & 1 \\
\hline $0454+844 \ldots \ldots \ldots \ldots$ & $2001 / 12 / 30$ & 0.35 & 0.34 & 0.23 & 0.79 & 0.29 & 0.33 & 0.13 & $>3.57 \mathrm{e}+10$ & 153 & 6 & 0 \\
\hline $0458-020 \ldots \ldots \ldots . .$. & $1995 / 07 / 28$ & 2.85 & 2.41 & 1.62 & 0.85 & 2.04 & 0.30 & 0.12 & $1.06 \mathrm{e}+12$ & -47 & 4 & 0 \\
\hline $0521-365 \ldots \ldots \ldots \ldots$ & 1999/11/06 & 4.45 & 1.79 & 1.20 & 0.40 & 1.40 & 0.17 & $<0.15$ & $>3.09 \mathrm{e}+11$ & -41 & 3 & 2 \\
\hline $0524+034 \ldots \ldots \ldots \ldots$ & $1998 / 12 / 05$ & 0.70 & 0.78 & 0.70 & 1.01 & 0.72 & 0.22 & 0.04 & $>4.37 \mathrm{e}+11$ & -37 & 2 & 0 \\
\hline $0528+134 \ldots \ldots \ldots \ldots$ & $1995 / 07 / 28$ & 7.51 & 7.95 & 4.21 & 1.00 & 7.07 & 0.22 & $<0.03$ & $>2.06 \mathrm{e}+13$ & 48 & 6 & 3 \\
\hline $0529+075 \ldots \ldots \ldots \ldots$ & $2002 / 05 / 31$ & 1.37 & 1.34 & 0.10 & 0.95 & 1.07 & 0.70 & 0.56 & $>1.48 \mathrm{e}+10$ & -38 & 2 & 0 \\
\hline $0529+483 \ldots \ldots \ldots \ldots$ & $2002 / 10 / 09$ & 1.04 & 1.03 & 0.80 & 0.99 & 0.72 & 0.09 & $<0.01$ & $>7.89 \mathrm{e}+12$ & 33 & 1 & 1 \\
\hline $0537-286 \ldots \ldots \ldots \ldots$ & $1998 / 09 / 29$ & 1.45 & 0.86 & 0.60 & 0.54 & 0.83 & 0.20 & 0.05 & $1.95 \mathrm{e}+12$ & 89 & 2 & 0 \\
\hline
\end{tabular}


TABLE 2-Continued

\begin{tabular}{|c|c|c|c|c|c|c|c|c|c|c|c|c|}
\hline $\begin{array}{l}\text { Source } \\
\text { (1) }\end{array}$ & $\begin{array}{l}\text { Epoch } \\
\text { (2) }\end{array}$ & $\begin{array}{l}S_{\text {tot }} \\
(3)\end{array}$ & $\begin{array}{l}S_{\mathrm{VLBA}} \\
(4)\end{array}$ & $\begin{array}{c}S_{\text {unres }} \\
(5)\end{array}$ & $\begin{array}{l}\frac{S_{\mathrm{VLBA}}}{S_{\mathrm{iot}}} \\
(6)\end{array}$ & $\begin{array}{c}S_{\text {core }} \\
\text { (7) }\end{array}$ & $\begin{array}{c}\theta_{\text {maj }} \\
(8)\end{array}$ & $\begin{array}{c}\theta_{\min } \\
(9)\end{array}$ & $\begin{array}{c}T_{b} \\
(10)\end{array}$ & $\begin{array}{l}\mathrm{PA}_{\text {jet }} \\
(11)\end{array}$ & $\begin{array}{c}\text { No. of } \\
\text { Epochs } \\
\text { (12) }\end{array}$ & $\begin{array}{l}\text { No. Unresolved } \\
\text { (13) }\end{array}$ \\
\hline $0552+398 \ldots \ldots \ldots \ldots$ & 1999/01/02 & 4.50 & 4.51 & 1.60 & 0.97 & 3.21 & 0.28 & 0.19 & $1.12 \mathrm{e}+12$ & -72 & 5 & 0 \\
\hline $0602+673 \ldots \ldots \ldots \ldots$ & 1999/07/19 & 0.90 & 0.99 & 0.66 & 0.99 & 0.93 & 0.43 & 0.13 & $2.78 \mathrm{e}+11$ & 158 & 4 & 1 \\
\hline $0605-085 \ldots \ldots \ldots \ldots$ & $1996 / 10 / 27$ & 2.78 & 1.89 & 0.83 & 0.80 & 1.79 & 0.69 & $<0.11$ & $>2.44 \mathrm{e}+11$ & 122 & 5 & 5 \\
\hline $0607-157 \ldots \ldots \ldots \ldots$ & $1998 / 10 / 30$ & 7.89 & 7.28 & 4.95 & 0.77 & 6.92 & 0.23 & 0.16 & $1.34 \mathrm{e}+12$ & 66 & 7 & 4 \\
\hline $0615+820 \ldots \ldots \ldots \ldots$ & $1994 / 08 / 31$ & 0.40 & 0.43 & 0.14 & 0.97 & 0.24 & 0.43 & 0.10 & $5.34 \mathrm{e}+10$ & .. & 5 & 1 \\
\hline $0642+449 \ldots \ldots \ldots \ldots$ & $2003 / 03 / 29$ & 4.45 & 4.27 & 1.67 & 0.97 & 2.92 & 0.21 & 0.08 & $4.32 \mathrm{e}+12$ & 90 & 6 & 4 \\
\hline $0648-165 \ldots \ldots \ldots \ldots$ & $2002 / 11 / 23$ & 2.84 & 2.68 & 1.38 & 0.76 & 2.33 & 0.22 & $<0.02$ & $>2.55 \mathrm{e}+12$ & -90 & 2 & 1 \\
\hline $0707+476 \ldots \ldots \ldots \ldots$ & $1994 / 08 / 31$ & 0.70 & 0.61 & 0.47 & 0.95 & 0.49 & 0.39 & 0.04 & $3.83 \mathrm{e}+11$ & -24 & 5 & 0 \\
\hline $0710+439 \ldots \ldots \ldots \ldots$ & $1996 / 10 / 27$ & 0.80 & 0.50 & 0.14 & 0.74 & $\ldots$ & $\ldots$ & $\ldots$ & $\ldots$ & 179 & 4 & $\ldots$ \\
\hline $0711+356 \ldots \ldots \ldots \ldots$ & 1999/01/02 & 0.40 & 0.40 & 0.09 & 1.00 & 0.26 & 0.72 & 0.58 & $8.79 \mathrm{e}+09$ & 158 & 1 & 0 \\
\hline $0716+714 \ldots \ldots \ldots \ldots$ & $2003 / 08 / 28$ & 2.37 & 2.55 & 2.51 & 0.69 & 2.46 & 0.08 & $<0.01$ & $>1.85 \mathrm{e}+13$ & 16 & 6 & 5 \\
\hline $0723-008 \ldots \ldots \ldots \ldots$ & $1997 / 08 / 18$ & 1.10 & 1.01 & 0.52 & 0.94 & 0.58 & 0.23 & $<0.06$ & $>2.37 \mathrm{e}+11$ & -45 & 2 & 1 \\
\hline $0727-115 \ldots \ldots \ldots \ldots$ & $2001 / 01 / 21$ & 4.49 & 4.27 & 3.15 & 0.92 & 3.75 & 0.13 & 0.09 & $4.55 \mathrm{e}+12$ & -97 & 7 & 3 \\
\hline $0730+504 \ldots \ldots \ldots \ldots$ & $2003 / 06 / 15$ & 1.19 & 1.36 & 1.17 & 1.10 & 1.25 & 0.21 & 0.06 & $9.38 \mathrm{e}+11$ & -141 & 2 & 1 \\
\hline $0735+178 \ldots \ldots \ldots \ldots$ & 1995/04/07 & 1.83 & 1.63 & 0.81 & 0.83 & 0.95 & 0.18 & 0.12 & $>2.40 \mathrm{e}+11$ & 68 & 8 & 4 \\
\hline $0736+017 \ldots \ldots \ldots \ldots$ & $2003 / 03 / 01$ & 2.08 & 1.78 & 1.07 & 0.94 & 1.45 & 0.19 & $<0.02$ & $>2.51 \mathrm{e}+12$ & -63 & 7 & 6 \\
\hline $0738+313^{\mathrm{a}} \ldots \ldots \ldots \ldots$ & $1995 / 04 / 07$ & 1.80 & 1.94 & 1.14 & 0.95 & 0.87 & 0.43 & $<0.03$ & $>6.54 \mathrm{e}+11$ & 179 & 9 & 8 \\
\hline $0742+103 \ldots \ldots \ldots \ldots$ & $1995 / 07 / 28$ & 1.50 & 1.42 & 0.37 & 0.82 & 0.81 & 0.87 & 0.21 & $8.90 \mathrm{e}+10$ & -10 & 7 & 2 \\
\hline $0745+241 \ldots \ldots \ldots \ldots$ & $1997 / 08 / 18$ & 0.88 & 0.95 & 0.65 & 0.87 & 0.83 & 0.22 & 0.05 & $5.74 \mathrm{e}+11$ & -64 & 9 & 3 \\
\hline $0748+126 \ldots \ldots \ldots \ldots$ & $1995 / 07 / 28$ & 2.85 & 3.13 & 2.34 & 0.96 & 2.86 & 0.23 & 0.06 & $2.03 \mathrm{e}+12$ & 115 & 7 & 2 \\
\hline $0754+100 \ldots \ldots \ldots \ldots$ & $2002 / 11 / 23$ & 1.96 & 1.82 & 1.39 & 0.86 & 1.42 & 0.26 & 0.05 & $7.91 \mathrm{e}+11$ & 18 & 9 & 5 \\
\hline $0804+499 \ldots \ldots \ldots \ldots$ & $1995 / 04 / 07$ & 1.05 & 1.14 & 0.96 & 0.90 & 1.02 & 0.14 & 0.07 & $1.45 \mathrm{e}+12$ & 128 & 5 & 2 \\
\hline $0805-077 \ldots \ldots \ldots \ldots$ & $2002 / 06 / 15$ & 1.62 & 1.57 & 1.17 & 0.97 & 1.34 & 0.27 & 0.10 & $7.80 \mathrm{e}+11$ & -21 & 1 & 0 \\
\hline $0808+019 \ldots \ldots \ldots \ldots$ & $1995 / 07 / 28$ & 1.59 & 1.34 & 1.26 & 0.85 & 1.27 & 0.08 & $<0.02$ & $>9.19 \mathrm{e}+12$ & -176 & 4 & 3 \\
\hline $0814+425 \ldots \ldots \ldots \ldots$ & $2000 / 12 / 28$ & 1.40 & 1.28 & 1.07 & 0.92 & 1.08 & 0.10 & 0.04 & $>1.40 \mathrm{e}+12$ & 89 & 7 & 5 \\
\hline $0821+394 \ldots \ldots \ldots \ldots$ & $2002 / 05 / 31$ & 1.63 & 1.38 & 1.26 & 0.79 & 1.35 & 0.19 & 0.04 & $2.23 \mathrm{e}+12$ & -47 & 2 & 0 \\
\hline $0823+033 \ldots \ldots \ldots \ldots$ & $1998 / 10 / 30$ & 1.60 & 1.38 & 1.14 & 0.89 & 1.10 & 0.11 & 0.05 & $1.72 \mathrm{e}+12$ & 28 & 8 & 7 \\
\hline $0827+243 \ldots \ldots \ldots \ldots$ & $2002 / 05 / 31$ & 1.93 & 1.99 & 1.59 & 1.00 & 1.82 & 0.18 & 0.06 & $1.93 \mathrm{e}+12$ & 114 & 2 & 0 \\
\hline $0829+046 \ldots \ldots \ldots \ldots$ & $1995 / 07 / 28$ & 1.23 & 1.35 & 0.75 & 0.90 & 0.76 & 0.14 & $<0.04$ & $>8.23 \mathrm{e}+11$ & 61 & 7 & 7 \\
\hline $0831+557 \ldots \ldots \ldots \ldots$ & 1999/01/02 & 1.66 & 0.79 & 0.09 & 0.57 & $\ldots$ & $\ldots$ & $\ldots$ & $\ldots$ & .. & 2 & $\ldots$ \\
\hline $0834-201 \ldots \ldots \ldots \ldots$ & $2002 / 05 / 29$ & 3.82 & 3.25 & 1.65 & 0.83 & 3.08 & 0.27 & 0.21 & $1.10 \mathrm{e}+12$ & -150 & 3 & 0 \\
\hline $0836+710 \ldots \ldots \ldots \ldots$ & $2003 / 03 / 29$ & 1.88 & 1.98 & 1.17 & 1.05 & 1.00 & 0.06 & 0.05 & $6.18 \mathrm{e}+12$ & -142 & 3 & 0 \\
\hline $0838+133 \ldots \ldots \ldots \ldots$ & $1998 / 09 / 29$ & 1.05 & 0.74 & 0.38 & 0.70 & 0.45 & 0.19 & 0.10 & $2.18 \mathrm{e}+11$ & 88 & 2 & 0 \\
\hline $0850+581 \ldots \ldots \ldots \ldots$ & $2000 / 12 / 28$ & 0.70 & 0.52 & 0.33 & 0.74 & 0.07 & 0.10 & $<0.08$ & $>1.09 \mathrm{e}+11$ & 150 & 5 & 4 \\
\hline $0851+202 \ldots \ldots \ldots \ldots$ & $2002 / 10 / 09$ & 4.19 & 4.14 & 3.32 & 0.88 & 3.55 & 0.12 & $<0.05$ & $>3.89 \mathrm{e}+12$ & -103 & 10 & 7 \\
\hline $0859-140 \ldots \ldots \ldots \ldots$ & $1995 / 07 / 28$ & 1.65 & 1.58 & 1.11 & 0.77 & 1.17 & 0.27 & $<0.03$ & $>1.58 \mathrm{e}+12$ & 158 & 4 & 3 \\
\hline $0859+470 \ldots \ldots \ldots \ldots$ & $2002 / 06 / 02$ & 0.89 & 0.66 & 0.45 & 0.74 & 0.50 & 0.29 & 0.06 & $3.75 \mathrm{e}+11$ & -4 & 2 & 0 \\
\hline $0906+015 \ldots \ldots \ldots \ldots$ & $2001 / 01 / 21$ & 2.52 & 2.74 & 2.03 & 1.00 & 2.36 & 0.28 & $<0.09$ & $>9.83 \mathrm{e}+11$ & 42 & 6 & 3 \\
\hline $0917+449 \ldots \ldots \ldots \ldots$ & $1995 / 04 / 07$ & 1.40 & 1.42 & 1.07 & 0.92 & 1.01 & 0.20 & $<0.03$ & $>2.62 \mathrm{e}+12$ & 178 & 6 & 4 \\
\hline $0917+624 \ldots \ldots \ldots \ldots . . .$. & $2002 / 06 / 15$ & 0.89 & 0.90 & 0.59 & 1.02 & 0.64 & 0.53 & 0.06 & $2.74 \mathrm{e}+11$ & -34 & 2 & 0 \\
\hline $0919-260 \ldots \ldots \ldots \ldots$ & $1998 / 06 / 05$ & 1.68 & 1.33 & 0.80 & 0.79 & 1.14 & 0.24 & 0.18 & $4.71 \mathrm{e}+11$ & -98 & 1 & 0 \\
\hline $0923+392^{\mathrm{a}} \ldots \ldots \ldots \ldots$ & $1995 / 04 / 07$ & 12.45 & 12.69 & 3.69 & 0.94 & 0.23 & 0.40 & 0.29 & $1.80 \mathrm{e}+10$ & 105 & 9 & 7 \\
\hline $0945+408 \ldots \ldots \ldots \ldots$ & $2002 / 10 / 09$ & 1.77 & 1.58 & 1.04 & 0.89 & 0.99 & 0.14 & $<0.03$ & $>2.73 \mathrm{e}+12$ & 116 & 7 & 3 \\
\hline $0953+254 \ldots \ldots \ldots \ldots$ & $1995 / 04 / 07$ & 1.20 & 1.31 & 0.55 & 1.01 & 0.36 & 0.23 & $<0.07$ & $>2.05 \mathrm{e}+11$ & -124 & 6 & 5 \\
\hline $0954+658 \ldots \ldots \ldots \ldots$ & $2003 / 03 / 01$ & 0.51 & 0.55 & 0.46 & 1.08 & 0.45 & 0.14 & $<0.03$ & $>9.06 \mathrm{e}+11$ & -32 & 1 & 1 \\
\hline $0955+476 \ldots \ldots \ldots \ldots$ & $2002 / 06 / 15$ & 1.53 & 1.76 & 1.18 & 1.03 & 1.73 & 0.28 & 0.16 & $6.01 \mathrm{e}+11$ & 125 & 2 & 0 \\
\hline $1012+232 \ldots \ldots \ldots \ldots$ & $2001 / 11 / 07$ & 1.59 & 1.16 & 0.88 & 0.95 & 1.08 & 0.17 & $<0.03$ & $>1.67 \mathrm{e}+12$ & 109 & 6 & 4 \\
\hline $1015+359 \ldots \ldots \ldots \ldots$ & $1996 / 05 / 16$ & 0.79 & 0.82 & 0.65 & 1.00 & 0.71 & 0.17 & 0.10 & $5.34 \mathrm{e}+11$ & -170 & 7 & 1 \\
\hline $1032-199 \ldots \ldots \ldots . . .$. & $2002 / 05 / 29$ & 0.97 & 0.96 & 0.44 & 0.96 & 0.90 & 0.67 & 0.21 & $1.12 \mathrm{e}+11$ & -149 & 2 & 0 \\
\hline $1034-293 \ldots \ldots \ldots . . .$. & $1998 / 06 / 05$ & 1.44 & 1.49 & 1.09 & 1.03 & 1.36 & 0.32 & $<0.03$ & $>9.08 \mathrm{e}+11$ & 132 & 1 & 1 \\
\hline $1036+054 \ldots \ldots \ldots \ldots$ & $2002 / 05 / 31$ & 2.60 & 2.66 & 2.35 & 0.99 & 2.62 & 0.23 & 0.09 & $>7.12 \mathrm{e}+11$ & -8 & 2 & 0 \\
\hline $1038+064 \ldots \ldots \ldots \ldots$ & 2003/05/09 & 1.67 & 1.69 & 1.34 & 1.02 & 1.40 & 0.28 & 0.04 & $1.52 \mathrm{e}+12$ & 156 & 3 & 0 \\
\hline $1045-188 \ldots \ldots \ldots \ldots$ & $2002 / 06 / 15$ & 1.26 & 1.32 & 1.19 & 1.04 & 1.17 & 0.51 & $<0.04$ & $>4.43 \mathrm{e}+11$ & 148 & 2 & 2 \\
\hline $1049+215 \ldots \ldots \ldots \ldots$ & $1995 / 04 / 07$ & 1.40 & 1.44 & 0.51 & 0.93 & 1.22 & 0.37 & 0.07 & $5.81 \mathrm{e}+11$ & 114 & 6 & 4 \\
\hline $1055+018 \ldots \ldots \ldots \ldots$ & $2002 / 05 / 29$ & 5.67 & 5.30 & 4.28 & 0.89 & 4.93 & 0.23 & $<0.02$ & $>1.36 \mathrm{e}+13$ & -50 & 8 & 5 \\
\hline $1055+201 \ldots \ldots \ldots \ldots$ & $1999 / 11 / 06$ & 0.54 & 0.38 & 0.30 & 0.65 & 0.26 & 0.27 & $<0.04$ & $>2.45 \mathrm{e}+11$ & -10 & 8 & 6 \\
\hline $1101+384 \ldots \ldots \ldots \ldots$ & $1997 / 03 / 13$ & 0.69 & 0.52 & 0.39 & 0.75 & 0.45 & 0.16 & 0.07 & $2.19 \mathrm{e}+11$ & -28 & 7 & 0 \\
\hline $1116+128 \ldots \ldots \ldots \ldots$ & $1998 / 06 / 05$ & 1.12 & 0.79 & 0.39 & 0.71 & 0.47 & 0.43 & 0.05 & $3.42 \mathrm{e}+11$ & 5 & 1 & 0 \\
\hline $1124-186 \ldots \ldots \ldots \ldots$ & 1998/11/01 & 2.84 & 2.82 & 2.31 & 0.99 & 2.67 & 0.18 & $<0.03$ & $>6.15 \mathrm{e}+12$ & 169 & 3 & 1 \\
\hline $1127-145^{\mathrm{a}} \ldots \ldots \ldots \ldots$ & 1999/11/06 & 3.75 & 3.38 & 1.91 & 0.81 & 1.95 & 0.15 & 0.06 & $2.60 \mathrm{e}+12$ & 84 & 8 & 4 \\
\hline $1128+385 \ldots \ldots \ldots \ldots$ & $1996 / 07 / 10$ & 1.05 & 1.00 & 0.93 & 0.97 & 0.94 & 0.16 & $<0.02$ & $>4.94 \mathrm{e}+12$ & -161 & 6 & 1 \\
\hline $1144+402 \ldots \ldots \ldots \ldots$ & $2002 / 05 / 31$ & 0.81 & 0.78 & 0.62 & 0.96 & 0.77 & 0.28 & 0.14 & $2.21 \mathrm{e}+11$ & -70 & 1 & 0 \\
\hline $1145-071 \ldots \ldots \ldots \ldots$ & $2002 / 04 / 02$ & 0.86 & 0.70 & 0.27 & 0.81 & 0.64 & 0.32 & 0.19 & $1.37 \mathrm{e}+11$ & -65 & 3 & 2 \\
\hline $1148-001 \ldots \ldots \ldots \ldots$ & 1998/11/01 & 0.90 & 0.86 & 0.24 & 0.84 & 0.39 & 0.26 & $<0.05$ & $>5.41 \mathrm{e}+11$ & -123 & 3 & 3 \\
\hline
\end{tabular}


TABLE 2-Continued

\begin{tabular}{|c|c|c|c|c|c|c|c|c|c|c|c|c|}
\hline $\begin{array}{l}\text { Source } \\
\text { (1) }\end{array}$ & $\begin{array}{l}\text { Epoch } \\
\text { (2) }\end{array}$ & $\begin{array}{l}S_{\text {tot }} \\
(3)\end{array}$ & $\begin{array}{l}S_{\mathrm{VLBA}} \\
\text { (4) }\end{array}$ & $\begin{array}{l}S_{\text {unres }} \\
(5)\end{array}$ & $\frac{\frac{S_{\mathrm{VLBA}}}{S_{\mathrm{tot}}}}{(6)}$ & $\begin{array}{l}S_{\text {core }} \\
(7)\end{array}$ & $\begin{array}{l}\theta_{\text {maj }} \\
(8)\end{array}$ & $\begin{array}{l}\theta_{\min } \\
(9)\end{array}$ & $\begin{array}{c}T_{b} \\
(10)\end{array}$ & $\begin{array}{l}\mathrm{PA}_{\text {jet }} \\
(11)\end{array}$ & $\begin{array}{c}\text { No. of } \\
\text { Epochs } \\
\text { (12) }\end{array}$ & $\begin{array}{c}\text { No. Unresolved } \\
\text { (13) }\end{array}$ \\
\hline $1150+812 \ldots \ldots \ldots \ldots$ & $2002 / 06 / 15$ & 1.40 & 1.49 & 0.96 & 0.99 & 1.06 & 0.22 & 0.09 & $6.67 \mathrm{e}+11$ & 176 & 2 & 0 \\
\hline $1155+251 \ldots \ldots \ldots \ldots$ & $1995 / 04 / 07$ & 0.40 & 0.24 & 0.14 & 0.56 & 0.12 & 0.47 & $<0.09$ & $>1.73 \mathrm{e}+10$ & $\ldots$ & 3 & 1 \\
\hline $1156+295 \ldots \ldots \ldots \ldots$ & 1998/11/01 & 2.80 & 3.29 & 2.99 & 0.94 & 3.20 & 0.09 & 0.07 & $4.95 e+12$ & -4 & 10 & 1 \\
\hline $1213-172^{\mathrm{a}} \ldots \ldots \ldots \ldots$ & $1998 / 06 / 05$ & 2.77 & 2.56 & 0.98 & 1.00 & 0.50 & 0.18 & $<0.03$ & $>5.33 \mathrm{e}+11$ & 110 & 3 & 2 \\
\hline $1219+044 \ldots \ldots \ldots \ldots$ & $2002 / 06 / 15$ & 0.84 & 0.94 & 0.92 & 1.03 & 0.92 & 0.14 & $<0.01$ & $>9.73 \mathrm{e}+12$ & 178 & 2 & 1 \\
\hline $1219+285 \ldots \ldots \ldots \ldots$ & $1998 / 03 / 07$ & 0.85 & 0.54 & 0.28 & 0.79 & 0.34 & 0.19 & 0.12 & $9.26 \mathrm{e}+10$ & 105 & 7 & 4 \\
\hline $1222+216 \ldots \ldots \ldots \ldots$ & $2003 / 05 / 09$ & 1.08 & 0.89 & 0.70 & 0.82 & 0.71 & 0.26 & 0.05 & $4.47 \mathrm{e}+11$ & -6 & 2 & 0 \\
\hline $1226+023^{\mathrm{a}} \ldots \ldots \ldots \ldots$ & $1999 / 05 / 21$ & 35.91 & 29.12 & 7.36 & 0.74 & 1.87 & 0.13 & $<0.06$ & $>1.69 \mathrm{e}+12$ & -117 & 15 & 11 \\
\hline $1228+126 \ldots \ldots \ldots \ldots$ & $2003 / 02 / 05$ & 28.10 & 2.63 & 0.73 & 0.07 & 1.39 & 0.41 & 0.27 & $6.96 \mathrm{e}+10$ & -77 & 13 & 5 \\
\hline $1244-255 \ldots \ldots \ldots \ldots$ & $1998 / 06 / 05$ & 1.60 & 1.35 & 1.18 & 0.84 & 1.22 & 0.24 & 0.06 & $8.01 \mathrm{e}+11$ & 143 & 1 & 0 \\
\hline $1253-055^{\mathrm{a}} \ldots \ldots \ldots \ldots$ & $1996 / 05 / 16$ & 22.20 & 18.49 & 11.21 & 0.91 & 15.15 & 0.30 & $<0.05$ & $>8.76 \mathrm{e}+12$ & -121 & 14 & 8 \\
\hline $1255-316 \ldots \ldots \ldots$ & $1998 / 06 / 05$ & 1.90 & 0.91 & 0.38 & 0.48 & 0.85 & 0.93 & 0.20 & $7.15 \mathrm{e}+10$ & 23 & 1 & 0 \\
\hline $1302-102 \ldots \ldots \ldots \ldots$ & $1995 / 07 / 28$ & 0.80 & 0.69 & 0.45 & 0.86 & 0.53 & 0.29 & $<0.03$ & $>3.72 \mathrm{e}+11$ & 27 & 5 & 3 \\
\hline $1308+326 \ldots \ldots \ldots$ & $2003 / 03 / 29$ & 2.84 & 2.97 & 2.36 & 0.99 & 2.59 & 0.20 & 0.10 & $1.47 \mathrm{e}+12$ & -45 & 7 & 2 \\
\hline $1313-333 \ldots \ldots \ldots \ldots$ & $1998 / 06 / 05$ & 1.30 & 1.02 & 0.57 & 0.78 & 0.71 & 0.17 & 0.09 & $5.52 \mathrm{e}+11$ & -99 & 1 & 0 \\
\hline $1323+321 \ldots \ldots \ldots \ldots$ & $1996 / 05 / 16$ & 1.04 & 0.65 & 0.06 & 0.62 & $\ldots$ & $\ldots$ & $\ldots$ & $\ldots$ & $\ldots$ & 5 & $\ldots$ \\
\hline $1324+224 \ldots \ldots \ldots \ldots$ & $2002 / 10 / 09$ & 0.63 & 0.62 & 0.44 & 0.98 & 0.53 & 0.27 & 0.12 & $2.09 \mathrm{e}+11$ & -37 & 1 & 0 \\
\hline $1328+307 \ldots \ldots \ldots \ldots$ & $1995 / 04 / 07$ & 3.44 & 1.22 & 0.20 & 0.32 & $\ldots$ & $\ldots$ & $\ldots$ & $\ldots$ & $\ldots$ & 3 & $\ldots$ \\
\hline $1334-127 \ldots \ldots \ldots \ldots$ & $2001 / 03 / 15$ & 7.82 & 8.88 & 7.17 & 0.98 & 7.40 & 0.16 & $<0.01$ & $>3.19 \mathrm{e}+13$ & 150 & 6 & 4 \\
\hline $1345+125 \ldots \ldots \ldots \ldots$ & $1996 / 04 / 22$ & 1.40 & 0.98 & 0.07 & 0.51 & $\ldots$ & $\ldots$ & $\ldots$ & $\ldots$ & 162 & 5 & $\ldots$ \\
\hline $1354-152 \ldots \ldots \ldots \ldots$ & 1999/11/06 & 0.89 & 0.82 & 0.79 & 0.90 & 0.81 & 0.13 & $<0.03$ & $>2.94 \mathrm{e}+12$ & 38 & 2 & 1 \\
\hline $1354+195 \ldots \ldots \ldots \ldots$ & $2002 / 08 / 12$ & 1.24 & 1.12 & 0.70 & 0.90 & 0.97 & 0.47 & 0.07 & $2.88 \mathrm{e}+11$ & 145 & 3 & 1 \\
\hline $1402+044 \ldots \ldots \ldots \ldots$ & $1998 / 06 / 05$ & 0.65 & 0.56 & 0.33 & 0.86 & 0.31 & 0.22 & 0.07 & $4.40 \mathrm{e}+11$ & -24 & 3 & 0 \\
\hline $1404+286 \ldots \ldots \ldots$ & $1998 / 10 / 30$ & 1.05 & 1.20 & 0.54 & 0.87 & 0.97 & 0.47 & 0.28 & $4.27 \mathrm{e}+10$ & -144 & 11 & 0 \\
\hline $1413+135 \ldots \ldots \ldots \ldots$ & $2001 / 01 / 21$ & 1.48 & 1.60 & 1.34 & 0.92 & 1.42 & 0.07 & 0.03 & $4.09 \mathrm{e}+12$ & -113 & 8 & 6 \\
\hline $1417+385 \ldots \ldots \ldots \ldots$ & $2002 / 06 / 15$ & 0.84 & 0.89 & 0.80 & 1.08 & 0.84 & 0.08 & 0.04 & $4.72 \mathrm{e}+12$ & 162 & 2 & 0 \\
\hline $1418+546 \ldots \ldots \ldots \ldots$ & $2003 / 05 / 09$ & 1.00 & 0.92 & 0.61 & 0.99 & 0.67 & 0.32 & $<0.04$ & $>3.23 \mathrm{e}+11$ & 130 & 2 & 2 \\
\hline $1424+366 \ldots \ldots \ldots \ldots$ & $1995 / 04 / 07$ & 0.60 & 0.60 & 0.50 & 0.88 & 0.59 & 0.16 & $<0.04$ & $>1.14 \mathrm{e}+12$ & -117 & 5 & 2 \\
\hline $1458+718^{\mathrm{a}} \ldots \ldots \ldots \ldots$ & $2001 / 12 / 30$ & 1.99 & 1.47 & 0.87 & 0.63 & 0.86 & 0.26 & 0.01 & $2.81 \mathrm{e}+12$ & 164 & 5 & 1 \\
\hline $1502+106 \ldots \ldots \ldots \ldots$ & $2003 / 03 / 29$ & 2.06 & 1.93 & 0.97 & 0.93 & 1.55 & 0.27 & $<0.03$ & $>3.22 \mathrm{e}+12$ & 119 & 4 & 4 \\
\hline $1504-166^{\mathrm{a}} \ldots \ldots \ldots \ldots$ & $2000 / 01 / 11$ & 2.59 & 2.02 & 1.76 & 0.86 & 1.65 & 0.41 & 0.06 & $7.47 \mathrm{e}+11$ & -172 & 3 & 1 \\
\hline $1504+377 \ldots \ldots \ldots \ldots$ & $1997 / 08 / 28$ & 0.80 & 0.71 & 0.53 & 0.77 & 0.69 & 0.48 & 0.10 & $1.26 \mathrm{e}+11$ & -140 & 3 & 2 \\
\hline $1508-055 \ldots \ldots \ldots \ldots$ & $1995 / 07 / 28$ & 1.05 & 0.66 & 0.35 & 0.50 & 0.59 & 0.23 & $<0.04$ & $>7.84 \mathrm{e}+11$ & 81 & 9 & 6 \\
\hline $1510-089 \ldots \ldots \ldots . . .$. & $2002 / 11 / 23$ & 2.85 & 2.91 & 2.78 & 0.82 & 2.75 & 0.28 & $<0.01$ & $>5.60 \mathrm{e}+12$ & -29 & 9 & 4 \\
\hline $1511-100 \ldots \ldots \ldots \ldots$ & $1997 / 08 / 18$ & 1.50 & 1.33 & 0.52 & 0.93 & 1.28 & 0.28 & $<0.04$ & $>1.48 \mathrm{e}+12$ & 95 & 2 & 1 \\
\hline $1514+004$.................. & $1998 / 06 / 05$ & 1.01 & 0.96 & 0.80 & 0.95 & 0.80 & 0.58 & $<0.04$ & $>2.19 \mathrm{e}+11$ & -22 & 1 & 1 \\
\hline $1514-241 \ldots \ldots \ldots \ldots$ & $1997 / 08 / 18$ & 2.30 & 2.22 & 1.19 & 0.91 & 1.61 & 0.87 & 0.18 & $5.74 \mathrm{e}+10$ & 166 & 2 & 1 \\
\hline $1519-273 \ldots \ldots \ldots$ & $2002 / 04 / 02$ & 1.90 & 1.65 & 1.11 & 0.88 & 1.57 & 0.22 & 0.17 & $5.09 \mathrm{e}+11$ & -79 & 2 & 1 \\
\hline $1532+016 \ldots \ldots \ldots \ldots$ & $1995 / 07 / 28$ & 0.90 & 0.72 & 0.38 & 0.72 & 0.32 & 0.37 & 0.15 & $7.36 \mathrm{e}+10$ & 128 & 6 & 1 \\
\hline $1538+149 \ldots \ldots \ldots \ldots$ & $2002 / 08 / 12$ & 1.37 & 1.06 & 0.92 & 0.71 & 0.77 & 0.31 & $<0.03$ & $>8.40 \mathrm{e}+11$ & -34 & 4 & 4 \\
\hline $1546+027 \ldots \ldots \ldots$ & $1996 / 10 / 27$ & 2.50 & 2.82 & 2.45 & 0.93 & 2.76 & 0.24 & $<0.03$ & $>2.72 \mathrm{e}+12$ & 173 & 8 & 4 \\
\hline $1548+056 \ldots \ldots \ldots \ldots$ & $2003 / 03 / 01$ & 3.35 & 2.90 & 1.91 & 0.91 & 0.88 & 0.22 & $<0.06$ & $>9.31 \mathrm{e}+11$ & -19 & 6 & 2 \\
\hline $1555+001 \ldots \ldots \ldots \ldots$ & $2002 / 08 / 12$ & 0.72 & 0.76 & 0.40 & 1.01 & 0.72 & 0.24 & $<0.05$ & $>9.46 \mathrm{e}+11$ & 97 & 3 & 2 \\
\hline $1606+106 \ldots \ldots \ldots \ldots$ & $2003 / 08 / 28$ & 2.15 & 2.26 & 1.45 & 1.03 & 1.85 & 0.23 & 0.14 & $6.71 \mathrm{e}+11$ & -59 & 7 & 1 \\
\hline $1607+268^{\mathrm{a}}$ & $1995 / 07 / 23$ & 0.42 & 0.36 & 0.06 & 0.69 & 0.08 & 0.36 & 0.23 & $7.95 \mathrm{e}+09$ & -165 & 3 & 0 \\
\hline $1611+343^{\mathrm{a}} .$. & $1995 / 04 / 07$ & 4.19 & 4.50 & 3.03 & 0.94 & 3.37 & 0.22 & 0.09 & $2.20 \mathrm{e}+12$ & 171 & 7 & 1 \\
\hline $1622-253 \ldots \ldots \ldots$ & $1997 / 08 / 18$ & 3.45 & 2.51 & 2.19 & 0.73 & 2.35 & 0.12 & $<0.02$ & $>8.47 \mathrm{e}+12$ & -8 & 3 & 2 \\
\hline $1622-297 \ldots \ldots \ldots \ldots$ & $1998 / 06 / 05$ & 2.00 & 1.73 & 1.04 & 0.86 & 1.15 & 0.22 & $<0.04$ & $>1.39 \mathrm{e}+12$ & -66 & 1 & 1 \\
\hline $1624+416 \ldots \ldots \ldots \ldots$ & $1999 / 01 / 02$ & 0.57 & 0.49 & 0.18 & 0.86 & 0.26 & 0.21 & 0.12 & $2.07 \mathrm{e}+11$ & -111 & 1 & 0 \\
\hline $1633+382 \ldots \ldots \ldots \ldots$ & $2003 / 03 / 29$ & 4.08 & 4.27 & 3.26 & 0.88 & 3.53 & 0.12 & 0.10 & $4.81 \mathrm{e}+12$ & -86 & 10 & 5 \\
\hline $1637+574 \ldots \ldots \ldots \ldots$ & $2002 / 05 / 31$ & 1.81 & 1.88 & 1.55 & 1.02 & 1.74 & 0.26 & 0.07 & $8.54 \mathrm{e}+11$ & -154 & 2 & 1 \\
\hline $1638+398 \ldots \ldots \ldots \ldots$ & $1997 / 08 / 28$ & 1.60 & 1.60 & 1.22 & 0.98 & 1.46 & 0.15 & 0.13 & $1.12 \mathrm{e}+12$ & -137 & 7 & 1 \\
\hline $1641+399^{\mathrm{a}} \ldots \ldots \ldots \ldots$ & $1999 / 07 / 19$ & 9.39 & 8.73 & 4.38 & 0.86 & 5.08 & 0.20 & 0.04 & $5.42 \mathrm{e}+12$ & -90 & 12 & 6 \\
\hline 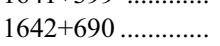 & $2001 / 12 / 30$ & 1.40 & 1.34 & 1.18 & 0.82 & 1.18 & 0.17 & $<0.02$ & $>3.19 \mathrm{e}+12$ & -171 & 7 & 6 \\
\hline $1652+398 \ldots \ldots \ldots \ldots$ & $1995 / 12 / 15$ & 1.26 & 0.81 & 0.41 & 0.62 & 0.54 & 0.32 & 0.15 & $6.32 \mathrm{e}+10$ & 150 & 7 & 0 \\
\hline $1655+077 \ldots \ldots \ldots \ldots$ & $1997 / 03 / 13$ & 2.10 & 1.72 & 1.36 & 0.97 & 1.59 & 0.52 & 0.11 & $2.55 \mathrm{e}+11$ & -35 & 7 & 1 \\
\hline $1656+053 \ldots \ldots \ldots \ldots$ & $1995 / 07 / 28$ & 1.07 & 0.68 & 0.29 & 0.64 & 0.66 & 0.79 & $<0.07$ & $>1.28 \mathrm{e}+11$ & 71 & 4 & 4 \\
\hline $1656+477 \ldots \ldots \ldots$ & $1997 / 03 / 13$ & 1.10 & 1.05 & 0.69 & 1.02 & 0.68 & 0.21 & 0.04 & $1.06 \mathrm{e}+12$ & -2 & 5 & 0 \\
\hline $1726+455 \ldots \ldots \ldots \ldots$ & $2002 / 05 / 31$ & 2.33 & 2.18 & 1.88 & 0.99 & 2.12 & 0.13 & 0.10 & $1.59 \mathrm{e}+12$ & -116 & 2 & 1 \\
\hline $1730-130 \ldots \ldots \ldots \ldots$ & $1996 / 10 / 27$ & 14.31 & 10.95 & 7.49 & 0.84 & 10.58 & 0.23 & $<0.03$ & $>1.50 \mathrm{e}+13$ & 12 & 7 & 5 \\
\hline $1739+522 \ldots \ldots \ldots \ldots$ & $2003 / 03 / 29$ & 1.26 & 1.43 & 1.11 & 0.99 & 0.99 & 0.11 & 0.09 & $1.32 \mathrm{e}+12$ & 43 & 3 & 0 \\
\hline $1741-038 \ldots \ldots \ldots . .$. & $2003 / 03 / 01$ & 7.04 & 6.99 & 4.55 & 0.99 & 5.71 & 0.16 & $<0.02$ & $>2.03 \mathrm{e}+13$ & -160 & 3 & 1 \\
\hline $1749+096 \ldots \ldots \ldots \ldots$ & $1995 / 07 / 28$ & 6.69 & 5.57 & 5.13 & 0.96 & 5.55 & 0.16 & $<0.02$ & $>1.34 \mathrm{e}+13$ & 21 & 6 & 4 \\
\hline $1749+701 \ldots \ldots \ldots \ldots$ & $2002 / 02 / 18$ & 0.75 & 0.79 & 0.63 & 0.76 & 0.57 & 0.16 & $<0.04$ & $>8.27 \mathrm{e}+11$ & -67 & 7 & 5 \\
\hline $1751+288 \ldots \ldots \ldots$ & $2003 / 05 / 09$ & 1.85 & 2.03 & 1.78 & 1.10 & 2.00 & 0.17 & 0.09 & $>7.07 \mathrm{e}+11$ & $\ldots$ & 2 & 0 \\
\hline $1758+388 \ldots \ldots \ldots . . . . . .$. & $1996 / 05 / 16$ & 1.70 & 1.75 & 1.42 & 0.99 & 1.62 & 0.20 & 0.09 & $1.47 \mathrm{e}+12$ & -96 & 6 & 0 \\
\hline
\end{tabular}


TABLE 2-Continued

\begin{tabular}{|c|c|c|c|c|c|c|c|c|c|c|c|c|}
\hline $\begin{array}{l}\text { Source } \\
\text { (1) }\end{array}$ & $\begin{array}{l}\text { Epoch } \\
\text { (2) }\end{array}$ & $\begin{array}{l}S_{\text {tot }} \\
(3)\end{array}$ & $\begin{array}{l}S_{\mathrm{VLBA}} \\
\quad(4)\end{array}$ & $\begin{array}{c}S_{\text {unres }} \\
(5)\end{array}$ & $\begin{array}{l}\frac{S_{\mathrm{VLBA}}}{S_{\mathrm{tot}}} \\
(6)\end{array}$ & $\begin{array}{l}S_{\text {core }} \\
(7)\end{array}$ & $\begin{array}{l}\theta_{\text {maj }} \\
(8)\end{array}$ & $\begin{array}{l}\theta_{\min } \\
(9)\end{array}$ & $\begin{array}{c}T_{b} \\
(10)\end{array}$ & $\begin{array}{l}\mathrm{PA}_{\text {jet }} \\
(11)\end{array}$ & $\begin{array}{l}\text { No. of } \\
\text { Epochs } \\
\text { (12) }\end{array}$ & $\begin{array}{c}\text { No. Unresolved } \\
\text { (13) }\end{array}$ \\
\hline $1800+440 .$. & $1996 / 05 / 16$ & 1.05 & 1.48 & 1.36 & 0.91 & 1.38 & 0.14 & $<0.01$ & $>9.35 \mathrm{e}+12$ & -162 & 7 & 4 \\
\hline $1803+784^{\mathrm{a}}$. & $1999 / 11 / 06$ & 2.64 & 2.45 & 1.62 & 0.89 & 1.61 & 0.15 & 0.08 & $1.25 \mathrm{e}+12$ & -92 & 8 & 0 \\
\hline 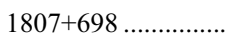 & $2001 / 12 / 30$ & 1.65 & 1.35 & 0.95 & 0.82 & 0.83 & 0.31 & $<0.05$ & $>3.40 \mathrm{e}+11$ & -105 & 11 & 6 \\
\hline $1821+107 \ldots \ldots \ldots \ldots \ldots$ & $1998 / 09 / 29$ & 0.48 & 0.39 & 0.24 & 0.78 & 0.29 & 0.41 & 0.13 & $6.77 \mathrm{e}+10$ & -17 & 2 & 0 \\
\hline $1823+568 \ldots \ldots \ldots \ldots \ldots$ & $1995 / 12 / 15$ & 2.01 & 2.31 & 1.94 & 0.93 & 2.14 & 0.28 & 0.06 & $1.21 \mathrm{e}+12$ & -161 & 9 & 6 \\
\hline $1828+487 \ldots \ldots \ldots \ldots$ & $2003 / 03 / 29$ & 3.04 & 1.89 & 1.29 & 0.61 & 1.30 & 0.20 & $<0.03$ & $>2.26 \mathrm{e}+12$ & -40 & 6 & 4 \\
\hline $1845+797 \ldots \ldots \ldots \ldots \ldots$ & $1997 / 08 / 28$ & 1.70 & 0.42 & 0.28 & 0.22 & 0.30 & 0.64 & $<0.03$ & $>9.66 \mathrm{e}+10$ & -38 & 11 & 3 \\
\hline $1849+670 \ldots \ldots \ldots \ldots \ldots$ & $2003 / 06 / 15$ & 1.60 & 1.74 & 1.52 & 1.09 & 1.61 & 0.20 & 0.04 & $1.76 \mathrm{e}+12$ & -42 & 1 & 0 \\
\hline $1901+319 \ldots \ldots \ldots \ldots$ & $1999 / 05 / 21$ & 1.22 & 1.12 & 0.69 & 0.80 & 0.78 & 0.19 & 0.05 & $7.34 \mathrm{e}+11$ & 119 & 9 & 5 \\
\hline $1908-201 \ldots \ldots \ldots \ldots$ & $1998 / 06 / 05$ & 3.30 & 2.82 & 2.20 & 0.85 & 2.60 & 0.49 & 0.12 & $5.27 \mathrm{e}+11$ & 24 & 1 & 0 \\
\hline $1921-293 \ldots \ldots \ldots \ldots$ & $2001 / 03 / 15$ & 14.22 & 12.16 & 7.58 & 0.85 & 10.41 & 0.38 & 0.10 & $1.91 \mathrm{e}+12$ & 20 & 5 & 0 \\
\hline $1928+738^{\mathrm{a}} \ldots$ & $2002 / 06 / 15$ & 3.48 & 3.90 & 2.65 & 0.81 & 2.58 & 0.20 & 0.07 & $1.37 \mathrm{e}+12$ & 156 & 13 & 1 \\
\hline $1936-155 \ldots \ldots \ldots \ldots$ & $1998 / 09 / 29$ & 2.15 & 1.77 & 1.26 & 0.91 & 1.62 & 0.15 & 0.08 & $1.87 \mathrm{e}+12$ & 119 & 4 & 0 \\
\hline 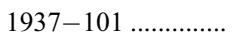 & $1998 / 09 / 29$ & 0.42 & 0.30 & 0.16 & 0.69 & 0.21 & 0.30 & 0.12 & $1.53 \mathrm{e}+11$ & 16 & 2 & 0 \\
\hline $1954-388 \ldots \ldots \ldots \ldots$ & $1998 / 06 / 05$ & 2.70 & 2.76 & 1.84 & 1.02 & 2.32 & 0.35 & 0.12 & $4.97 \mathrm{e}+11$ & -61 & 1 & 0 \\
\hline 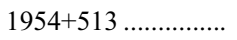 & $1999 / 05 / 21$ & 0.95 & 0.94 & 0.56 & 0.99 & 0.68 & 0.21 & 0.05 & $7.51 \mathrm{e}+11$ & -52 & 3 & 1 \\
\hline 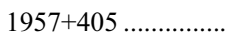 & $2002 / 11 / 23$ & 94.28 & 1.50 & 0.27 & 0.02 & $\ldots$ & 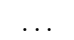 & $\ldots$ & $\ldots$ & -78 & 10 & 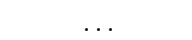 \\
\hline $1958-179$.............. & $1998 / 06 / 05$ & 2.90 & 2.67 & 2.22 & 0.91 & 2.62 & 0.16 & 0.11 & $1.28 \mathrm{e}+12$ & -153 & 2 & 0 \\
\hline 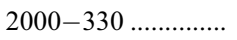 & $1998 / 09 / 29$ & 0.54 & 0.43 & 0.16 & 0.72 & 0.21 & 0.35 & 0.06 & $2.54 \mathrm{e}+11$ & -36 & 2 & 1 \\
\hline $2005+403 \ldots \ldots \ldots \ldots \ldots$ & $2001 / 03 / 04$ & 2.83 & 2.63 & 0.59 & 0.93 & 1.80 & 0.39 & 0.31 & $2.22 \mathrm{e}+11$ & 87 & 7 & 0 \\
\hline $2007+777 \ldots \ldots \ldots \ldots$ & $1994 / 08 / 31$ & 1.53 & 1.09 & 0.81 & 0.90 & 0.81 & 0.53 & $<0.05$ & $>2.34 \mathrm{e}+11$ & -90 & 10 & 7 \\
\hline $2008-159 \ldots \ldots \ldots \ldots$ & $2003 / 06 / 15$ & 1.99 & 2.14 & 1.66 & 0.97 & 2.08 & 0.32 & 0.09 & $8.35 \mathrm{e}+11$ & 8 & 2 & 0 \\
\hline $2010+463 \ldots \ldots \ldots \ldots$ & $2002 / 11 / 23$ & 0.33 & 0.28 & 0.23 & 0.85 & 0.25 & 0.45 & 0.12 & $>2.46 \mathrm{e}+10$ & -41 & 1 & 0 \\
\hline $2021+317 \ldots \ldots \ldots \ldots \ldots$ & $1995 / 04 / 07$ & 2.15 & 2.13 & 0.90 & 0.86 & 1.73 & 0.65 & 0.21 & $>7.01 \mathrm{e}+10$ & -167 & 6 & 0 \\
\hline $2021+614 \ldots \ldots \ldots \ldots \ldots$ & $1997 / 08 / 28$ & 2.55 & 2.73 & 0.81 & 0.91 & $\ldots$ & $\ldots$ & $\ldots$ & $\ldots$ & -147 & 8 & $\ldots$ \\
\hline 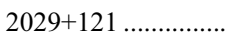 & $1998 / 12 / 05$ & 0.95 & 1.01 & 0.63 & 1.04 & 0.79 & 0.22 & 0.13 & $3.42 \mathrm{e}+11$ & -151 & 2 & 0 \\
\hline $2037+511 \ldots \ldots \ldots \ldots$ & $2002 / 10 / 09$ & 2.70 & 2.32 & 1.56 & 0.86 & 1.79 & 0.29 & 0.11 & $8.33 \mathrm{e}+11$ & -141 & 2 & 0 \\
\hline 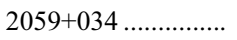 & $1998 / 12 / 05$ & 0.95 & 0.99 & 0.82 & 1.05 & 0.92 & 0.26 & 0.11 & $3.60 \mathrm{e}+11$ & 29 & 2 & 0 \\
\hline $2113+293 \ldots \ldots \ldots \ldots \ldots$ & $1995 / 04 / 07$ & 0.87 & 0.93 & 0.96 & 0.91 & 0.91 & 0.30 & $<0.04$ & $>9.29 \mathrm{e}+11$ & 164 & 5 & 3 \\
\hline $2121+053 \ldots \ldots \ldots \ldots \ldots$ & $1999 / 11 / 06$ & 2.30 & 2.48 & 1.98 & 1.06 & 1.98 & 0.13 & $<0.03$ & $>7.39 \mathrm{e}+12$ & -87 & 4 & 3 \\
\hline $2126-158 \ldots \ldots \ldots \ldots$ & $1998 / 09 / 29$ & 1.25 & 1.23 & 0.91 & 0.95 & 1.14 & 0.23 & 0.13 & $8.55 \mathrm{e}+11$ & -168 & 2 & 0 \\
\hline $2128+048 \ldots \ldots \ldots \ldots$ & $2002 / 10 / 20$ & 0.78 & 0.47 & 0.07 & 0.60 & $\ldots$ & $\ldots$ & $\ldots$ & $\ldots$ & $\ldots$ & 3 & $\ldots$ \\
\hline $2128-123^{\mathrm{a}} \ldots \ldots \ldots \ldots$ & $1999 / 11 / 06$ & 2.90 & 2.36 & 1.11 & 0.90 & 0.46 & 0.51 & $<0.06$ & $>1.29 \mathrm{e}+11$ & -153 & 5 & 4 \\
\hline $2131-021 \ldots \ldots \ldots \ldots$ & $2003 / 05 / 09$ & 2.33 & 2.19 & 0.50 & 0.94 & 1.15 & 0.30 & $<0.06$ & $>7.44 \mathrm{e}+11$ & 109 & 8 & 4 \\
\hline 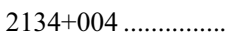 & $1996 / 10 / 27$ & 6.17 & 4.44 & 1.61 & 0.88 & 2.02 & 0.34 & $<0.07$ & $>1.31 \mathrm{e}+12$ & -101 & 8 & 2 \\
\hline $2136+141 \ldots \ldots \ldots \ldots \ldots$ & $2002 / 11 / 23$ & 2.79 & 2.75 & 1.32 & 0.94 & 2.04 & 0.32 & 0.05 & $2.30 \mathrm{e}+12$ & -68 & 7 & 3 \\
\hline $2144+092 \ldots \ldots \ldots \ldots \ldots$ & $1996 / 10 / 27$ & 0.75 & 0.80 & 0.60 & 0.97 & 0.55 & 0.15 & $<0.04$ & $>9.81 \mathrm{e}+11$ & 81 & 6 & 3 \\
\hline $2145+067 \ldots \ldots \ldots \ldots$ & $1999 / 11 / 06$ & 10.66 & 10.33 & 6.03 & 0.97 & 7.97 & 0.20 & 0.07 & $6.01 \mathrm{e}+12$ & 135 & 9 & 3 \\
\hline $2155-152 \ldots \ldots \ldots \ldots \ldots$ & $2002 / 10 / 20$ & 2.13 & 2.13 & 1.35 & 0.87 & 1.31 & 0.21 & $<0.09$ & $>6.53 \mathrm{e}+11$ & -153 & 3 & 3 \\
\hline $2200+420 \ldots \ldots \ldots \ldots \ldots$ & $1996 / 05 / 16$ & 5.47 & 5.67 & 2.78 & 0.91 & 2.96 & 0.37 & $<0.03$ & $>1.45 \mathrm{e}+12$ & -162 & 14 & 10 \\
\hline $2201+171 \ldots \ldots \ldots \ldots$ & $2003 / 06 / 15$ & 1.92 & 2.01 & 1.56 & 1.05 & 1.74 & 0.13 & $<0.02$ & $>9.49 \mathrm{e}+12$ & 37 & 1 & 1 \\
\hline $2201+315 \ldots \ldots \ldots \ldots \ldots$ & $2001 / 12 / 22$ & 3.31 & 3.28 & 2.73 & 0.97 & 2.71 & 0.26 & $<0.03$ & $>2.77 \mathrm{e}+12$ & -143 & 8 & 4 \\
\hline $2209+236 \ldots \ldots \ldots \ldots$ & $1996 / 10 / 27$ & 1.60 & 1.59 & 0.96 & 0.99 & 1.55 & 0.20 & 0.04 & $2.04 \mathrm{e}+12$ & 23 & 5 & 2 \\
\hline $2216-038 \ldots \ldots \ldots \ldots$ & $2002 / 05 / 31$ & 2.65 & 2.52 & 1.65 & 0.95 & 2.02 & 0.28 & 0.11 & $7.04 \mathrm{e}+11$ & -172 & 3 & 1 \\
\hline $2223-052 \ldots \ldots \ldots \ldots$ & $2000 / 01 / 11$ & 7.61 & 4.78 & 2.72 & 0.81 & 4.38 & 0.22 & $<0.04$ & $>6.53 \mathrm{e}+12$ & 94 & 9 & 7 \\
\hline $2227-088 \ldots \ldots \ldots \ldots \ldots$ & $2002 / 10 / 20$ & 2.09 & 2.15 & 1.87 & 0.87 & 2.03 & 0.17 & 0.08 & $2.05 \mathrm{e}+12$ & -36 & 5 & 2 \\
\hline 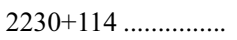 & $1998 / 03 / 07$ & 5.17 & 4.61 & 3.11 & 0.83 & 3.52 & 0.12 & $<0.03$ & $>1.27 \mathrm{e}+13$ & 142 & 9 & 5 \\
\hline $2234+282 \ldots \ldots \ldots \ldots \ldots$ & $2001 / 01 / 21$ & 1.34 & 1.44 & 0.82 & 1.00 & 0.46 & 0.41 & 0.26 & $4.20 \mathrm{e}+10$ & -136 & 7 & 2 \\
\hline $2243-123 \ldots \ldots \ldots \ldots \ldots$ & $1997 / 03 / 10$ & 2.70 & 2.56 & 1.99 & 0.88 & 1.92 & 0.29 & 0.11 & $5.13 \mathrm{e}+11$ & -5 & 5 & 2 \\
\hline $2251+158^{\mathrm{a}} \ldots \ldots \ldots \ldots \ldots$ & $1996 / 05 / 16$ & 10.80 & 10.13 & 3.77 & $\begin{array}{l}0.00 \\
0.91\end{array}$ & 2.95 & 0.26 & 0.11 & $1.05 \mathrm{e}+12$ & -88 & 11 & 4 \\
\hline $2255-282 \ldots \ldots \ldots \ldots \ldots$ & $1997 / 08 / 18$ & 6.80 & 6.79 & 5.50 & 0.99 & 6.70 & 0.13 & $<0.02$ & $>2.24 \mathrm{e}+13$ & -133 & 2 & 1 \\
\hline $2318+049 \ldots \ldots \ldots \ldots \ldots$ & $1998 / 09 / 29$ & 1.19 & 1.22 & 0.94 & 1.03 & 1.20 & 0.29 & 0.15 & $2.48 \mathrm{e}+11$ & -40 & 5 & 1 \\
\hline $2329-162 \ldots \ldots \ldots \ldots$ & $1998 / 06 / 05$ & 1.05 & 0.83 & 0.21 & 0.79 & 0.61 & 0.46 & 0.33 & $4.73 \mathrm{e}+10$ & 84 & 1 & 0 \\
\hline $2331+073 \ldots \ldots \ldots \ldots \ldots$ & $2002 / 06 / 15$ & 1.22 & 1.24 & 0.77 & 0.99 & 0.87 & 0.12 & $<0.02$ & $>1.75 \mathrm{e}+12$ & -120 & 2 & 2 \\
\hline $2345-167^{\mathrm{a}} \ldots \ldots \ldots \ldots$ & $1995 / 07 / 28$ & 2.65 & 2.55 & 1.29 & 0.83 & 1.46 & 0.30 & $<0.04$ & $>1.10 \mathrm{e}+12$ & 128 & 6 & 4 \\
\hline $2351+456^{\mathrm{a}} \ldots \ldots \ldots \ldots \ldots$ & $2002 / 05 / 31$ & 2.46 & 1.79 & 1.11 & 0.83 & 1.34 & 0.19 & 0.14 & $8.53 \mathrm{e}+11$ & -48 & 2 & 0 \\
\hline
\end{tabular}

Notes.-The printed table lists, for each source, the parameters at the epoch for which the unresolved flux density $S_{\text {unres }}$ was greatest. Col. (1): IAU source name. Col. (2): Epoch of observations ( YYYY/MM/DD). Col. (3): Filled-aperture (singe antenna) flux density (Jy) interpolated to the epoch from col. (2). Col. (4): Total CLEAN flux density of the map $S_{\mathrm{VLBA}}(\mathrm{Jy})$. Col. (5): Flux density from the most compact component of the map, $S_{\text {unres }}$ (Jy). Col. (6): As an exception, we present here the median value of $S_{\mathrm{VLBA}} / S_{\text {tot }}$ over all available epochs ( $S_{\mathrm{VLBA}} / S_{\text {tot }}$ is only slightly variable if it is close to unity, which is the case for most sources). Col. (7): Flux density $S_{\text {core }}$ for a VLBA core component (Jy). Col. (8): FWHM major axis of the VLBA core component $\theta_{\text {maj }}$ (mas). Col. (9): FWHM minor axis of the VLBA core component $\theta_{\text {min }}$ (mas). Col. (10): Brightness temperature of a VLBA core component (K). Col. (11): Position angle of the jet $\mathrm{PA}_{\text {jet }}(\mathrm{deg})$ defined as the median of the position angle of the second component location with respect to the core position in our model from the multiepoch observations. Col. (12): Number of epochs of observations. Col. (13): Number of epochs when the source core is unresolved in at least one direction. A version of Table 2 with the parameters at all epochs is published in the electronic edition of the Astronomical Journal.

${ }^{a}$ More than two components were used to model the structure. 


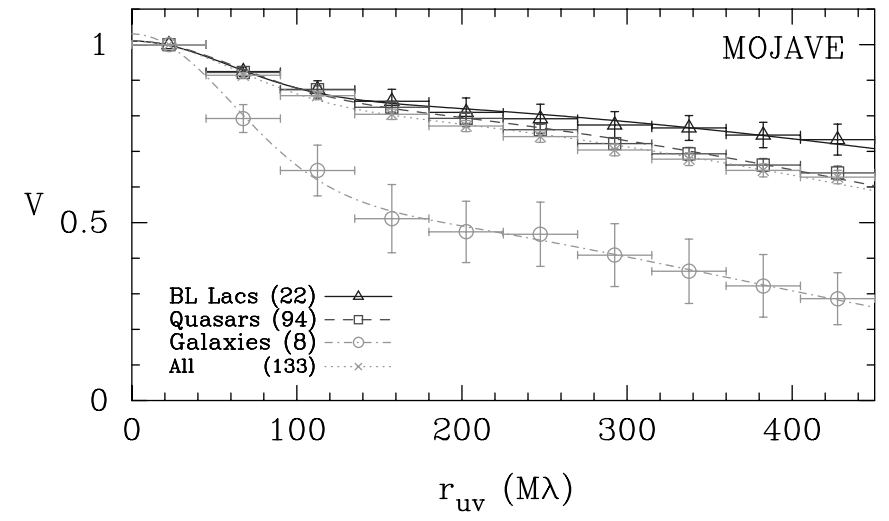

FIG. 6.-Nonweighted mean of the fringe visibility vs. projected spacing for the MOJAVE sample. The distribution is normalized to 1.0 at $25 \mathrm{M} \lambda$. Visibility data at the epoch with the maximum correlated flux density at maximum VLBA spacings for each source are used. Before averaging over the samples, the fringe visibility amplitude for each source was binned and averaged. Vertical bars represent the $\pm 1 \sigma$ formal error, and horizontal bars the intervals of visibility data (10 bins in total). The lines represent the best-fit two-component models. See model parameters in Table 3. [See the electronic edition of the Journal for a color version of this figure.]

MOJAVE sample and averaged over the MOJAVE quasars, BL Lac objects, and active galaxies, separately. The best-fit parameter values for a model consisting of two Gaussian components are listed in Table 3 for each of these mean visibility curves.

The active galaxies are, on average, the least VLBA core dominated and the least compact on arcsecond (Fig. 5) and submilliarcsecond (Figs. 5 and 6, Table 3) scales. The fact that the relative contribution of an extended component (i.e., a jet) is significantly greater for active galaxies is consistent with unification models in which radio galaxies are viewed at larger angles to the line of sight than BL Lac objects or quasars (e.g., Antonucci et al. 1987; Antonucci 1993; Urry \& Padovani 1995; Wills 1999), so that the latter have higher Doppler factors, their cores are more boosted, and thus, they appear more core dominated. A Kolmogorov-Smirnov (K-S) test confirms that for both the full and the MOJAVE sample the probability is less than $1 \%$ that the active galaxies have the same parent distribution as the quasars or the BL Lac objects with regard to their compactness on arcsecond scales, $S_{\mathrm{VLBA}} / S_{\text {tot }}$, or their compactness on submilliarcsecond scales, $S_{\text {unres }} / S_{\mathrm{VLBA}}$; with regard to their core dominance, $S_{\text {core }} / S_{\mathrm{VLBA}}$, the probability is less than $2 \%$.

For the BL Lac objects versus quasars, K-S tests were inconclusive. However, Figure 6 and Table 3 show that the BL Lac objects are, on average, even more compact on sub-milliarcsecond scales than the quasars. We have also found this distinction between subsamples of quasars and BL Lac objects chosen to have statistically indistinguishable redshift distributions. The differences between the quasars and the BL Lac objects in angular size at sub-milliarcsecond scales in the sample as a whole are therefore not related to the different overall redshift distributions of these groups. As discussed in $\S 2$, classifying objects is a complex issue, particularly with regard to BL Lac objects. With our tabulated data, others could repeat the analysis using their own classification procedure if desired. However, the optical classification scheme we have used is evidently "clean" enough that, after the fact, it turns out to correspond to differences in radio compactness. We cannot image any hypothetical optical classification bias that could be fully responsible for the correspondence with radio compactness, and we conclude that it is an actual physical phenomenon. Our sample does not show a significant dependence on redshift of the index of compactness on sub-milliarcsecond scales,
TABLE 3

Results of Two-Component Modeling of the Mean Visibility

\begin{tabular}{|c|c|c|c|c|c|}
\hline $\begin{array}{l}\text { Sample } \\
\text { (1) }\end{array}$ & $\begin{array}{c}\text { No. of } \\
\text { Sources } \\
\text { (2) }\end{array}$ & $\begin{array}{l}\mathcal{V}_{1} \\
(3)\end{array}$ & $\begin{array}{c}\theta_{1} \\
(4)\end{array}$ & $\begin{array}{l}\mathcal{V}_{2} \\
(5)\end{array}$ & $\begin{array}{c}\theta_{2} \\
(6)\end{array}$ \\
\hline \multicolumn{6}{|l|}{ MOJAVE sample: } \\
\hline BL Lac objects. & 22 & 0.16 & 1.353 & 0.85 & 0.105 \\
\hline Quasars... & 94 & 0.16 & 1.278 & 0.85 & 0.144 \\
\hline Active galaxies. & 8 & 0.46 & 1.314 & 0.57 & 0.216 \\
\hline 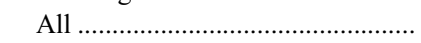 & 133 & 0.18 & 1.296 & 0.83 & 0.144 \\
\hline \multicolumn{6}{|l|}{ Full sample: } \\
\hline EGRET. & 52 & 0.16 & 1.260 & 0.85 & 0.138 \\
\hline Non-EGRET & 198 & 0.26 & 1.394 & 0.76 & 0.151 \\
\hline \multicolumn{6}{|l|}{ MOJAVE sample: } \\
\hline EGRET. & 35 & 0.15 & 1.211 & 0.86 & 0.135 \\
\hline Non-EGRET & 98 & 0.20 & 1.260 & 0.81 & 0.143 \\
\hline VSOP sampl & 116 & 0.25 & 1.314 & 0.76 & 0.147 \\
\hline VSOP Pearson-Readhead sample.. & 26 & 0.23 & 1.484 & 0.79 & 0.148 \\
\hline
\end{tabular}

Notes.-From modeling of mean fringe visibility versus projected spacing dependence at $15 \mathrm{GHz}$. Col. (1): Sample type. Col. (2): Number of sources. Col. (3): Peak value at zero spacing of the first Gaussian component. Col. (4): Angular size of the first Gaussian component (mas). Cols. (5) and (6): The same as cols. (3) and (4), but for the second Gaussian component.

$S_{\text {unres }} / S_{\mathrm{VLBA}}$, although the few heavily resolved sources are mostly active galaxies at low redshift.

\subsection{Frequency Dependence}

Horiuchi et al. (2004) have presented a plot, similar to Figure 6, based on $5 \mathrm{GHz}$ VLBA and VSOP observations of 189 radio sources that cover a range of spatial frequencies comparable to our $15 \mathrm{GHz}$ VLBA data. They find that the average fringe visibility in the range $400-440 \mathrm{M} \lambda$ is $0.21-0.24$. For the 116 sources in common to the two samples (see Table 1), we find an average fringe visibility at $15 \mathrm{GHz}$ of about 0.6 . The compact component emission dominates at $15 \mathrm{GHz}(>75 \%$; see Table 3$)$ but not at $5 \mathrm{GHz}$ (40\%; Horiuchi et al. 2004). This reflects the fact that the $5 \mathrm{GHz}$ observations detect a larger contribution from steepspectrum, optically thin, large-scale components. The $5 \mathrm{GHz} V \mathrm{VOP}$ survey sample and our $15 \mathrm{GHz}$ VLBA sample are not identical, but this result is confirmed if only the subset of overlapping PearsonReadhead VSOP survey sources (Lister et al. 2001; Horiuchi et al. 2004) is used for comparison.

\subsection{Brightness Temperatures}

Figure 7 shows distributions of the core parameters. The ratio of the major axis of the core to the beam width in the same direction varies by more than an order of magnitude, so, in most cases, we believe that our measured core dimensions are not an artifact of the finite beam size.

The cores are always resolved along their major axis. However, for 158 sources in our full sample, there is at least one epoch at which the core component appears unresolved along the minor axis, where it is then typically less than 0.05 mas in size. In 19 of these sources, including five BL Lac objects, the core is unresolved along the minor axis at all observed epochs.

Figure 8 shows the distribution of the difference between the position angle of the major axis of the core, $\mathrm{PA}_{\text {core }}$, and the jet direction, $\mathrm{PA}_{\text {jet }}$; the latter was taken to be the median over all epochs of the position angle of the jet component with respect to the core. All possible values of $\left|\mathrm{PA}_{\text {core }}-\mathrm{PA}_{\text {jet }}\right|$ between $0^{\circ}$ and $90^{\circ}$ are observed. Not unexpectedly, the peak of the distribution is close to zero; that is, the Gaussian component representing the 

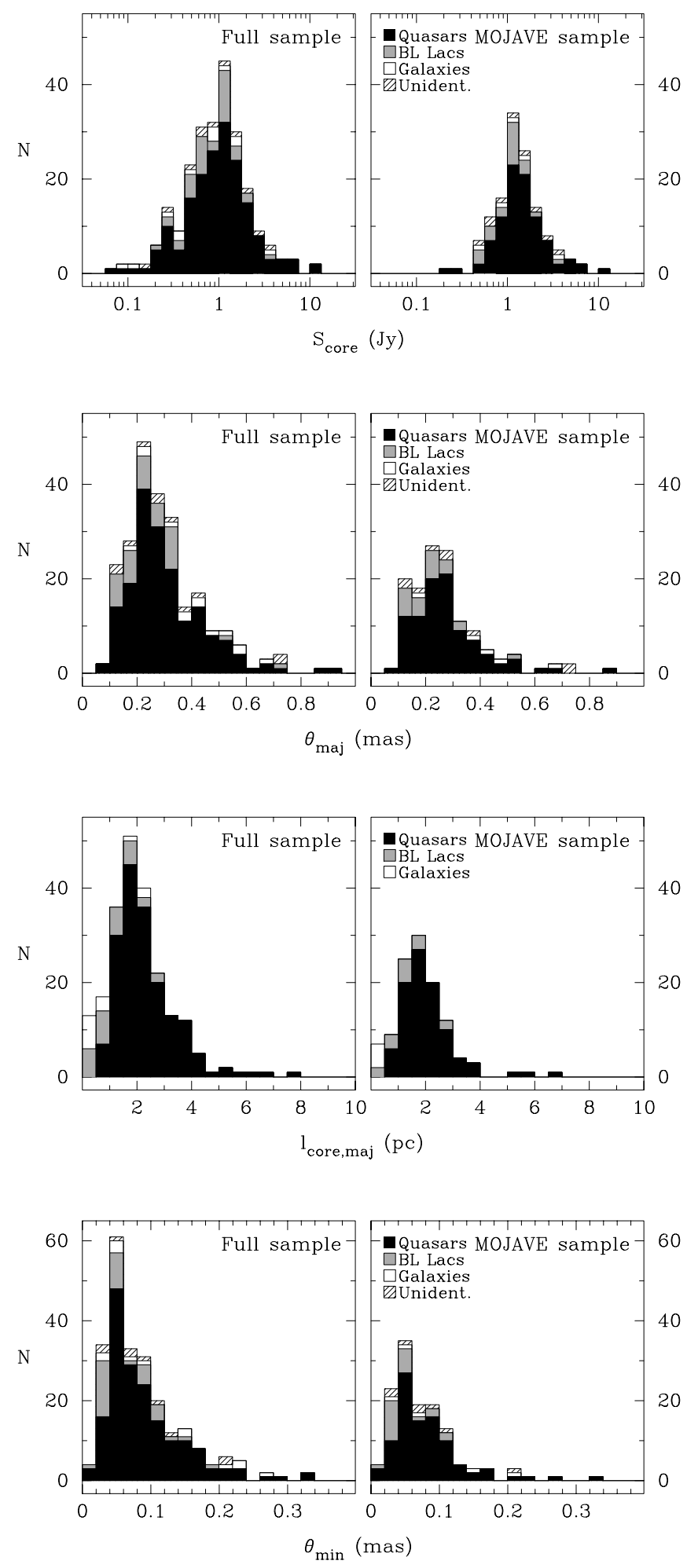

FIG. 7.-From top to bottom, the distributions of the median flux density and the angular and linear dimensions of the core model components derived from the multiepoch observations for each source.

core is typically extended along the jet direction. For the majority of sources that have multiepoch modeling data, the orientation of the core is stable in time, with a scatter around the average $\mathrm{PA}_{\text {core }}$ of less than $10^{\circ}$. Figure 8 also demonstrates that the position angle of the core is not correlated with the position angle of the VLBA beam, so that the measured core orientation is, in most cases, not distorted by the orientation of the VLBA beam.
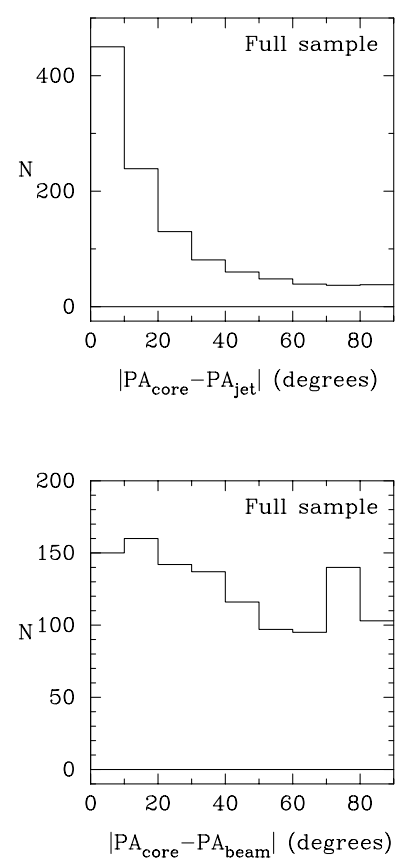

FIG. 8.-Distributions of the difference between the position angle of the major axis of the core and the position angle of a jet (left) and the difference between the position angle of the major axis of the core and the position angle of the major axis of the VLBA beam (right) for all the data modeled.

The brightness temperature of a slightly resolved component in the rest frame of the source is given by

$$
T_{b}=\frac{2 \ln 2}{\pi k} \frac{S_{\mathrm{core}} \lambda^{2}(1+z)}{\theta_{\mathrm{maj}} \theta_{\mathrm{min}}},
$$

where $S_{\text {core }}$ is the flux density of a VLBA core, $\theta_{\text {maj }}$ and $\theta_{\min }$ are the FWHMs of the elliptical Gaussian components along the major and the minor axes, $\lambda$ is the wavelength of observation, $z$ is the redshift, and $k$ is the Boltzmann constant. Observing at $\lambda=2 \mathrm{~cm}$ with $S_{\text {core }}$ measured in janskys and $\theta_{\text {maj }}$ and $\theta_{\text {min }}$ in milliarcseconds, we can write

$$
T_{b}=5.44 \times 10^{9} \frac{S_{\text {core }}(1+z)}{\theta_{\text {maj }} \theta_{\min }} \mathrm{K} .
$$

The brightness temperature can also be represented in terms of an effective baseline $D=\lambda /\left(\theta_{\text {maj }} \theta_{\text {min }}\right)^{1 / 2}$. If $D$ is measured in kilometers and $S_{\text {core }}$ in janskys, we have

$$
T_{b}=3.20 \times 10^{2} S_{\text {core }} D^{2}(1+z) \mathrm{K},
$$

which is independent of wavelength and depends only on the physical length of the effective projected baseline and on the core flux density. For sources without measured redshift (see Table 1) we use $z=0$ to define a limit to $T_{b}$.

Paper I and Paper II gave conservative estimates of the observed peak brightness temperature based on the observed angular size, which is the intrinsic size convolved with the VLBA beam width. Here, we derive the core brightness temperature using the dimensions or upper limits obtained from direct modeling of the complex visibility functions. For many sources the effective resolution is an order of magnitude better than given by Paper I and Paper II, so the corresponding derived brightness 

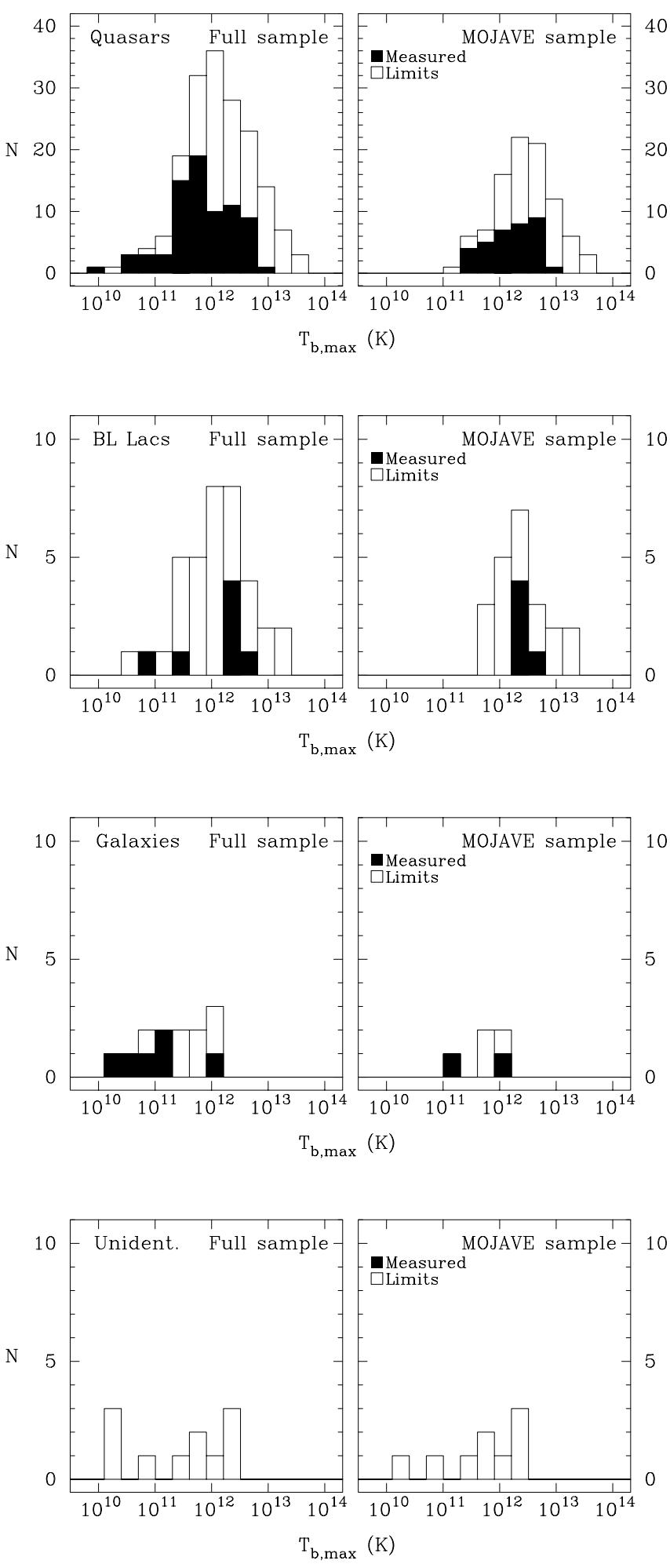

FIG. 9.-Distributions of the maximum observed VLBA core brightness temperature in the source frame. Each bin covers a factor of 2 in brightness temperature.

temperatures are as much as a factor of 100 greater. The median value of these VLBA core brightness temperatures, shown in Figure 9 , is near $10^{12} \mathrm{~K}$; they extend up to $5 \times 10^{13} \mathrm{~K}$. This is comparable with brightness temperatures derived from VSOP space VLBI observations (Hirabayashi et al. 2000; Frey et al. 2000; Tingay et al. 2001; Horiuchi et al. 2004). In many cases our measurement refers only to the upper limit of the angular size, corresponding to our minimum resolvable size derived

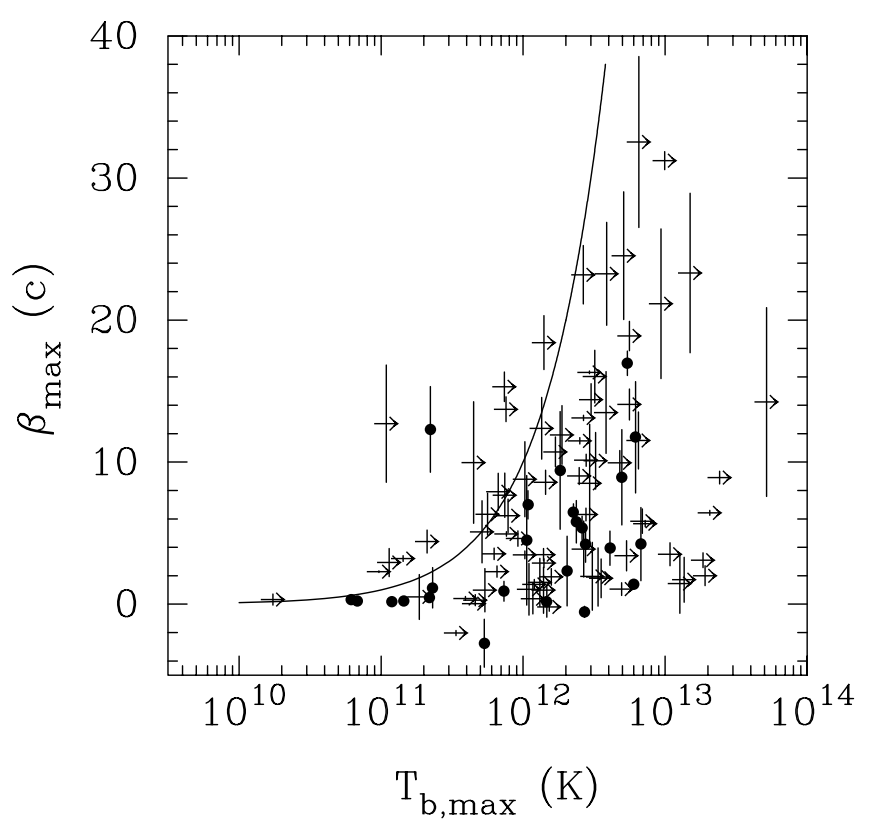

FIG. 10.-Apparent velocity $\beta_{\max }$ from Paper III vs. maximum core brightness temperature $T_{b, \max }$. Values of $\beta_{\max }$ are taken for the fastest components with ratings of " $E$ " or " $G$ " only. Lower limits of brightness temperature are plotted as arrows. The curve is plotted for $T_{b, \max }=\beta_{\max } T_{\mathrm{int}}$, where the intrinsic brightness temperature is taken as $T_{\text {int }}=10^{11} \mathrm{~K}$.

using equation (2). The effective resolution depends on the maximum baseline and on the SNR near the maximum resolution. The true brightness temperatures of many sources may extend to a much higher value, beyond the equipartition value of $10^{11} \mathrm{~K}$ (Readhead 1994; Singal \& Gopal-Krishna 1985) or the inverse Compton limit of $10^{12} \mathrm{~K}$ (Kellermann \& Pauliny-Toth 1969). These high brightness temperatures are probably due to Doppler boosting, but transient nonequilibrium events, coherent emission, emission by relativistic protons, or a combination of these effects (e.g., Kardashev 2000; Kellermann 2002, 2003) may also play a role.

If the high observed brightness temperatures are due to Doppler boosting and if the range of intrinsic brightness temperatures, $T_{\text {int }}$, is small, there should be a correlation between the apparent jet velocity, $\beta_{\text {app }}$, and the observed brightness temperature. For those sources listed in Paper III, Figure 10 shows the fastest observed jet velocity against the maximum observed brightness temperature of their cores. While this plot contains mostly lower limits to the brightness temperature, there are no sources with a low brightness temperature and a high observed speed; conversely, the highest speeds are observed only in sources with a high brightness temperature. This is the trend that we would expect if the observed brightness temperatures were Doppler boosted with $T_{\text {obs }}=\delta T_{\text {int }}$, where $\delta$ is the Doppler factor. At the optimum angle $\vartheta$ to the observer's line of sight for superluminal motion, $\beta=\cos \vartheta, \beta_{\text {app }}=\delta$, and therefore, $T_{\text {obs }} \simeq$ $\beta_{\text {app }} T_{\text {int }}$. As shown in Figure 10 , with $T_{\text {int }}=10^{11} \mathrm{~K}$ this curve tracks the trend of the data. Of course, the actual jet orientations deviate from the optimum viewing angle given by $\beta=\cos \vartheta$, and many of our brightness temperature estimates are lower limits. Both of these factors lead to a spread in the data, so we should not expect a tight correlation along the plotted line; however, the general agreement between the trend of the data and this simple model supports the idea that the intrinsic brightness temperatures have been Doppler-boosted by the same relativistic motion that gives us the observed component speeds. 

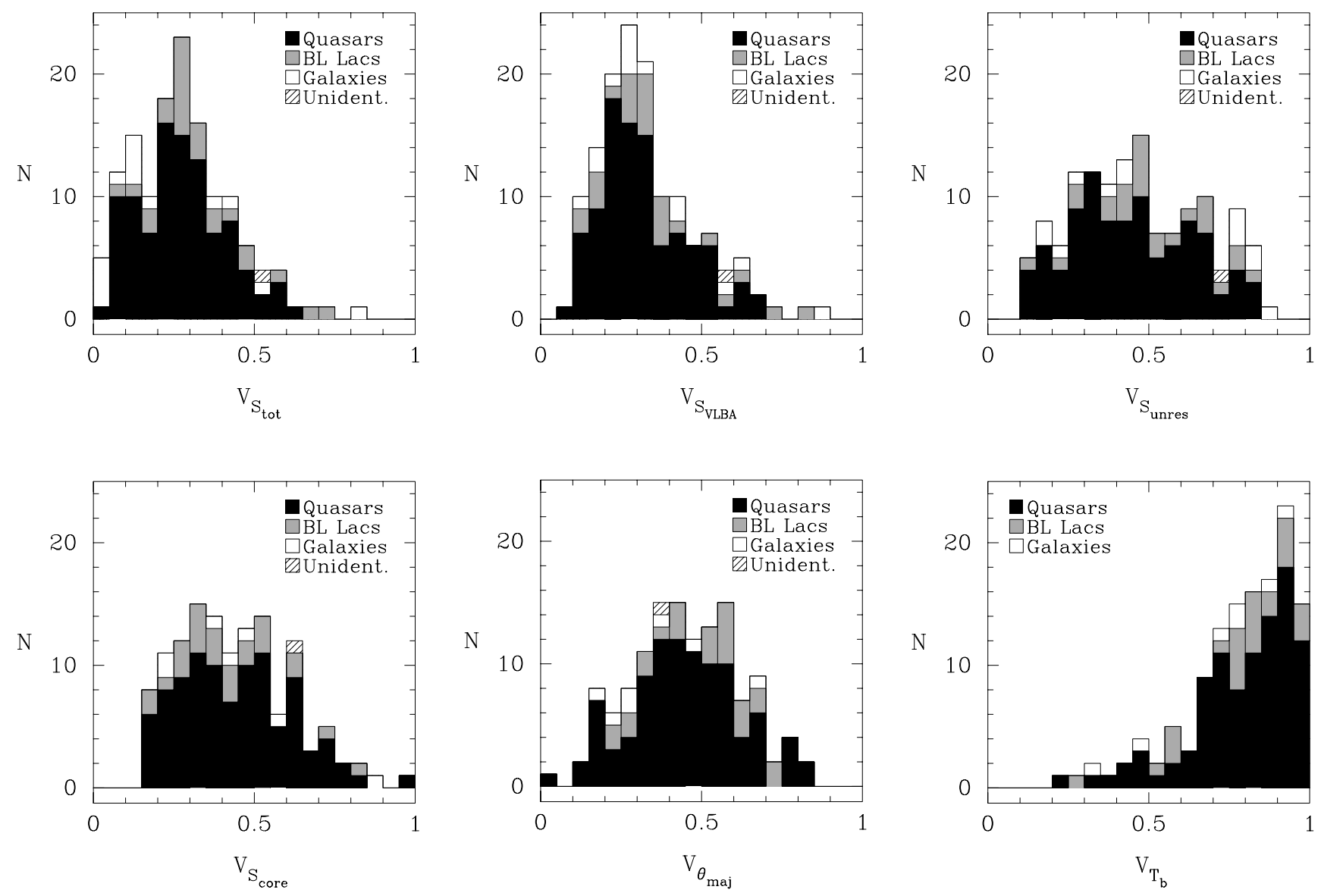

FIG. 11.-Distributions of the variability index $V$ derived for $S_{\text {tot }}, S_{\mathrm{VLBA}}, S_{\text {unres }}$, core flux density, major axis, and brightness temperature. The variability indices are calculated for 137 sources of the full sample observed four or more times.

We note that there are some sources with high brightness temperatures but low speeds. This is expected, as some sources will have an angle to the line of sight much smaller than $\beta=\cos \vartheta$, and those sources will have a small apparent motion but will still be highly beamed (M. H. Cohen et al. 2006, in preparation).

For those sources for which there are multiple epochs of observation, the core parameters, in particular the observed brightness temperatures, vary significantly with time. Population modeling of the distribution of brightness temperature, as well as comparisons with the results of other VLBI surveys (e.g., Lobanov et al. 2000), may give insight into the distributions of intrinsic brightness temperatures and Doppler factors.

We have not found any significant correlation between redshift and brightness temperature. This is in agreement with the $5 \mathrm{GHz}$ VSOP results of Horiuchi et al. (2004).

\subsection{Variability}

The long-term centimeter-wave monitoring data on our sources from UMRAO and RATAN show complex light curves with frequent flux density outbursts (e.g., Aller et al. 2003; Kovalev et al. 2002). These outbursts are thought to be associated with the birth of new compact features, which are often not apparent in VLBI images until they have moved sufficiently far down the jet. Changes usually appear sooner in the visibility function (Fig. 3), which in the case of our data probes angular scales roughly 10 times smaller than the typical image restoring beam.

Most new jet features typically increase in size and/or decrease in flux density after a few months to years as a result of adiabatic expansion and/or synchrotron losses. However, an interesting exception is M87 $(1228+126)$, in which the most compact feature appears to remain constant (Fig. 3), although the larger scale jet structure shows changes by up to a factor of 2 in correlated flux density. This unusual behavior, which was first noted by Kellermann et al. (1973), is remarkable in that the dimensions of this compact stable feature are only on the order of 10 lt-days or less. This weak $(\lesssim 0.2 \mathrm{Jy})$, stable feature in the center of M87 may be closely associated with the region where relativistic particles are accelerated. More sensitive observations with comparable linear resolution might show similar phenomena in more distant sources, but such observations will only be possible with large antennas in space.

We define a variability index as $V_{X}=\left(X_{\max }-X_{\min }\right) /\left(X_{\max }+\right.$ $\left.X_{\min }\right)$. Figure 11 shows distributions of the variability indices $V_{S_{\text {tot }}}, V_{S_{\mathrm{VLBA}}}$, and $V_{S_{\text {unres }}}$, as well as, to represent the cores, $V_{S_{\text {core }}}$, $V_{\theta_{\text {maj }}}$, and $V_{T_{b}}$. As expected, the variability indices for the flux density become larger with improved resolution, going from median values of $V_{S_{\mathrm{tot}}}=0.27$ and $V_{S_{\mathrm{VLBA}}}=0.30$ to $V_{S_{\text {core }}}=0.42$ and $V_{S_{\text {unres }}}=0.45$. For about $68 \%$ of the sources, the flux density of the core has varied by a factor of 2 or more, that is, $V>1 / 3$. Similarly, the size of the core major axis, $\theta_{\text {maj }}$, changed by as much as a factor of 5 , or $V>2 / 3$, in some cases. This is probably due to the creation or ejection of a new component, which initially is not resolved from the core but then separates from it, causing first an apparent increase and then an apparent decrease in the strength and size of the core. The observed strong variability of the brightness temperatures (median $V_{T_{b}}=0.82$ ) may reflect strong variations of particle density (due to ejections) and/or magnetic field strength. The most variable sources tend 

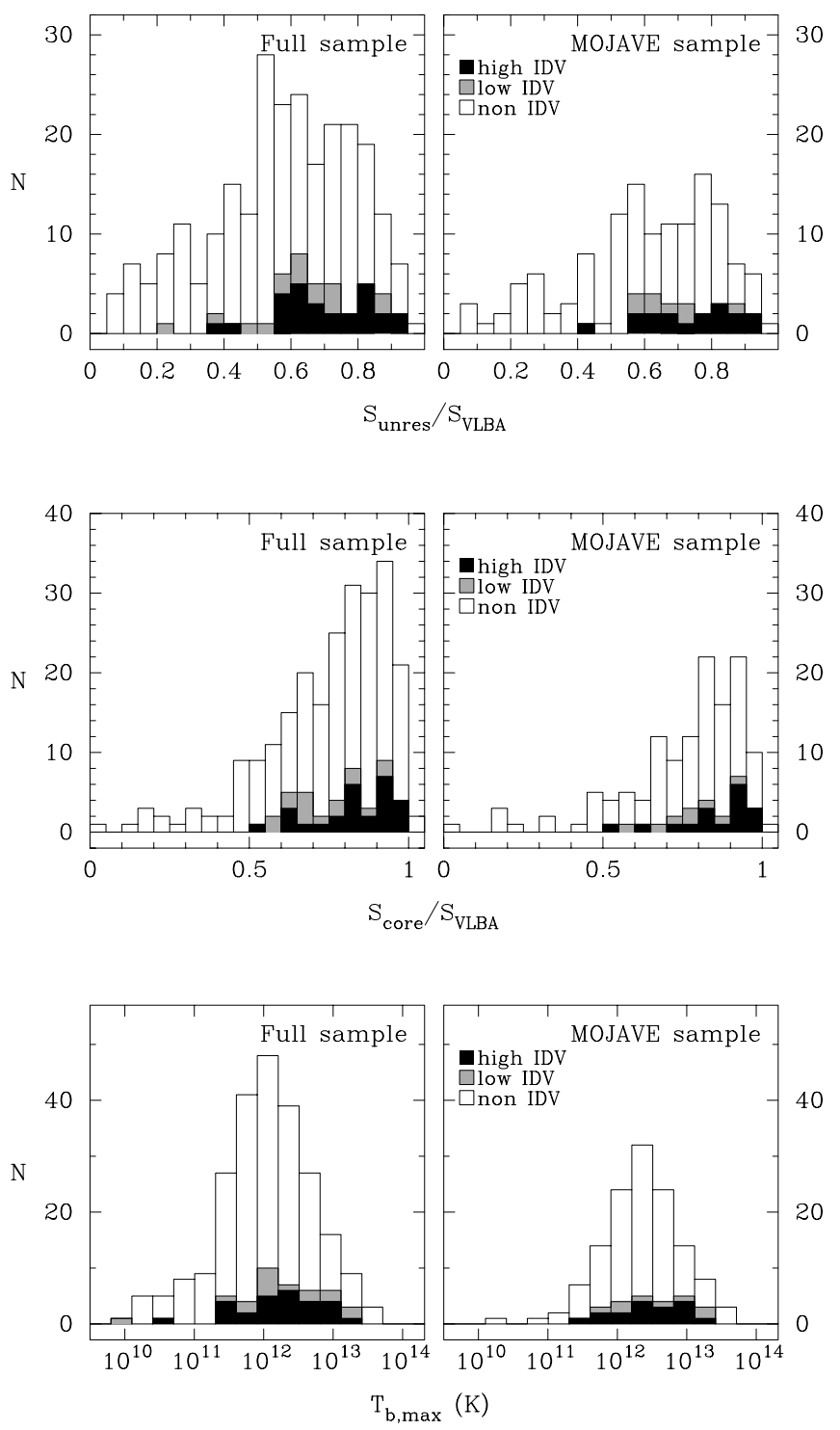

FIG. 12.-Distributions of the median compactness index on sub-milliarcsecond scales $S_{\text {unres }} / S_{\mathrm{VLBA}}$ (top panels), the VLBA core dominance $S_{\text {core }} / S_{\mathrm{VLBA}}$ (middle panels), and the maximum brightness temperature $T_{b, \max }$ (bottom panels) for IDVselected and -nonselected sources. We separate IDV sources with high modulation index $(m>0.02$ observed at least once: high $I D V)$ from ones with low modulation index (measured values of modulation index always less than 0.02 or not reported: low $(D V)$. to have the most compact structure. A variability index $V_{S_{\mathrm{VLBA}}}>$ 0.6 is observed for nine sources, all but one of which have submilliarcsecond compactness $S_{\text {unres }} / S_{\mathrm{VLBA}} \geq 0.75$.

\subsection{Intraday Variable Sources}

We have used the results of several IDV search and monitoring programs at the Effelsberg $100 \mathrm{~m}$ telescope, the VLA, and the Australia Telescope Compact Array at 1.4-15 GHz (Quirrenbach et al. 1992, 2000; Kedziora-Chudczer et al. 2001; Bignall et al. 2002; Kraus et al. 2003; Lovell et al. 2003) to identify IDV sources in our sample (Table 1). The biggest and most complete IDV survey so far, the $5 \mathrm{GHz}$ MASIV survey (Lovell et al. 2003), started at the VLA in 2002; the first results reported by Lovell et al. suggest that 85 of 710 compact flat-spectrum sources are IDV sources. The MASIV data, however, are not yet fully published. We labeled a source in our sample as an IDV source if there was a published statistically significant detection of flux density variations on a timescale of less than 3 days $(72 \mathrm{hr})$. However, we are not able to identify all the potential IDV sources in our sample consistently, because some sources are not (yet) listed in any of the published IDV survey results, and also because IDV is a transient phenomenon, and not all sources were monitored equally well.

Figure 12 shows the distribution of the sub-milliarcsecond compactness index, $S_{\text {unres }} / S_{\text {VLBA }}$; the median value over all observing epochs was taken for each source. The median VLBA core dominance, $S_{\text {core }} / S_{\mathrm{VLBA}}$, and the maximum brightness temperature are also shown. The full and MOJAVE samples are shown separately, and we have separated IDV sources with high modulation index ( $m>0.02$ observed at least once) from ones with low modulation index (measured values of modulation index always less than 0.02 or not reported).

We find that IDV sources have more compact and more core dominant structure on sub-milliarcsecond scales (Table 4) than non-IDV sources. IDV sources with a higher amplitude of intraday variation tend to have a higher unresolved flux density, $S_{\text {unres }}$. The results for core dominance are in agreement with previous findings (e.g., Witzel \& Quirrenbach 1993; Ojha et al. 2004). A K-S test yields a probability of less than $1 \%$ for both the full and the MOJAVE sample that the sub-milliarcsecond compactness (Fig. 12) has the same parent distribution for IDV and non-IDV sources.

One might expect IDV behavior in almost all the sources with high visibility amplitude at long VLBI spacings. However, this was not observed by IDV surveys, perhaps because of the intermittent nature of the IDV phenomenon.

Some IDV observations have suggested apparent brightness temperatures up to $10^{15} \mathrm{~K}$ if they are due to interstellar

TABLE 4

Parameters of IDV-Selected Subsamples

\begin{tabular}{|c|c|c|c|c|}
\hline $\begin{array}{l}\text { Sample } \\
\text { (1) }\end{array}$ & $\begin{array}{c}\text { No. of Sources } \\
\text { (2) }\end{array}$ & $\begin{array}{c}S_{\text {unres }} / S_{\text {VLBA }} \\
\text { (3) }\end{array}$ & $\begin{array}{l}S_{\text {core }} / S_{\text {VLBA }} \\
\text { (4) }\end{array}$ & $\begin{array}{c}\log \left(T_{b, \max }\right) \\
(5)\end{array}$ \\
\hline \multicolumn{5}{|l|}{ Full sample: } \\
\hline 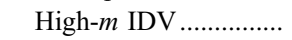 & 27 & $0.70 \pm 0.03$ & $0.83 \pm 0.02$ & $12.4 \pm 0.1$ \\
\hline 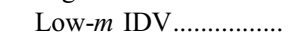 & 16 & $0.62 \pm 0.04$ & $0.73 \pm 0.03$ & $12.2 \pm 0.2$ \\
\hline Non-IDV …........................ & 207 & $0.55 \pm 0.02$ & $0.74 \pm 0.01$ & $12.0 \pm 0.1$ \\
\hline \multicolumn{5}{|l|}{ MOJAVE sample: } \\
\hline 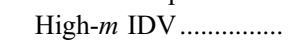 & 17 & $0.74 \pm 0.03$ & $0.85 \pm 0.03$ & $12.5 \pm 0.1$ \\
\hline 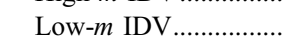 & 8 & $0.68 \pm 0.03$ & $0.77 \pm 0.04$ & $12.5 \pm 0.2$ \\
\hline 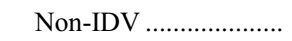 & 108 & $0.59 \pm 0.02$ & $0.74 \pm 0.02$ & $12.4 \pm 0.1$ \\
\hline
\end{tabular}

Notes.-Col. (1): Sample type. Col. (2): Number of sources. Col. (3): Average $S_{\text {unres }} / S_{\mathrm{VLBA}}$ and its dispersion. Col. (4): Average $S_{\text {core }} / S_{\mathrm{VLBA}}$ and its dispersion. Col. (5): Median value of $\log \left(T_{b, \max }\right)$ and dispersion of the average value. The $1 \sigma$ errors of the average values are calculated assuming a normal distribution of these values. 

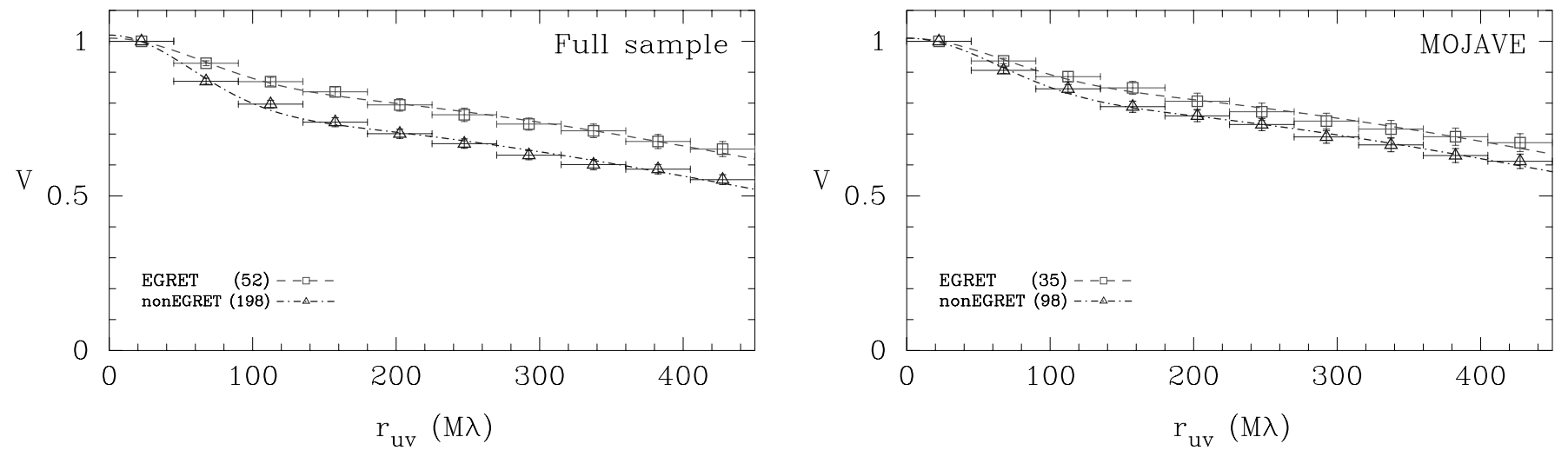

FIG. 13.- Nonweighted mean of the fringe visibility vs. projected spacing. The distribution is normalized to 1.0 at $25 \mathrm{M} \lambda$. The visibility data at the epoch with the maximum correlated flux density $S_{\text {unres }}$ are used for each source. The sample is divided into gamma-ray-bright (EGRET detections) and gamma-ray-weak (EGRET nondetections) sources (see Table 1 for details). The lines represent the best-fit two-component models. See the model parameters in Table 3. [See the electronic edition of the Journal for a color version of this figure.]

scintillations, and up to $10^{21} \mathrm{~K}$ if they are intrinsic (e.g., Kedziora-Chudczer et al. 1997). More recently, IDV observations of Lovell et al. (2003) have shown typical brightness temperature values on the order of $10^{12} \mathrm{~K}$, consistent with our results (Fig. 12). However, as seen from equation (5), the highest brightness temperature that we can reliably discern is on the order of $10^{13} \mathrm{~K}$, so we are not able to comment on the evidence for the extremely high brightness temperatures and the corresponding high Lorentz factors inferred for some IDV sources.

\subsection{Gamma-Ray Sources}

The third catalog of high-energy gamma-ray sources detected by the EGRET telescope of the Compton Gamma Ray Observatory (Hartman et al. 1999) includes 66 high-confidence identifications of blazars (Mattox et al. 2001; Sowards-Emmerd et al. $2003,2004)$. While the gamma-ray sources were identified with flat-spectrum extragalactic radio sources $(\alpha>-0.5)$, not all flat-spectrum sources have been detected as gamma-ray sources. This is not necessarily indicative of a bimodality in the gammaray loudness distribution of extragalactic radio sources (such as that found at radio wavelengths), since the sensitivity level of EGRET was such that many sources were only detected in their flaring state. With the next generation of gamma-ray telescopes, such as GLAST (Gehrels \& Michelson 1999), the sensitivity may be sufficient to actually separate the classes of gamma-ray-loud and gamma-ray-quiet objects and to define the relationship between radio and gamma-ray emission of the sources properly.

For the purpose of our test we have grouped the "highly probable" and "probable" EGRET identifications (Table 1) together, which yields 52 "EGRET detections" out of $250 \mathrm{ob}-$ jects for the full and 35 out of 133 for the MOJAVE sample.

In Paper I we did not find any clear differences in the submilliarcsecond scale structure between the EGRET (20\% of our radio sample) and non-EGRET sources. However, we find here that the sub-milliarcsecond compactness, $S_{\text {unres }} / S_{\mathrm{VLBA}}$, for EGRET detections is, on average, greater than for the EGRET nondetections. This can be seen in Figure 13, which shows the mean visibility function amplitudes versus projected spacing for EGRETdetected and -nondetected sources, for the full and MOJAVE samples. For both samples, the EGRET-detected sources have, on average, a higher contribution of compact VLBA structure (see Table 3 for the parameters of the two-component fit). This comparison is valid because the EGRET-detected and -nondetected blazars in our sample have indistinguishable redshift distribu- tions. This result still holds if we exclude the gigahertz-peaked spectrum and steep-spectrum sources, which are generally gamma-ray weak (see, e.g., Mattox et al. 1997). The difference is more pronounced for the full sample, which is not selected on the basis of the VLBI flux density. The difference for the MOJAVE sample is small but remains significant. These results suggest that a connection may exist between gamma-ray and beamed radio emission from extragalactic sources on sub-milliarcsecond scales, as has already been argued by others (e.g., Jorstad et al. 2001).

\section{SUMMARY}

We have analyzed visibility function data of 250 extragalactic radio sources, obtained with the VLBA at $15 \mathrm{GHz}$. Almost all the radio sources in our sample have unresolved radio emission brighter than $0.1 \mathrm{Jy}$ on the longest VLBA baselines. For 171 objects, more than half of the flux density comes from unresolved features. We have compiled a list of 163 sources with unresolved structure stronger than $0.5 \mathrm{Jy}$, which will form a target list of special interest for planned space VLBI observations such as RadioAstron, VSOP-2, and ARISE.

A few of the sources have an overall radio structure that is only slightly resolved at the longest spacings. Their total angular size is less than about 0.05 mas, at least in one dimension, at some epochs. However, even though most sources in our full sample are extended overall, there are 158 sources in which the VLBA core component appears unresolved, usually smaller than 0.05 mas, again in one direction, at least at one epoch. For 19 of these, the core was unresolved at all epochs.

The distribution of the brightness temperature of the cores peaks at $10^{12} \mathrm{~K}$ and extends up to $5 \times 10^{13} \mathrm{~K}$; this is close to the limit set by the dimensions of the VLBA. However, for many sources we only measure a lower limit to the brightness temperature. There is evidence that the observed brightness temperatures can be explained as the result of Doppler boosting, but transient phenomena, coherent emission, or synchrotron emission by relativistic protons may also be important.

On sub-milliarcsecond scales, active galaxies are on average larger and less core dominated than quasars, which is consistent with unification models in which the latter are viewed at smaller angles to the line of sight. In addition, the weak-lined objects classified as BL Lac objects tend to be smaller than the broadlined quasars in our sample. IDV sources show a higher compactness and core dominance on sub-milliarcsecond scales than non-IDV ones. IDV sources with a higher amplitude of intraday 
variation tend to have a higher flux density in an unresolved component. The most variable sources tend to have the most compact structure. EGRET-detected radio sources show a higher degree of sub-milliarcsecond compactness than non-EGRET sources, supporting emission models that relate the radio and gamma-ray emission, such as inverse Compton scattering (see, e.g., Bloom \& Marscher 1996).

The National Radio Astronomy Observatory is a facility of the National Science Foundation operated under cooperative agreement by Associated Universities, Inc. The University of Michigan Radio Astronomy Observatory has been supported by the University of Michigan Department of Astronomy and the National Science Foundation. Part of this work was done by M. L. L. and D. C. H. during their Jansky Postdoctoral Fellowships at the National Radio Astronomy Observatory. This work was supported partially by the NASA JURRISS program (W-19611), the NSF (AST 04-06923), and the Russian Foundation for Basic Research (02-02-16305, 05-02-17377). M. K. was supported through a stipend from the International Max Planck Research School for Radio and Infrared Astronomy at the University of Bonn. This research has made use of the NASA/IPAC Extragalactic Database, which is operated by the Jet Propulsion Laboratory, California Institute of Technology, under contract with the National Aeronautics and Space Administration. We thank the referee, Ski Antonucci, for many helpful comments, which have led us in particular to clarify the relationship between source classifications and our statistical results.

\section{REFERENCES}

Aller, H. D., Aller, M. F., Latimer, G. E., \& Hodge, P. E. 1985, ApJS, 59, 513 Aller, M. F., Aller, H. D., \& Hughes, P. A. 1992, ApJ, 399, 16

2003, in ASP Conf. Ser. 300, Radio Astronomy at the Fringe, ed. J. A. Zensus, M. H. Cohen, \& E. Ros (San Francisco: ASP), 159

Angel, J. R. P., \& Stockman, H. S. 1980, ARA\&A, 18, 321

Antonucci, R. 1993, ARA\&A, 31, 473

Antonucci, R. R. J., Hickson, P., Miller, J. S., \& Olszewski, E. W. 1987, AJ, 93, 785

Bertero, M., \& De Mol, C. 1996, in Progress in Optics, Vol. 36, ed. E. Wolf (Elsevier: Amsterdam), 129

Bertsch, D. 1998, IAU Circ., 6807, 2

Best, P. N., Peacock, J. A., Brookes, M. H., Dowsett, R. E., Röttgering, H. J. A., Dunlop, J. S., \& Lehnert, M. D. 2003, MNRAS, 346, 1021

Bignall, H. E., et al. 2002, Publ. Astron. Soc. Australia, 19, 29

Biretta, J. A., Schneider, D. P., \& Gunn, J. E. 1985, AJ, 90, 2508

Bloom, S. D., \& Marscher, A. P. 1996, ApJ, 461, 657

Carilli, C. L., Menten, K. M., Reid, M. J., Rupen, M. P., \& Yun, M. S. 1998, ApJ, 494, 175

Cohen, M. H., Cannon, W., Purcell, G. H., Shaffer, D. B., Broderick, J. J.,

Kellermann, K. I., \& Jauncey, D. L. 1971, ApJ, 170, 207

Cohen, M. H., et al. 1975, ApJ, 201, 249

Dennett-Thorpe, J., \& de Bruyn, A. G. 2002, Nature, 415, 57

Eracleous, M., \& Halpern, J. P. 2004, ApJS, 150, 181

Frey, S., et al. 2000, PASJ, 52, 975

Gehrels, N., \& Michelson, P. 1999, Astropart. Phys., 11, 277

Greisen, E. W. 1988, in Acquisition, Processing and Archiving of Astronomical Images, ed. G. Longo \& G. Sedmak (Naples: Oss. Astron. Capodimonte), 125

Greve, A., et al. 2002, A\&A, 390, L19

Hartman, R. C., et al. 1999, ApJS, 123, 79

Heidt, J., Tröller, M., Nilsson, K., Jäger, K., Takalo, L., Rekola, R., \& Sillanpää, A. 2004, A\&A, 418, 813

Hirabayashi, H., et al. 1998, Science, 281, 1825

. 2000, PASJ, 52, 997

2004, in Proc. 7th European VLBI Network Symp., ed. R. Bachiller et al. (Madrid: Obs. Astron. Nac.), 285

Högbom, J. A. 1974, A\&AS, 15, 417

Homan, D. C., Ojha, R., Wardle, J. F. C., Roberts, D. H., Aller, M. F., Aller, H. D., $\&$ Hughes, P. A. 2002, ApJ, 568, 99

Horiuchi, S., et al. 2004, ApJ, 616, 110

Jackson, C. A., Wall, J. V., Shaver, P. A., Kellermann, K. I., Hook, I. M., \& Hawkins, M. R. S. 2002, A\&A, 386, 97

Jauncey, D. L., \& Macquart, J.-P. 2001, A\&A, 370, L9

Jorstad, S. G., Marscher, A. P., Mattox, J. R., Wehrle, A. E., Bloom, S. D., \& Yurchenko, A. V. 2001, ApJS, 134, 181

Kardashev, N. S. 1997, Exp. Astron., 7, 329 . 2000, Astron. Rep., 44, 719

Kataoka, J., et al. 1999, ApJ, 514, 138

Kedziora-Chudczer, L., Jauncey, D. L., Wieringa, M. H., Tzioumis, A. K., \& Reynolds, J. 2001, MNRAS, 325, 1411

Kedziora-Chudczer, L., Jauncey, D. L., Wieringa, M. H., Walker, M. A., Nicolson, G. D., Reynolds, J. E., \& Tzioumis, A. K. 1997, ApJ, 490, L9 Kellermann, K. I. 2002, Publ. Astron. Soc. Australia, 19, 77

. 2003, in ASP Conf. Ser. 300, Radio Astronomy at the Fringe, ed. J. A. Zensus, M. H. Cohen, \& E. Ros (San Francisco: ASP), 185

Kellermann, K. I., Clark, B. G., Cohen, M. H., Shaffer, D. B., Broderick, J. J., \& Jauncey, D. L. 1973, ApJ, 179, L141
Kellermann, K. I., \& Pauliny-Toth, I. I. K. 1969, ApJ, 155, L71

Kellermann, K. I., Vermeulen, R. C., Zensus, J. A., \& Cohen, M. H. 1998, AJ, 115, 1295 (Paper I)

Kellermann, K. I., et al. 2004, ApJ, 609, 539 (Paper III)

Kollgaard, R. I., Wardle, J. F. C., Roberts, D. H., \& Gabuzda, D. C. 1992, AJ, 104,1687

Kovalev, Yu. A. 1998, Bull. Spec. Astrophys. Obs., 44, 50

Kovalev, Yu. A., Kovalev, Y. Y., \& Nizhelsky, N. A. 2000, PASJ, 52, 1027

Kovalev, Y. Y., Kovalev, Yu. A., Nizhelsky, N. A., \& Bogdantsov, A. V. 2002, Publ. Astron. Soc. Australia, 19, 83

Kovalev, Y. Y., Nizhelsky, N. A., Kovalev, Yu. A., Berlin, A. B., Zhekanis, G. V., Mingaliev, M. G., \& Bogdantsov, A. V. 1999, A\&AS, 139, 545

Kraus, A., et al. 2003, A\&A, 401, 161

Levy, G. S., et al. 1989, ApJ, 336, 1098

Lister, M. L. 2001, ApJ, 562, 208

Lister, M. L., \& Homan, D. C. 2005, AJ, 130, 1389

Lister, M. L., Tingay, S. J., Murphy, D. W., Piner, B. G., Jones, D. L., \& Preston, R. A. 2001, ApJ, 554, 948

Lobanov, A. P. 2005, A\&A, submitted (astro-ph/0503225)

Lobanov, A. P., et al. 2000, A\&A, 364, 391

Lovell, J. E. J., Jauncey, D. L., Bignall, H. E., Kedziora-Chudczer, L., Macquart, J.-P., Rickett, B. J., \& Tzioumis, A. K. 2003, AJ, 126, 1699

Lovell, J. E. J., et al. 2004, ApJS, 155, 27

Macomb, D. J., Gehrels, N., \& Shrader, C. R. 1999, ApJ, 513, 652

Macquart, J.-P., Kedziora-Chudczer, L., Rayner, D. P., \& Jauncey, D. L. 2000, ApJ, 538, 623

Maltby, P., \& Moffet, A. T. 1962, ApJS, 7, 141

Marcha, M. J. M., \& Browne, I. W. A. 1995, MNRAS, 275, 951

Mattox, J. R., Hartman, R. C., \& Reimer, O. 2001, ApJS, 135, 155

Mattox, J. R., Schachter, J., Molnar, L., Hartman, R. C., \& Patnaik, A. R. 1997, ApJ, 481, 95

Moellenbrock, G. A., et al. 1996, AJ, 111, 2174

Napier, P. J., Bagri, D. S., Clark, B. G., Rogers, A. E. E., \& Romney, J. D. 1994, Proc. IEEE, 82, 658

Ojha, R., Fey, A. L., Jauncey, D. L., Lovell, J. E. J., \& Johnston, K. J. 2004, ApJ, 614, 607

Pearson, T. J. 1999, in ASP Conf. Ser. 180, Synthesis in Radio Astronomy II, ed. G. B. Taylor, C. L. Carilli, \& R. A. Perley (San Francisco: ASP), 335

Pearson, T. J., \& Readhead, A. C. S. 1984, ARA\&A, 22, 97

Quirrenbach, A., et al. 1992, A\&A, 258, 279

. 2000, A\&AS, 141, 221

Readhead, A. C. S. 1994, ApJ, 426, 51

Rector, T. A., \& Stocke, J. T. 2001, AJ, 122, 565

Rickett, B. J., Witzel, A., Kraus, A., Krichbaum, T. P., \& Qian, S. J. 2001, ApJ, 550, L11

Rowson, B. 1963, MNRAS, 125, 177

Scarpa, R., \& Falomo, R. 1997, A\&A, 325, 109

Scott, W. K., et al. 2004, ApJS, 155, 33

Shepherd, M. C. 1997, in ASP Conf. Ser. 125, Astronomical Data Analysis Software and Systems VI, ed. G. Hunt \& H. E. Payne (San Francisco: ASP), 77 Singal, K. A., \& Gopal-Krishna 1985, MNRAS, 215, 383

Small, T. A., Sargent, W. L. W., \& Steidel, C. C. 1997, AJ, 114, 2254

Sowards-Emmerd, D., Romani, R. W., \& Michelson, P. F. 2003, ApJ, 590, 109

Sowards-Emmerd, D., Romani, R. W., Michelson, P. F., \& Ulvestad, J. S. 2004, ApJ, 609, 564

Stickel, M., Fried, J. W., Kühr, H., Padovani, P., \& Urry, C. M. 1991, ApJ, 374, 431 
Stickel, M., Meisenheimer, K., \& Kühr, H. 1994, A\&AS, 105, 211

Stocke, J. T., \& Rector, T. A. 1997, ApJ, 489, L17

Tingay, S. J., et al. 2001, ApJ, 549, L55

Tornikoski, M., et al. 1999, AJ, 118, 1161

Ulvestad, J. S. 2000, Adv. Space Res., 26, 735

Urry, C. M., \& Padovani, P. 1995, PASP, 107, 803

Vermeulen, R. C., Ogle, P. M., Tran, H. D., Browne, I. W. A., Cohen, M. H., Readhead, A. C. S., Taylor, G. B., \& Goodrich, R. W. 1995, ApJ, 452, L5

Vermeulen, R. C., Ros, E., Kellermann, K. I., Cohen, M. H., Zensus, J. A., \& van Langevelde, H. J. 2003, A\&A, 401, 113
Véron-Cetty, M. P., \& Véron, P. 2000, A\&A Rev., 10, 81 2003, A\&A, 412, 399

Whitney, A. R., et al. 1971, Science, 173, 225

Wills, B. J. 1999, in ASP Conf. Ser. 162, Quasars and Cosmology, ed. G. Ferland \& J. Baldwin (San Francisco: ASP), 101

Wills, B. J., et al. 1983, ApJ, 274, 62

Witzel, A., \& Quirrenbach, A. 1993, in Propagation Effects in Space VLBI, ed. L. I. Gurvits (Arecibo: NAIC), 33

Zensus, A., Ros, E., Kellermann, K. I., Cohen, M. H., \& Vermeulen, R. C. 2002, AJ, 124, 662 (Paper II) 


\section{ERRATUM: “SUB-MILLIARCSECOND IMAGING OF QUASARS AND ACTIVE GALACTIC NUCLEI. IV. FINE-SCALE STRUCTURE" (AJ, 130, 2473 [2005])}

Y. Y. Kovalev, K. I. Kellermann, M. L. Lister, D. C. Homan, R. C. Vermeulen, M. H. Cohen, E. Ros, M. Kadler, A. P. Lobanov, J. A. Zensus, N. S. Kardashev, L. I. Gurvits, M. F. Aller, and H. D. Aller

The limit flag on the minor core axis FWHM, $\theta_{\min }$, was incorrectly shown as "> " in the machine-readable version of Table 2, position 51. It should be " $<$," indicating an upper limit of $\theta_{\min }$ for all the cases in which the limit is defined. The printed version and HTML version of Table 2 are correct as published. This correction of the machine-readable version of Table 2 is only typographical in nature, and none of the results in the paper were affected.

Online material: machine-readable table

TABLE 2

Source Parameters at Maximum Unresolved Flux Density

The correct version of Table 2 is available in machine-readable form in the electronic edition of the Astronomical Journal. 